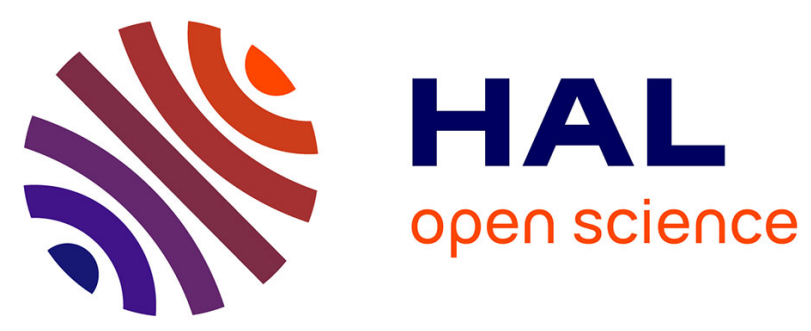

\title{
Le sanctuaire gallo-romain des Basiols à Saint-Beauzély (Aveyron)
}

\author{
Ariane Bourgeois, Jean Pujol, Jean-Pierre Séguret
}

\section{To cite this version:}

Ariane Bourgeois, Jean Pujol, Jean-Pierre Séguret. Le sanctuaire gallo-romain des Basiols à SaintBeauzély (Aveyron). Gallia - Fouilles et monuments archéologiques en France métropolitaine, 1993, 50, pp.139-179. 10.3406/galia.1993.2936 . hal-01913133

\section{HAL Id: hal-01913133 \\ https://hal.science/hal-01913133}

Submitted on 29 Jan 2020

HAL is a multi-disciplinary open access archive for the deposit and dissemination of scientific research documents, whether they are published or not. The documents may come from teaching and research institutions in France or abroad, or from public or private research centers.
L'archive ouverte pluridisciplinaire HAL, est destinée au dépôt et à la diffusion de documents scientifiques de niveau recherche, publiés ou non, émanant des établissements d'enseignement et de recherche français ou étrangers, des laboratoires publics ou privés.

\section{(ㅇ)(1) $\$$}

Distributed under a Creative Commons Attribution - NonCommercial - NoDerivatives| 4.0 


\title{
Le sanctuaire gallo-romain des Basiols à Saint-Beauzély (Aveyron)
}

\author{
par Ariane BOURGEOIS *, Jean PUJOL ** et Jean-Pierre SÉGURET ***
}

Le sanctuaire rutène des Basiols se trouve dans le massif montagneux du Lévézou, au sud du Massif central. Situé à un col, sur le tracé d'une route antique importante, mais isolé en pleine campagne, il a été intégralement fouillé. Bâti en pierre, il consiste en neuf petites cellae carrées ouvertes à l'est, enfermées dans un péribole dont on connaît seulement une petite entrée au sud. Trois des chapelles ont été arasées dans l'Antiquité lors de nouveaux aménagements. En outre il y avait un local annexe, hangar ou cuisine, cinq petits massifs de maçonnerie pleins ou évidés à destination incertaine, et une fosse.

Excepté trois cent vingt monnaies, le mobilier n'est pas très abondant. Il suggère que le sanctuaire, sans doute déjà vénéré à la fin de la République et aménagé sous Auguste, puis au milieu du $\mathrm{I}^{\mathrm{er}} \mathrm{s}$. de notre ère, a existé jusqu'à la fin du ${ }^{2} V^{e}$ s., avec une fréquentation maximale sous le Haut-Empire.

The rural sanctuary of Basiols is silualed on the Lévezou mountain range in the South of Massif Central. It is located in a pass, on an important ancient Roman road. It has been fully excavated. We found nine small square stone cellae, open at the Easl and enclosed in a peribolos whose only a small entry is known to be on the southern wall. Three cellae were pull down during the Antiquity, at the time of the new constructions. Besides them, there was a building (a warehouse or a kitchen?), five solid stoneworks, whose purpose is not known, and a pit.

The furniture is rare. Only 320 coins were found. It suggest that the sanctuary, which was already venerated at the end of the Roman Republic and fitted up during Augustus's reign, and in the middle of the 1st century, lasted until the end of the 4th century, and was most frequented during the first three centuries A.D.

Mots clés : sanctuaire rural, rutène, cellae, annexe, socles, fosses, intaille de Mercure, sigillée, marra, monnaies, denier, as, sesterces, dupondii, antoniniani, Saint-Beauzély, Aveyron.

* Maitre de Conférences, Université de Paris I, 18, passage d'Enfer, 75014 Paris.

** Membre du groupe archéologique de La Graufesenque, 15, rue Emma-Calvé, 12100 Creissels.

*** Membre du groupe archéologique de La Graufesenque, Musée archéologique de Millau, place du Maréchal Foch, 12100 Millau. 
Le sanctuaire gallo-romain des Basiols se trouve à $2, \bar{k} \mathrm{~km}$ au nord-ouest de l'abbaye médiévale de Comberoumal (ordre de Grandmont), sur la commune de Saint-Beauzély, canton de Saint-Beauzély et arrondissement de Millau, dans l'Aveyron (fig. 1). Des travaux de reboisement sont à l'origine de la découverte ${ }^{1}$. Ils ont permis durant l'été 1987 la mise au jour d'un ensemble cultuel de première importance dans la région Midi-Pyrénées ${ }^{2}$. Situé en bordure de la voie romaine signalée par la Table de Peutinger ${ }^{3}$, qui reliait Condatomagus (Millau) à Segodunum (Rodez), c'est un site de col implanté au point de franchissement du plateau du Lévézou, massif de grès et de schiste qui se dresse au centre du département de l'Aveyron. Tout l'environnement de ce secteur est aujourd'hui recouvert d'une épaisse forêt de

1 C'est M. Chauchard qui, le premier, en 1981, après un déboisement, signala la prèsence de legulae et de blocs de grès dans ce secteur. P. Querbes et les "Adralhans» confirmèrent cette découverte durant l'été 1986. Une prospection du Club archéologique de la MJC de Millau, en septembre 1986, laissa supposer l'existence d'édifices antiques. Avec l'autorisation de fouille de la Direction régionale des Antiquités historiques (DRAII) de Midi-Pyrénées, ce sauvetage a été effectué du ler août au 19 septembre 1987 par plus d'une vingtaine de fouilleurs bénévoles de Rodez et Millau, sous la direction de $J$. Pujol et J.-P. Séguret, avec le concours de A. Vernhet, chargé de recherches au CNRS. Pendant l'été 1991, le décapage du site a été achevé, hors de notre collaboration, par la DRAH, qui nous avait promis le rapport de fouille qu'à ce jour nous n'avons pas reçu. Nous la remercions tout de même de nous avoir permis d'utiliser certains renseignements donnés par $M$. Guilbaut (cf. infra, note 81). Cet article étant alors achevé, nous n'avons pas voulu changer la numérotation des édifices : nous reconnaissons ainsi que notre article a une allure un peu disparate, avec des chiffres pour 1987, des lettres pour 1991. Et si cette ultime fouille a répondu à certaines questions sur le secteur que nous ne connaissions pas, par exemple la présence d'une petite porte dans le mur sud-est pour pénétrer dans le sanctuaire, elle ne change rien à nos conclusions. Par ailleurs, comme nous n'avons que l'identification sommaire des neuf monnaies récoltées en 1991 , elles ne sont intégrées ni dans le catalogue ni dans son commentaire, mais sont énumérées dans la note 81 : elles ne modifient rien non plus! Elles ne figurent pas sur le croquis de localisation fait au fur et à mesure de la fouille de 1987 (voir la fig. 26), bien que M. Guilbaut nous ait communiqué le sien.

2 Cette découverte a déjà été publiée par J. Pujol, J.-P. SÉguret, Sanctuaire des Basiols, Saint-Beauzély (Aveyron), Vivre en Rouergue, Cahiers d'archéologie aveyronnaise, 31 , $\mathrm{n}^{\circ}$ spécial, 1989, p. 32-40. Outre la part qu'ils ont prise à la rédaction de l'article présenté ici, l'illustration graphique et photographique leur est due, notamment le plan général du sanctuaire et celui de la localisation des monnaies (fig. 3 et 26).

3 Cette voie est représentée sur la Table de Peutinger : Tabula Peutingeria, Codex Vindobonensis 324, Weber (E), Graz, 1976, Segment I, 3. Millau est à une vingtaine de kilomètres du sanctuaire au sud et Rodez à une cinquantaine au nord-ouest. résineux. Actuellement, cette haute futaie limite un point de vue qui embrassait une très grande partie du pays des Rutènes.

C'est dans cette contrée maintenant presque déserte, que les Gallo-Romains ont établi neuf petites cellae entourées d'une enceinte carrée de plus de $20 \mathrm{~m}$ de côté.

\section{LA FOUILLE}

\section{LE SITE}

I.e lieu-dit les Basiols est situé sur la parcelle 34, section B du cadastre de Saint-Beauzély (fig. 1) ${ }^{4}$. En bordure d'un chemin forestier, il se trouve aux limites des trois communes de Saint-Beauzély, Castelnau-Pégayrolles et Salles-Curan et au passage d'un col sur une ligne de crête étirée du nord-est au sud-ouest, à un peu plus de $1000 \mathrm{~m}$ d'altitude (fig. 2).

I.'ensemble du secteur a fait l'objet de plusieurs déboisements et reboisements successifs qui ont profondément marqué la physionomie des lieux : de larges sillons, soulignés par des levées de terre rappellent le passage des engins modernes qui ont défoncé le sol en bandes parallèles. Avant la fouille, l'endroit se présentait sous l'aspect d'une clairière bordée d'un chemin, au milieu de laquelle se trouvait un monticule de terre et de déchets d'exploitation, de plus de $2 \mathrm{~m}$ de haut sur 5 à $6 \mathrm{~m}$ de large. La présence de ce monticule et un sapin isolé ont èvité une plus grande dégradation du site. Et, en raison des risques encourus par un reboisement imminent, une autorisation de sauvetage fut accordée ${ }^{5}$.

Cette partie du Lévézou est assez pauvre en vestiges archéologiques - il faut tout de même rappeler la découverte à proximité, le même été, d'un fragment de statue-menhir, type de monument jusqu'à présent inconnu dans cette région ${ }^{6}$. De l'époque gallo-romaine, nous pouvons cependant mentionner dans les environs les restes d'un petit fanum près de

4 Coordonnées Lambert Ax 656,6-Ay 198,8, altitude 1026 m (carte IGN au 1/25000 no 2540 - Ouest).

5 Nous tenons à remercier particulièrement $M$. et $M^{\text {me }}$ Bastide, propriétaires des lieux, de nous avoir encouragés à fouiller, et d'être intervenus auprès de la Direction départementale de l'Agriculture, afin que la zone archéologique soit laissée libre de reboisement. Signalons que le sanctuaire vient d'être restauré par une consolidation des murs.

6 Cette découverte a été signalée par R. Lrquíment, Gallia Informations, 1989-1, p. 89. 


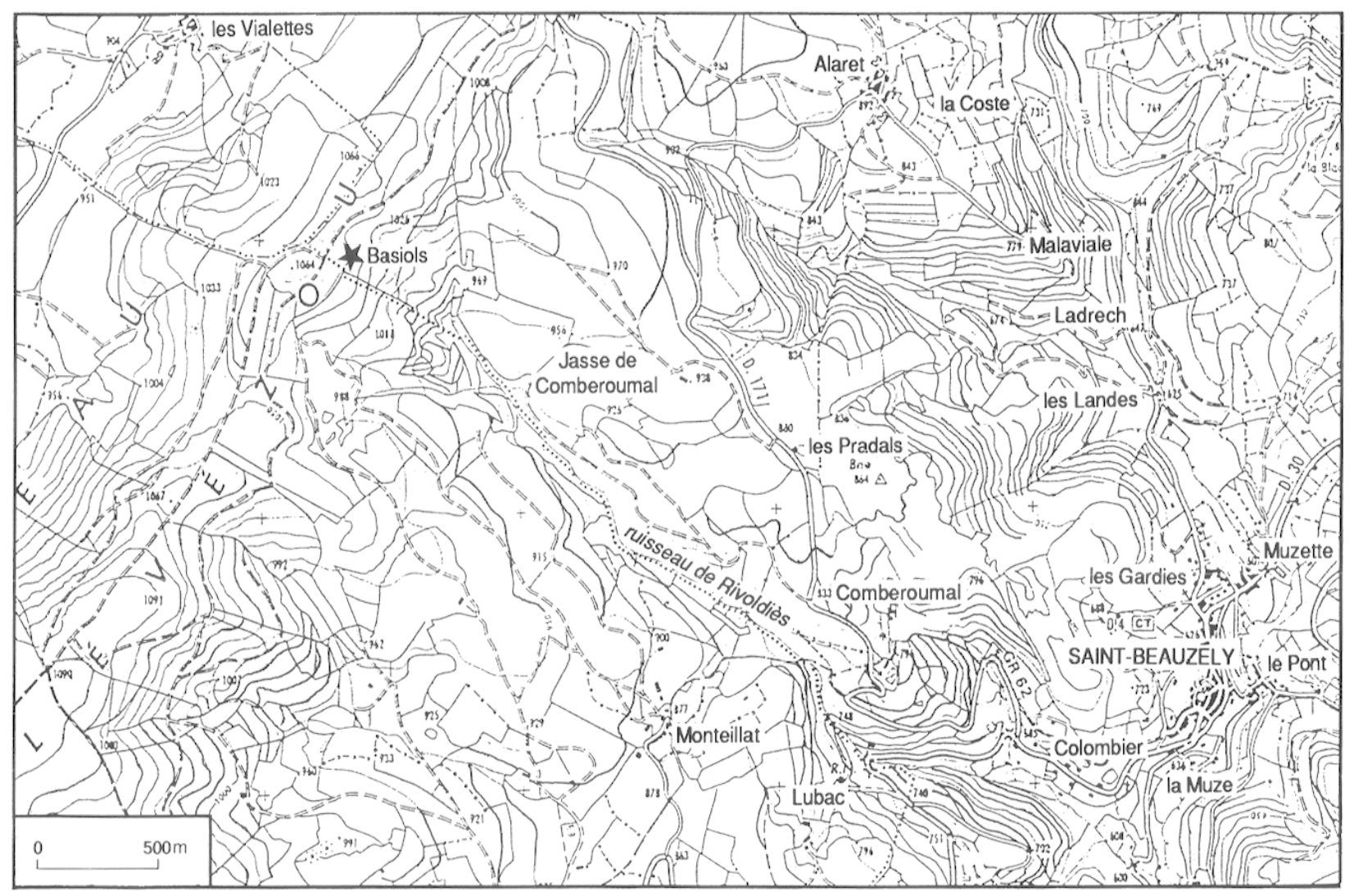

Fig. 1 - Localisation du site des Basiols, commune de Saint-Beauzély (Aveyron).

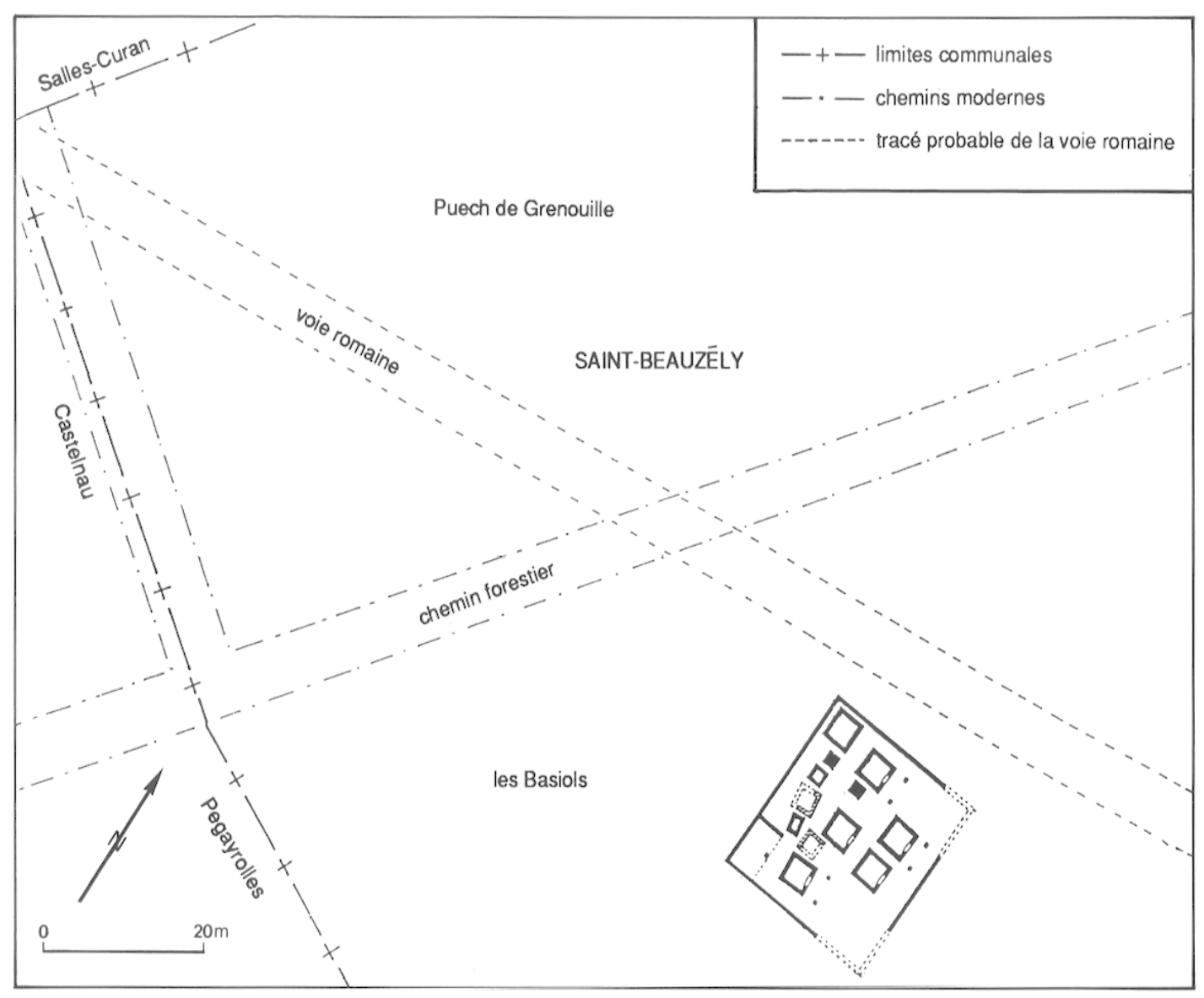

Fig. 2 - Situation du sanctuaire (plan 1987 : il manque la cella "a» découverte au cours de l'été 1991). 

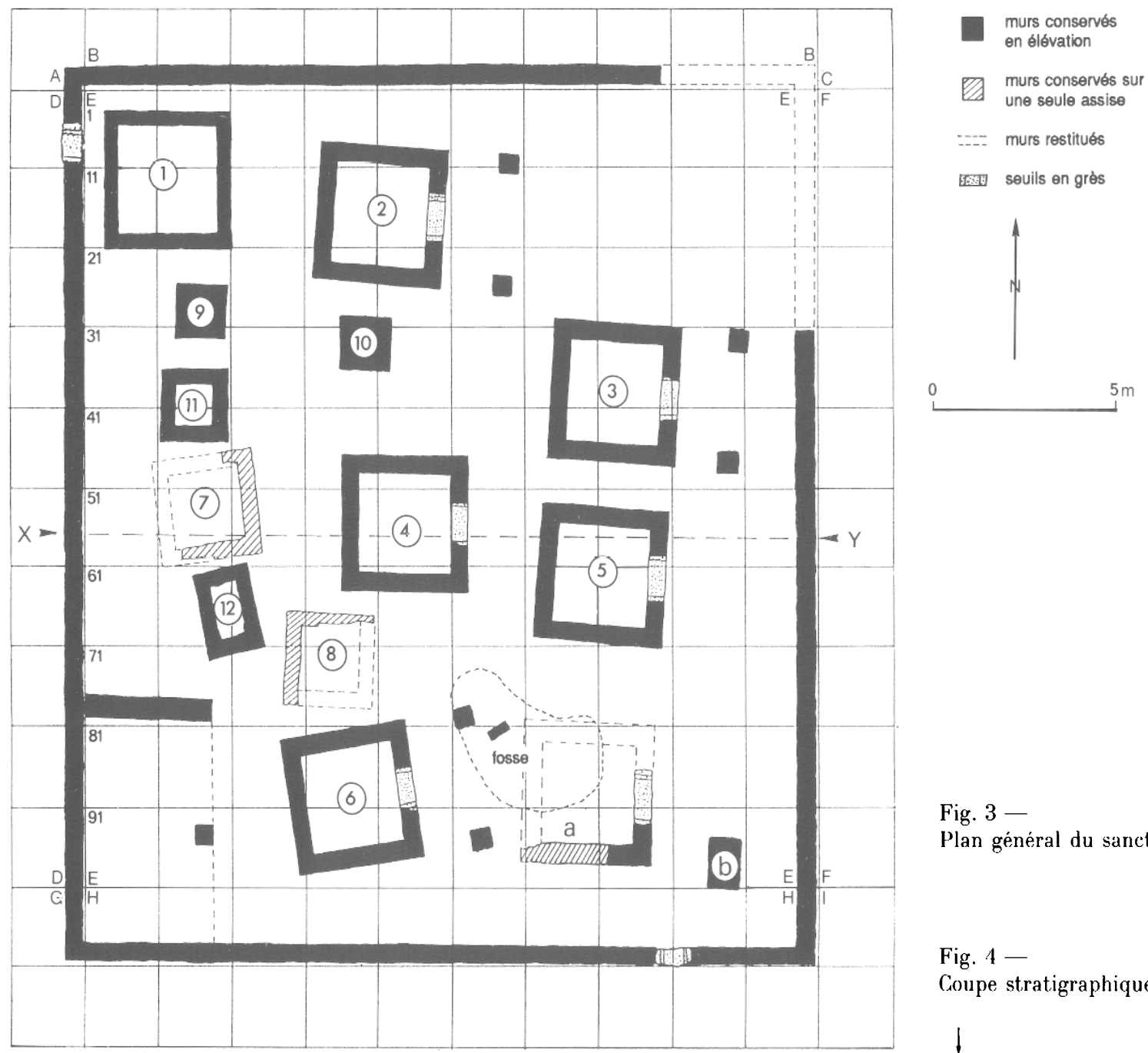

Fig. 3 -

Plan général du sanctuaire.

Fig. 4 -

Coupe stratigraphique.

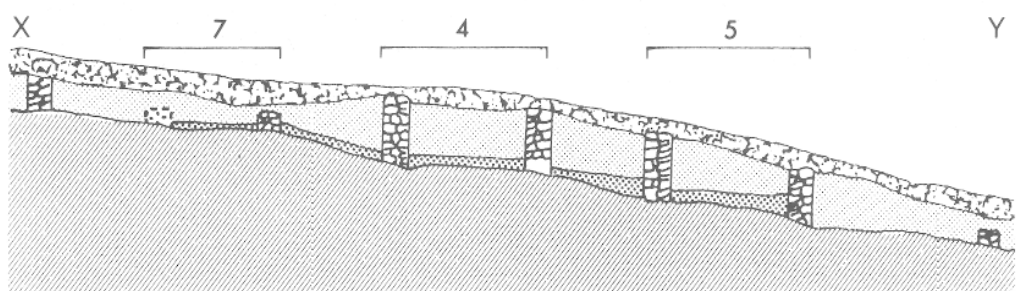

莌 terre végétale

niveau de comblement

niveau d'utilisation

stêrile

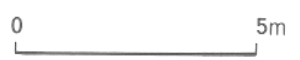

Bouloc, à moins de $1 \mathrm{~km}$ au sud des Basiols ${ }^{7}$, et la voie romaine de Cessero à Segodunum ${ }^{8}$, dont le tracé est établi avec certitude à l'ouest et à l'est du col, alors que les avis divergent pour le point exact de franchissement de la crête du Lévézou: A. Albenque ${ }^{9}$ cite plusieurs érudits qui ont proposé dif-

7 Voir L. Balsan, Temples et fana des Rutènes, PVSLA, XXXVIII, 1963, p. 265-271.

8 Supra note 3 . La Table de Peutinger donne comme distance entre les deux étapes 58 milles, 28 de Cessero (SaintThibéry) à Condatomagus, 30 de Condatomagus à Segodunum. férents points de passage et, plus récemment, P. Querbes l'a situé au-dessus de la jasse de Comberoumal, adoptant ainsi une tradition orale des habitants ${ }^{10}$. Or les larges dalles de schiste soulevées aux abords du site nous semblent bien indiquer la présence d'un tronçon de route en bordure de l'enceinte

9 A. Ambenque, Les Rutènes, Rodez, Carrère, 1948, p. 106-117.

10 P. Quérвes, Saint-Beauzély en Rouergue, Rodez, Subervie, 1972, p. 11-13. 
sacrée, du côté nord. Mais nous ne connaissons pas son aspect.

\section{STRATIGRAPHIE}

Malgré une fouille minutieuse, la stratigraphie est très difficile à mettre en évidence. Sous une mince pellicule de terre végétale, on trouve une épaisse couche de comblement due à la destruction progressive des édifices du sanctuaire (toits et murs). Vient ensuite une très fine couche d'occupation de quelques centimètres (fig. 4) qui est liée aux abords dallés des cellae. Cette couche contient, entre autre, des monnaies couvrant plusieurs siècles et il est impossible, malgré un tamisage systématique, d'affiner la stratigraphie, sauf dans la cella $\mathrm{n}^{\circ} 2$, à fosse intérieure (voir infra, p. 149, et fig. 8).

\section{DESCRIPTION ARCHITECTURALE}

\section{L'enceinte (fig. 3 et 5)}

Elle a une forme presque carrée (22,50 sur $20,60 \mathrm{~m}$ ) et son grand axe est orienté nord-sud. Clôture servant à délimiter la frontière entre le profane et le sacré, le péribole est marqué par un mur bien conservé sauf dans l'angle nord-est détruit par les engins forestiers. Il est constitué de dalles de schiste local, maçonnées au mortier de chaux et repose sur une fondation à semelle débordante. Il a $60 \mathrm{~cm}$ d'épaisseur, pour une élévation qui a pu être faible, compte tenu du peu de matériaux restant aux abords immédiats de l'ouvrage, à moins qu'ils n'aient été réutilisés. Ces vestiges semblent indiquer plutôt une limite symbolique qu'une clôture dissuasive.

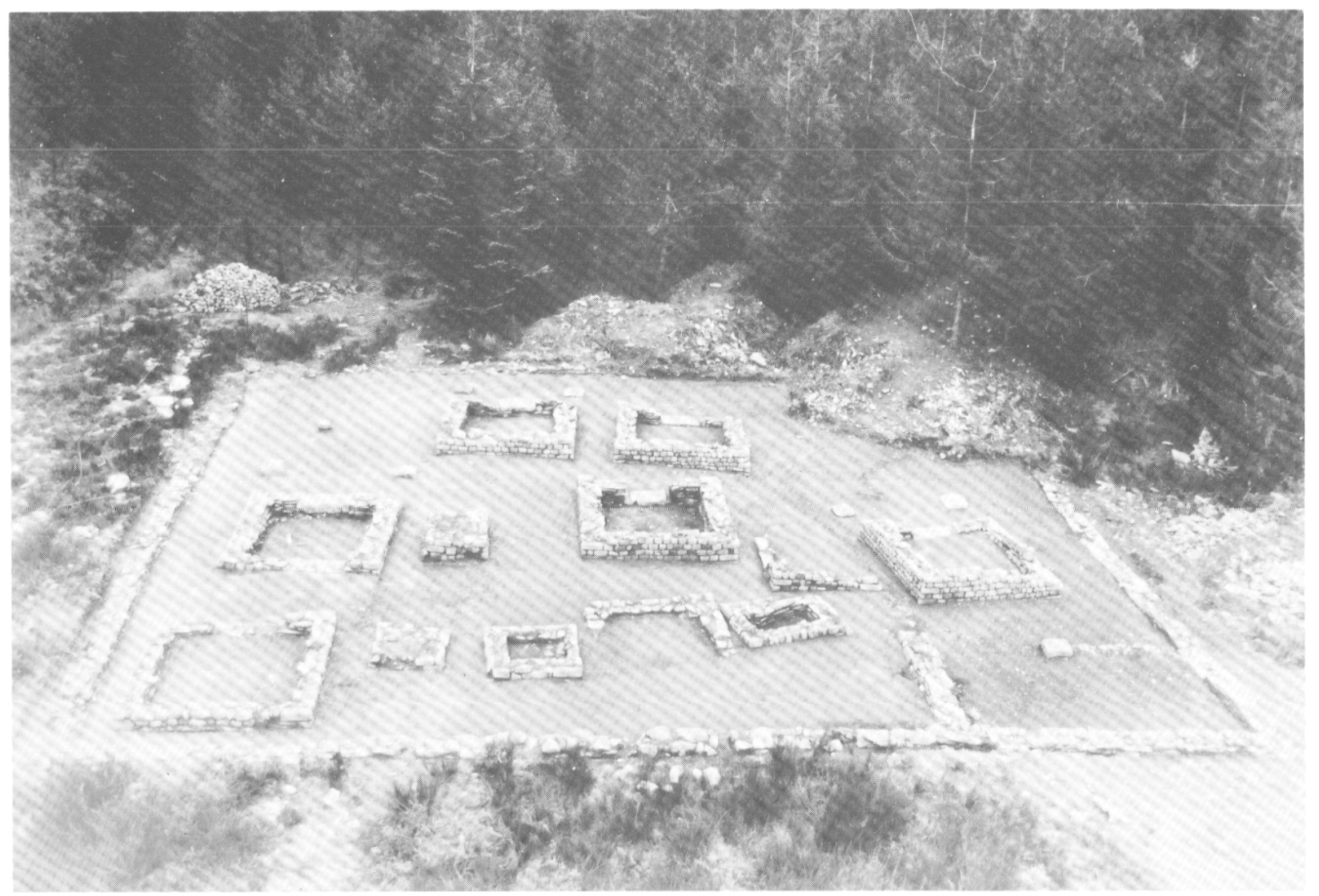

Fig. 5 - Vue générale du sanctuaire prise du côté ouest, à l'issue de la campagne 1987.

(L'angle sud-est fut dégagé pendant l'été 1991). Remarquer la tache noirâtre dans le bâtiment de l'angle sud-ouest. 
On ne connait avec certitude qu'une petite entrée latérale au sud-est, aménagée avec un seuil de $0,60 \mathrm{~m}$ sur $1 \mathrm{~m}$ qui comporte deux rainures latérales, comme ceux des cellae (infra, p. 145). On aurait pu attendre une entrée plus importante dans la partie détruite du péribole, ouvrant sur un assez vaste espace, au nord-est, libre de constructions et caractérisé par une grande quantité de monnaies éparses (infra, p. 163 et fig. 26). Par ailleurs, un autre seuil placé dans le mur d'enceinte, en arrière de la cella $\mathrm{n}^{\circ} 1$, est peut-être l'indice d'une deuxième petite porte latérale au nord-ouest (fig. 6) : lors de la fouille en 1987, on pensait plutôt à un seuil déplacé depuis cette cella, qui en est actuellement dépourvue ${ }^{\mathbf{1 1}}$.

\section{Les édifices du sanctuaire ${ }^{12}$}

Il y a donc neuf cellae, de forme carrée. Elles se divisent en deux groupes, les unes assez bien conservées $\left(\mathrm{n}^{\mathrm{os}} 1\right.$ à 6$)$, identiques par leur mode de construction et leurs dimensions, les autres (nos 7 et 8), de facture plus ancienne et en très mauvais état. Au sud-est, la cella "a», bien que non fouillée par nos soins, entre dans la première catégorie par ses dimensions, mais ne subsiste que par les murs sud et est (tabl. I). On remarquera la disposition assez régulière des cellae en deux lignes parallèles, toutes ouvrant à l'est, les façades de la rangée orientale bien alignées, une troisième ligne, le long du mur occidental au fond, étant plus disparate, par la forme, les dimensions et la destination.

11 Derrière l'entrée conservée au sud-est, dégagée par M. Guilbaut en 1991, il n'y a guère de place (environ 1,20 m) entre le mur sud de la cella "a" et le péribole. La même objection vaut pour l'éventuelle entrée nord-ouest : si le seuil est en place, il y a un étroit passage (environ $0,60 \mathrm{~m}$ ) entre les murs ouest et nord de la cella $\mathrm{n}^{\circ} 1$ et ceux du péribole.

Sur le rôle primordial du péribole chez les Gaulois, voir Brunaux, Les Gaulois..., p. 29-31; chez les Gréco-Romains, voir D.S., article : téménos.

12 L'orientation à l'est, le mode de construction en dur, la couverture s'inscrivent dans tout un ensemble de traditions gallo-romaines, d'origine soit celtique, soit romaine, recensées par C. Ballester (Les sanctuaires...), voir en particulier les pages $19 s q$ et $42 s q$. Une question - sans réponse ici - est de savoir si cet ensemble gallo-romain a été précédé par un sanctuaire celtique et, si c'est le cas, à quoi il ressemblait : aucune trace ne subsiste d'un quelconque aménagement antérieur en matériaux légers. Quant au mobilier, mis à part un denier républicain ct dcux ou trois vases modelćs à décor peigné, peut-ĉtre du $\mathrm{I}^{\mathrm{er}} \mathrm{s}$. avant J.-C., il est de l'époque impériale (infra, p. 156).

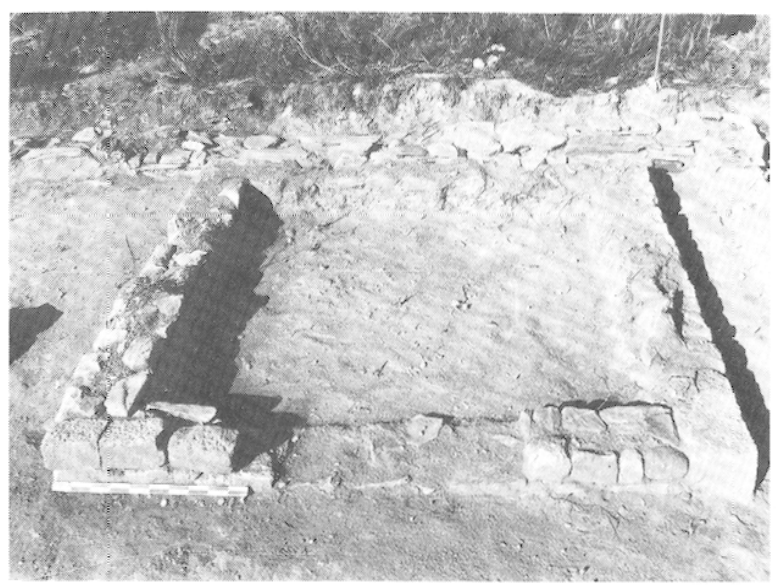

Fig. 6 - Cella ${ }^{\circ} 1$ (le seuil a disparu. Est-ce celui qu'on devine à l'arrière, dans le mur du péribole?).

Les deux édifices les plus anciens devaient être détruits au moment de la construction des sept autres, et il ne subsiste que la première assise, sans fondation. Nous ignorons où était l'entrée, sans doute à l'est. Leurs dimensions sont très réduites ( $2,80 \mathrm{~m}$ de côté) et leur mode de construction assez grossier, en moellons de grès inégaux, moins bien travaillés que dans les cellae plus tardives (fig. 7).

Les chapelles 1 à 6 et «a" présentent entre elles de nombreuses similitudes. De forme carrée, elles sont plus grandes que les précédentes, avec $3,50 \mathrm{~m}$ de côté. Elles ont une orientation identique et un seuil ouvrant à l'est (fig. 6, 8a, 9, 10). Les murs, très soignés, présentent actuellement une élévation de 0,40 à $1 \mathrm{~m}$ et sont édifiés sur une fondation à semelle débordante (fig. 8c); une première assise, verticale, permet d'éviter les remontées d'humidité dans les murs (fig. 11). Bâtis en schiste local ou avec des blocs de grès provenant des environs de Comberoumal, liés au mortier de chaux aujourd'hui disparu - ils semblent en pierres sèches -, ils sont en excellent état de conservation. De $0,50 \mathrm{~m}$ d'épaisseur en moyenne, ils ont un parement externe en petits moellons de grès rectangulaires de 10 à $30 \mathrm{~cm}$ de longueur pour une hauteur variant selon les assises de 10 à $15 \mathrm{~cm}$, ce qui donne à l'ensemble un aspect très régulier (fig. 12 et 13). Le parement interne, en schiste mêlé à quelques blocs de quartz, ne porte aucune trace d'enduit, peint ou non (fig. 10, 14). 
Tabl. I - Description des cellae.

Les dimensions des édifices, telles qu'elles apparaissent dans la deuxième colonne, sont particulièrement modestes (Ballester, Les sanctuaires ..., p. 42 ; M. Labrousse, in : Histoire du Rouergue, p. 66, donnent des dimensions moyennes de 5 à $8 \mathrm{~m}$ pour les temples indigènes: mais ce sont en général des fana carrés entourés d'une galerie).

\begin{tabular}{|c|c|c|c|c|c|c|}
\hline cella & dimensions & $\begin{array}{l}\text { épaisseur } \\
\text { des murs }\end{array}$ & seuil en place & fosse & auvent & autres remarques \\
\hline 1 & $3,50 / 3,50 \mathrm{~m}$ & $\begin{array}{l}0,40 \mathrm{~m} \\
\text { dans le péribole? }\end{array}$ & disparu ou déplacé & & & \\
\hline 2 & $3,50 / 3,50 \mathrm{~m}$ & $0,50 \mathrm{~m}$ & à l'est & interne (monnaies) & 2 socles & \\
\hline 3 & $3,50 / 3,50 \mathrm{~m}$ & $0,50 \mathrm{~m}$ & à l'est & & 2 socles & \\
\hline 4 & $3,50 / 3,50 \mathrm{~m}$ & $0,50 \mathrm{~m}$ & à l'est & & & dallage interne \\
\hline 5 & $3,50 / 3,50 \mathrm{~m}$ & $0,50 \mathrm{~m}$ & à l'est & & & dallage interne \\
\hline 6 & $3,50 / 3,50 \mathrm{~m}$ & $0,50 \mathrm{~m}$ & à l'est & $\begin{array}{l}\text { extérieure (beaucoup de } \\
\text { mobilier); creusée } \\
\text { au détriment de la } \\
\text { cella «a» }\end{array}$ & 2 socles & $\begin{array}{l}\text { paroi interne avec assise de grès } \\
\text { entre deux assises de schiste } \\
\text { (remploi de la cella } 8 \text { ?) }\end{array}$ \\
\hline 7 & $2,80 / 2,80 \mathrm{~m}$ & $0,40 / 0,50 \mathrm{~m}$ & - & & & moellons de grès inégaux \\
\hline 8 & $2,80 / 2,80 \mathrm{~m}$ & $0,40 / 0,50 \mathrm{~m}$ & - & & & moellons de grès inégaux \\
\hline «a» & $3,50 / 3,50 \mathrm{~m}$ & $0,50 \mathrm{~m} ?$ & à l'est & (voir la cella 6 ) & & $\begin{array}{l}\text { amas de tuiles entre l'angle sud-est, } \\
\text { le socle «b» et le péribole sud. }\end{array}$ \\
\hline
\end{tabular}

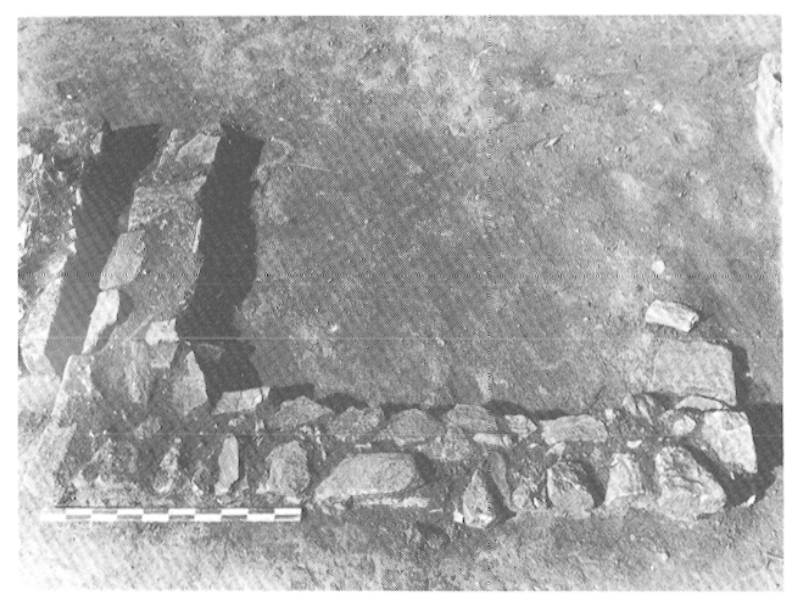

Fig. 7 - Vestiges de la cella $\mathrm{n}^{\circ} 7$ (on aperçoit à gauche la paroi sud du socle 11 et à droite le mur nord du socle 12).

Les seuils conservés des édifices 2 à 6 et "a" consistent en un bloc de grès bien taillé, de 0,80 à $0,90 \mathrm{~m}$ de longueur pour une largeur légèrement supérieure à celle des murs. Ils présentent tous, de part et d'autre, une rainure large de 6 à $8 \mathrm{~cm}$ et profonde de 3 à $5 \mathrm{~cm}$, dont l'usage n'est pas parfaitement défini (fig. 8a et 8c, 9, 10 et 15). En effet, il n'y a aucune trace de crapaudine, ni d'une "barre" en ressaut dans le prolongement des pàrois pour arrêter unc porte - mais on a peut-être trouvé une serrure dans la cella $\mathrm{n}^{\circ} 4$ (infra, p. 154).
L'entrée de trois cellae ( $\mathrm{n}^{\text {os }} 2,3$ et 6 ) au moins était précédée d'un auvent soutenu par des colonnes reposant sur des bases constituées d'un bloc de grès de $0,50 \mathrm{~m}$ de côté, taillé au burin, et situées au droit des murs latéraux, à $1,20 \mathrm{~m}$ à l'avant de la façade (fig. 3, 5, 8a et 9) ${ }^{\mathbf{1 3}}$.

A l'intérieur de chaque cella et à certains endroits à l'extérieur, le sol était, semble-t-il, dallé de plaques de schiste posées bord à bord. Ailleurs, il est simplement en terre battue. On remarquera l'existence d'une fosse intérieure dans la cella $\mathrm{n}^{0} 2$, profonde de $0,30 \mathrm{~m}$ à $0,40 \mathrm{~m}^{14}$, d'où proviennent une douzaine de monnaies (fig. $8 \mathrm{a}$ et b).

Quant à la couverture des six édifices, elle était en tegulae et imbrices dont on a récolté partout des fragments, certains avec un trou de fixation. Une quantité particulière a été trouvée derrière l'entrée sud du péribole, témoin d'un petit toit au dessus d'elle, ou provenant de la cella "a». Ces tuiles sont à première vue plus petites que celles trouvées à La Graufesenque. Il n'y a aucune trace d'antéfixe. Les clous de charpente sont très nombreux (infra, p. 154).

13 On peut les rapprocher de la reconstitution proposée par A. Grenier de petits temples in antis avec deux colonnes en façade ou deux pilastres latéraux qui supportaient un entablement ou un fronton (Ghenier, Manuel, p. 540-541, fig. 169).

14 Infra note 19. 


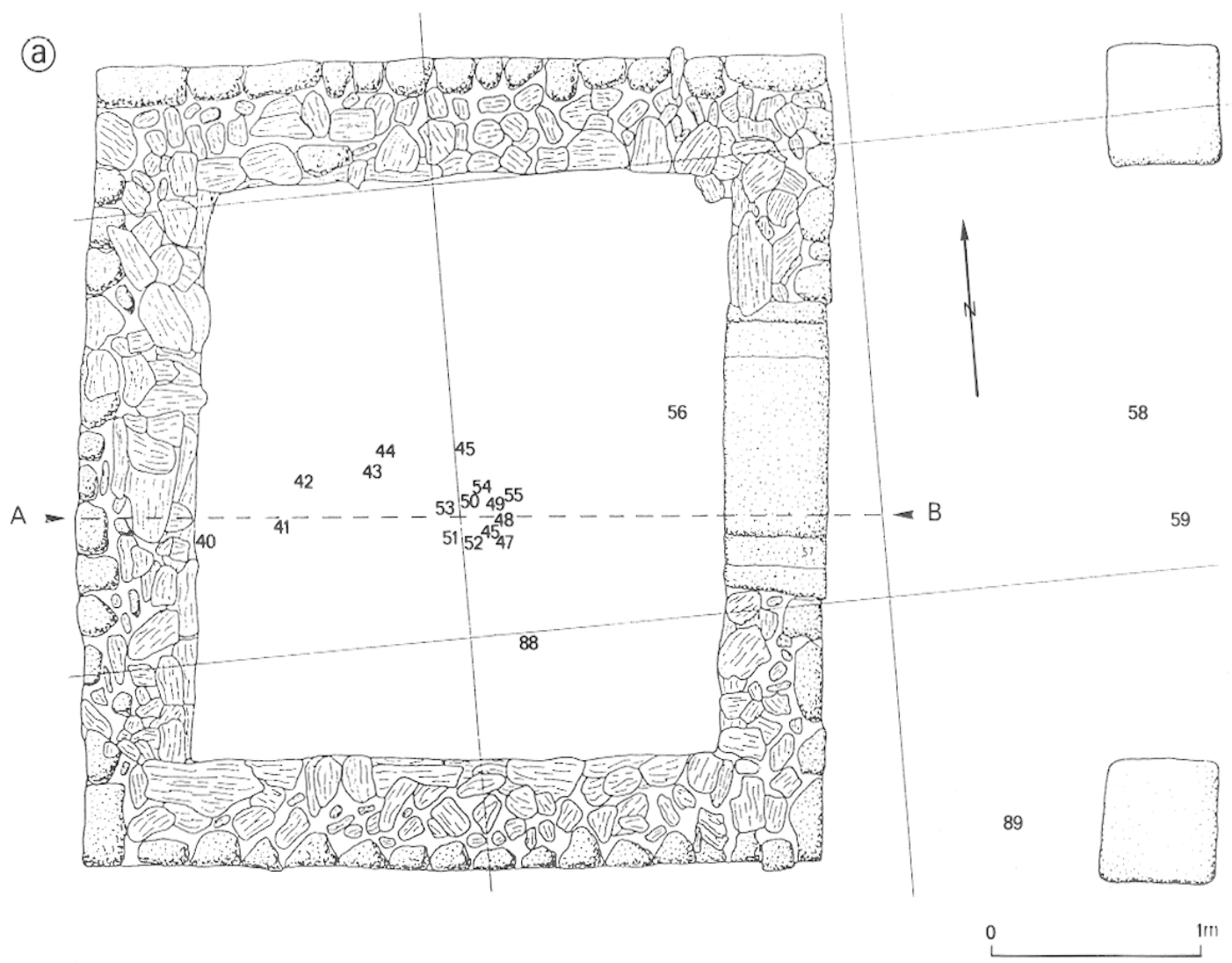

(b)

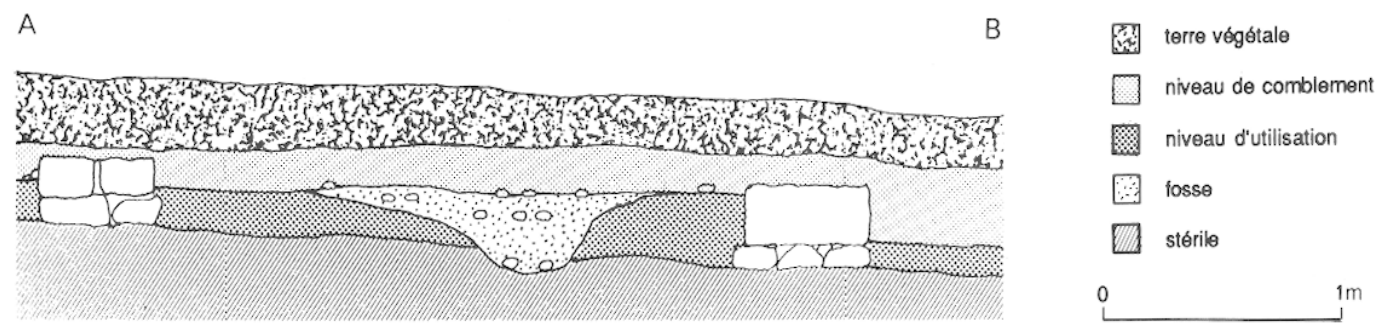

(C)
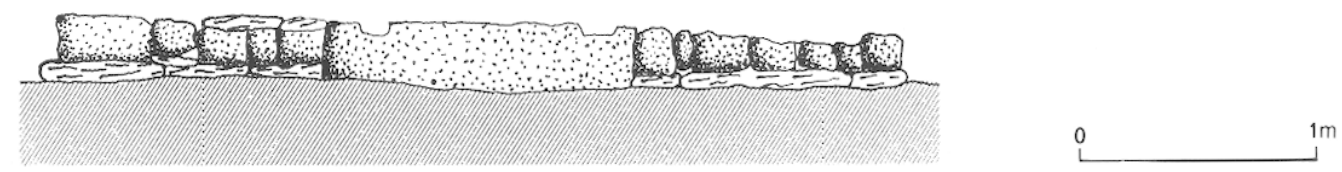

Fig. $8-$ Cella $\mathrm{n}^{0} 2$.

a, plan (les numéros 40 et suivants sont ceux de l'enregistrement des monnaies pendant la fouille; ce numéro d'inventaire est indiqué dans chaque notice du catalogue, cf. infra, note 68$)$; b, coupe stratigraphique; c, élévation de la façade est et seuil. 


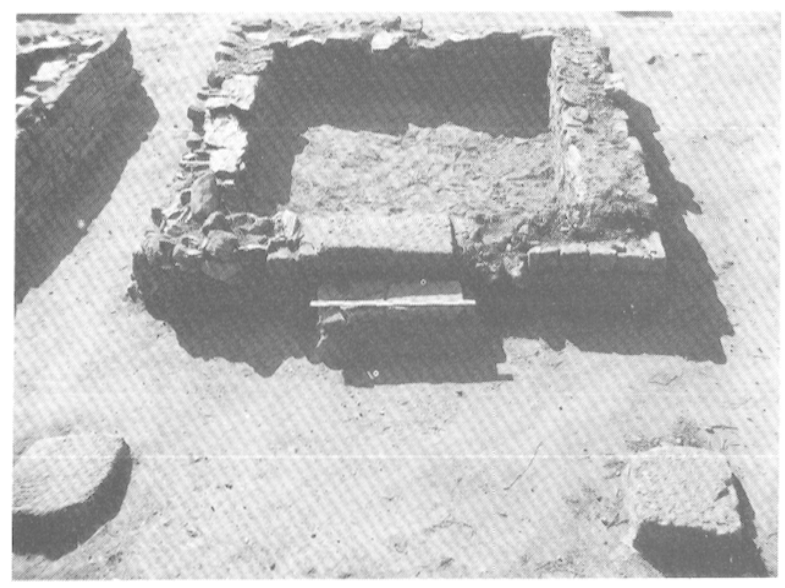

Fig. 9 - Vue de la cella $\mathrm{n}^{\circ} 3$ avec les pilastres de l'auvent et le seuil en place.

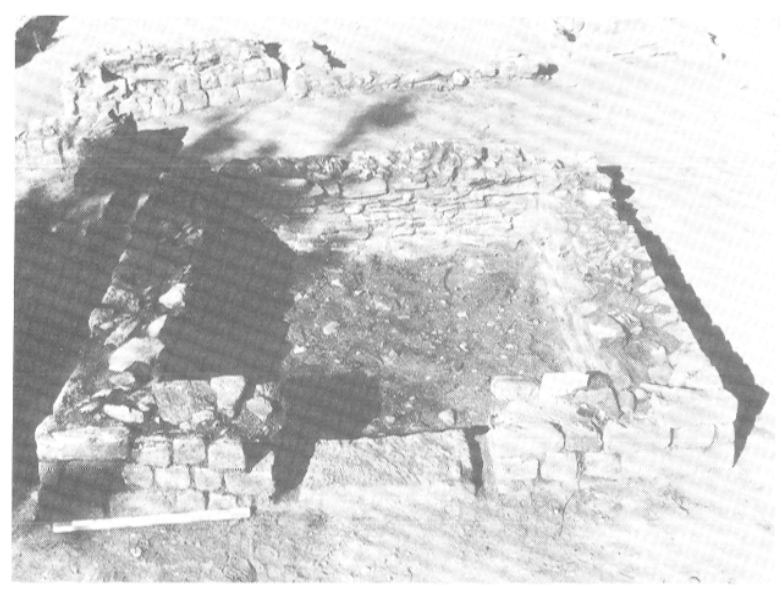

Fig. 10 - Seuil et élévation de la cella $\mathrm{n}^{\circ} 4$ : comparer le parement interne du mur ouest a ceux des cellae 2 (fig. 11) et 6 (fig. 14).

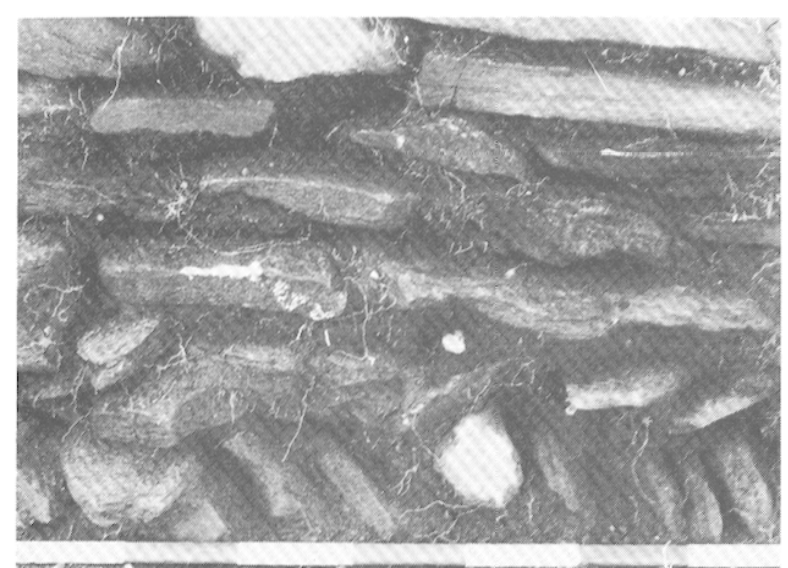

Fig. 11 - Vue du parement, interne en schiste de la cella $n^{\prime \prime} 2$ avec une première assise verticale.

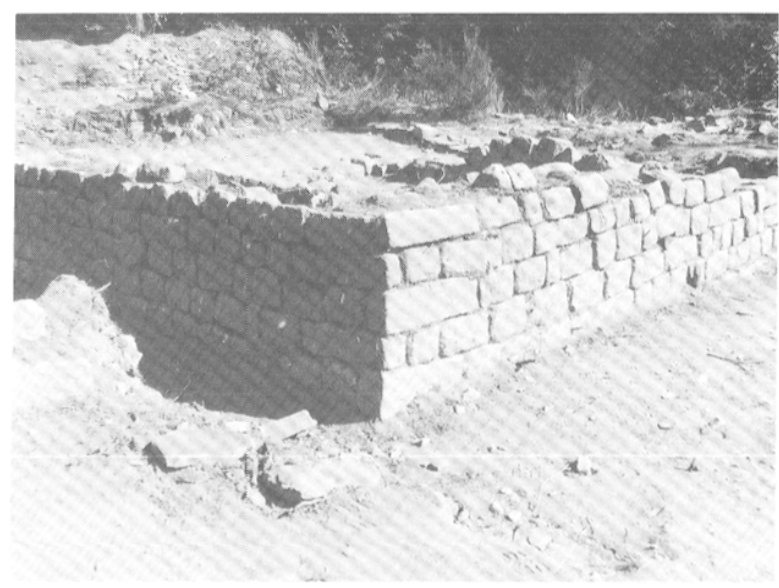

Fig. 12 - Angle nord-ouest de la cella $n^{\circ} 6$ (parement externe et élévation).

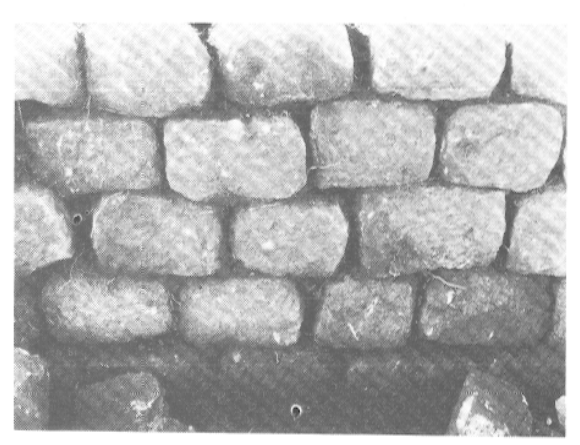

Fig. 13 - Parement externe en petits moellons de grès de la cella $\mathrm{n}^{\circ} 5$.

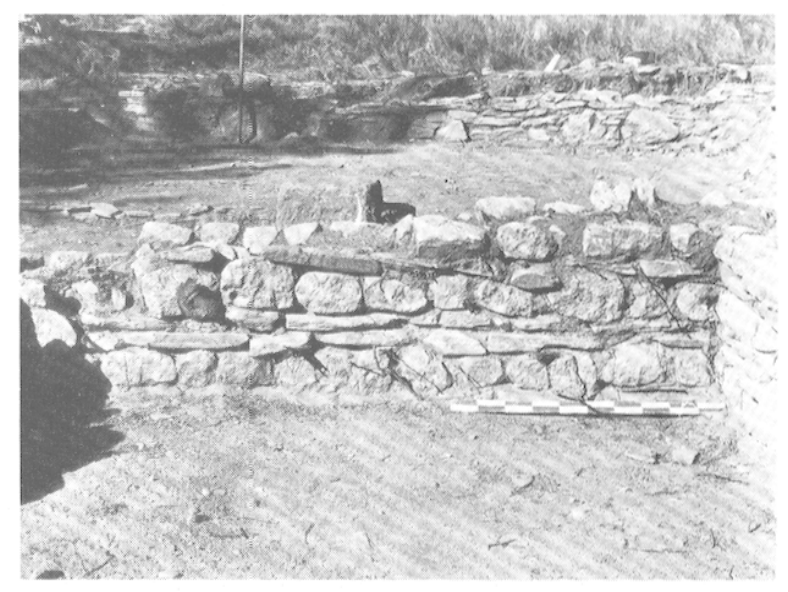

Fig. 14 - Parement interne de la cella $n^{0} 6$

(assises de schiste entre des assises de blocs de grès usés, sans doute repris des cellae plus anciennes, détruites). 


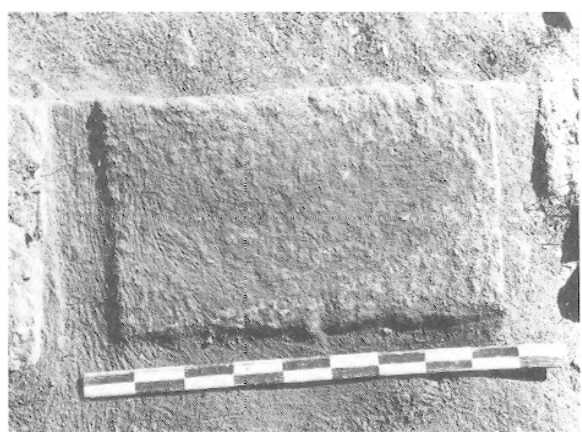

Fig. 15 - Seuil de la cella $\mathrm{n}^{0} 6$.

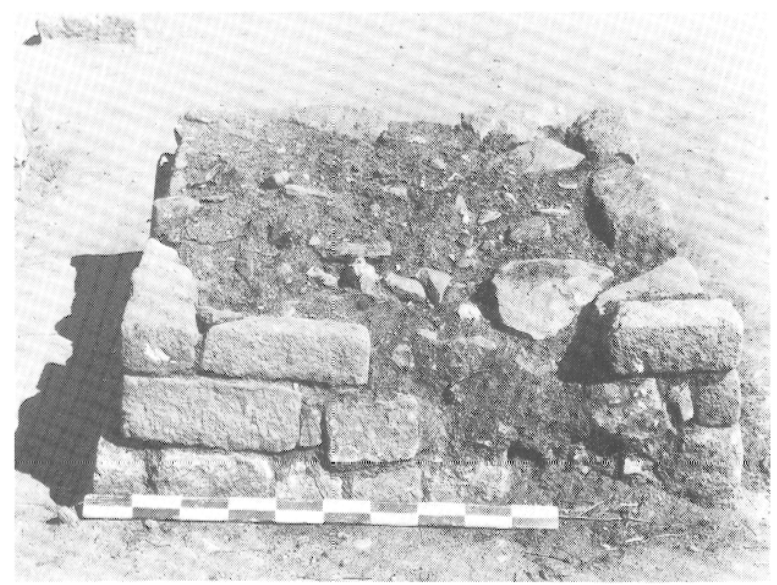

Fig. $16-$ Socle $n^{\circ} 9$.

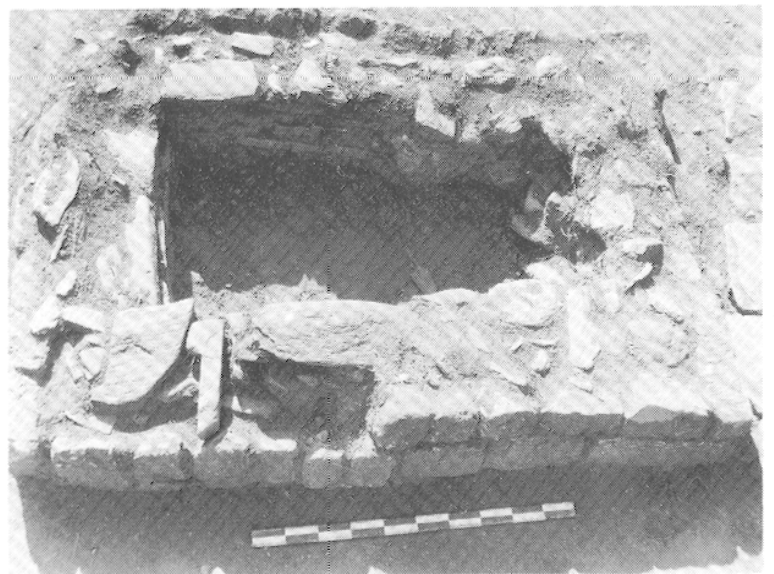

Fig. $17-$ Socle $n^{0} 12$.
Tabl. II - Description des socles.

\begin{tabular}{|r|l|l|l|}
\hline socle & dimensions & massif & description \\
\hline 9 & $1,40 / 1,40 \mathrm{~m}$ & plein & hauteur conservée sur $0,60 \mathrm{~m}$ \\
10 & $1,40 / 1,40 \mathrm{mI}$ & plein & hauteur conservée sur $0,60 \mathrm{~m}$ \\
11 & $1,80 / 1,85 \mathrm{~m}$ & creux & mur épais de $0,45 \mathrm{~m}$ \\
12 & $1,50 / 2,25 \mathrm{~m}$ & creux & mur épais de 0,40 à $0,45 \mathrm{~m}$ \\
$« \mathrm{~b} »$ & $\simeq 1,40 / 0,90 \mathrm{~m}$ & creux & hauteur conservée inconnue \\
\hline
\end{tabular}

\section{Les socles ou piliers maçonnés}

On en dénombre cinq, quatre situés dans la partie ouest de l'enclos et le dernier devant la cella "a" (fig. 3 et 5). Trois sont carrés (socles 9, 10, 11), les autres rectangulaires (socles 12 et "b») (tabl. II). Comme les chapelles, ils ont un appareil de moellons de grès à l'extérieur, alors que l'intérieur est en blocage de schiste. Les socles 9 et 10 sont pleins (fig. 16), les autres sont creux (fig. 17). Leur usage est probablement cultuel, bien que rien, ni décor peint, ni élément de sculpture ou d'inscription, ne vienne étayer ou infirmer cette hypothèse. Faut-il y voir dans tous les cas des autels pour les offrandes et les sacrifices? On peut alors se demander à quoi correspond la dissemblance de construction : la différence technique et symbolique entre les rites aux divinités vuraniennes et chtoniennes l'expliquerait-elle? Ou bien vient-elle de deux types d'utilisation, des autels et aussi des supports de statues divines, disparues ${ }^{15}$ ? Ou encore est-ce l'indice d'une construction décalée dans le temps, et alors quels sont les plus anciens? En tout cas, la localisation des cinq "socles", envisagés seuls ou par rapport aux cellae, n'apporte apparemment aucune indication.

Des éléments comparables existent à La Graufesenque, à Millau ${ }^{16}$. En effet, autour des deux fana fouillés dans le quartier des potiers, il y a des socles ou piliers identiques, de structure pleine. Mais on n'en connaît pas d'autre exemple dans la région.

15 Voir D.S., article : ara;-Dictionnaire des Mythologies, article : sacrifices à Rome. Voir également la représentation d'un sacrifice sur un côté de la mosaïque de Lillebonne : J.-P. Darmon, Les restaurations modernes de la grande mosaïque de Lillebonne (Seine-Maritime), Gallia, 36, 1978, p. 65-88, plus particulièrement p. 70 et fig. 6 «détail du tableau 1": on aperģoit, côte à côte, l'autel du sacrifice et une colonne massive et basse, support d'une statue de divinité, en l'occurrence Diane.

16 M. Labrousse, Informations archéologiques, Gallia, 38,1980 , p. 466 . 


\section{$L^{\prime}$ 'abri»}

Dans l'angle interne sud-ouest de l'enceinte ont été dégagées les bases d'un appentis d'une surface au sol de $25 \mathrm{~m}^{2}$ environ (fig. 3 et 18). Adossé au mur de clôture qui constitue deux des trois côtés bâtis - un mur de refend forme le troisième -, cet édifice, différent des cellae par sa forme et sa destination, était largement ouvert sur l'ensemble du sanctuaire : la façade est comporte en son milieu un simple socle ou pilier, identique à ceux des trois auvents déjà décrits, qui soutenait la toiture de tuile (doit-on supposer qu'à l'arrière le mur d'enceinte était assez haut pour constituer l'autre support des poutres de la charpente?).

Devant et à l'intérieur de cet édicule, le sol, sans doute pavé de schiste - à en juger par les nombreuses trouvailles de dalles surtout en façade - est plus noir que partout ailleurs sur le site ${ }^{17}$ (fig. 5). Il a livré la plus grande partie de la céramique trouvée dans tout le sanctuaire ainsi que des os d'animaux. Cela semble indiquer une activité domestique et utilitaire plutôt que sacrée dans ce secteur. Mais sa large ouverture à l'est exclut d'y voir un habitat permanent, car le climat est très rude sur le Lévézou, surtout l'hiver. Il s'agirait donc vraisemblablement d'un local de rangement du matériel nécessaire au culte et à l'entretien du sanctuaire ainsi que d'une sorte de cuisine, indispensable car, après les sacrifices aux divinités bienfaisantes, les animaux offerts étaient consommés, après cuisson, par les participants. A La Panouse-de-Cernon le temple a une annexe comparable ${ }^{18}$.

\section{Les fosses (fig. 3, 8 et 19)}

Nous avons déjà signalé la fosse profonde de 0,30 à $0,40 \mathrm{~cm}$ au centre de la cella $\mathrm{n}^{\circ} 2$ dont nous ignorons s'il s'agit d'un aménagement plus ancien que l'édifice aurait ainsi mis à l'abri ${ }^{19}$, car la dou-

17 Cela se voyait bien lors de la fouille et on le remarque aussi sur les photographies en couleurs.

18 A. Sourou, Trois sites gallo-romains du Rouergue, Gallia, 25, 1967, p. 111-151.

19 Observons que la cella $\mathrm{n}^{\circ} 2$ n'est pas au centre du sanctuaire mais bien la cella $\mathrm{n}^{0} 4$, sans fosse. Il n'y a donc pas de fosse centrale comme il y en avait dans certains sanctuaires préromains (J.-L. Brunaux, dans Les Gaulois ..., p. 33, propose plusieurs interprétations pour ces fosses centrales d'époque gauloise, le plus souvent abritées par une construction sommaire; notamment, il les rapproche du mundus latin, ouverture sur le monde souterrain des morts et des divinités chtoniennes. Sur le mundus, voir G. DumÉzıL, La religion romaine archaique, Paris, 1966, p. 344-346). Le rapprochement avec les fosses de Gournay-sur-Aronde, datées de la fin du III $^{\mathrm{e}}$ et du

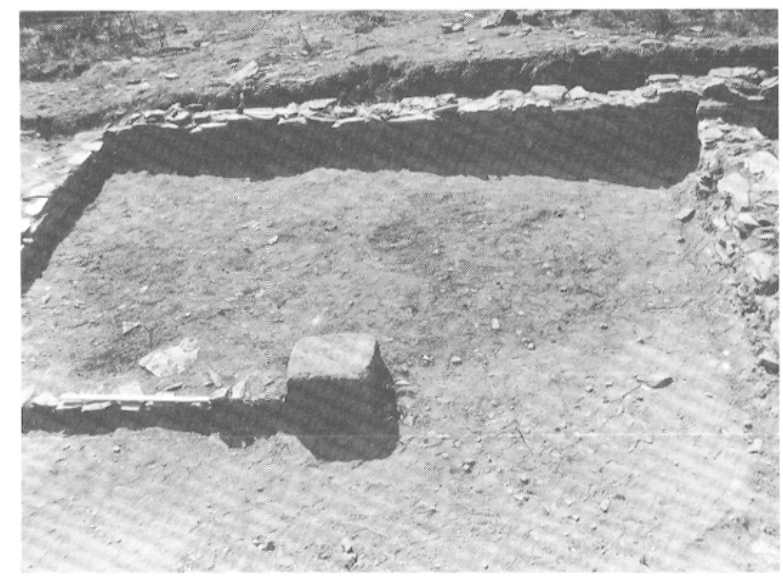

Fig. 18 - Vue de l'habitat situé au sud-ouest du péribole, avec des traces de dalles de schiste et également une zone cendreuse.

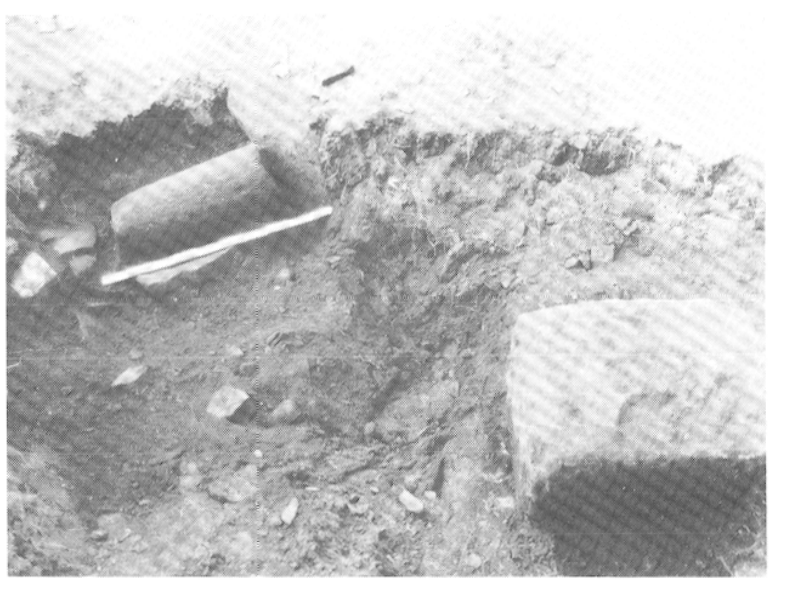

Fig. 19 - Vue de la fosse avec un débris de colonne, à l'avant de la cella $\mathrm{n}^{\circ} 6$, creusée au détriment de la cella "a" mise au jour en 1991 .

$\mathrm{II}^{\mathrm{e}}$ s. avant J.-C. et celle des Basiols du $\mathrm{I}^{\mathrm{er}}$ s. après J.-C. serait ici tout à fait hasardeux, à cause du trop grand décalage dans le temps et dans l'espace (de la Picardie au Rouergue): J.-L. Brunaux, P. Méniri, F. Poplin, Gournay I, les fouilles sur le sancluaire et l'oppidum (1975-1984), no spécial de la Revue archéologique de Picardie, 1985. La fosse de la cella $\mathrm{n}^{\circ} 2$ des Basiols n'a donné aucun ossement. Elle est plutôt à rapprocher de celle, plus élaborée et contenant des vases et des monnaies non précisées, de la chapelle CB III de Lioux (Informations archéologiques, Gallia, 42, 1984, p. 418-422, ainsi que le catalogue de l'exposition Les premiers temps chrétiens en Gaule méridionale, Antiquilé lardive et Haut Moyen Age $I I^{e}-V_{I I I^{e}}$ s., $\mathrm{n}^{\circ}$ spécial d'Archéologie en Rhône-Alpes, 1986, p. 120-122, $\left.\mathrm{n}^{\circ} 259\right)$. 
zaine de monnaies retrouvées s'échelonnent des alentours de l'ère chrétienne (as de Nîmes) à Probus, comme dans les autres cellae, datant moins les modifications de l'aménagement de ce petit secteur que la période de sa fréquentation. Elle peut aussi résulter de l'installation d'un petit autel ou d'un socle de statue, disparu lors de l'édification du temple ou après son abandon, ne contenant plus que des monnaies ${ }^{20}$. En tout cas, les deux pièces découvertes au fond de la fosse étaient du $\mathrm{I}^{\mathrm{er}} \mathrm{s}$. de notre ère (voir fig. $8 \mathrm{a}$ et infra, p. 163 et note 47 , monnaies $n^{\circ} 3$ [inv. 54] et no 26 [inv. 44]).

Une autre fosse existe à l'avant de la cella $\mathrm{n}^{\circ} 6$ (sur la figure 3 , elle est délimitée par un tireté). D'une surface de 5 à $6 \mathrm{~m}^{2}$ et irrégulière, elle descend en entonnoir jusqu'à 1,60 $\mathrm{m}$ de profondeur. La fouille de l'été 1991 a révélé qu'elle avait été creusée au détriment de la neuvième cella "a», car les murs et leur fondation ont complètement disparu à son emplacement. De plus, elle contenait des matériaux de construction, nombreuses dalles de schiste, moellons de grès, tegulae et tambour de colonne (fig. 19). D'où provient-il au juste ${ }^{21}$ ? Il y avait également, en assez grande quantité, de la céramique commune et des monnaies. L'une d'elles, découverte au fond, permet de situer le comblement de cette excavation à la fin du $\mathrm{IV}^{\mathrm{e}} \mathrm{s}$. au plus tôt, à moins qu'elle ne date la destruction de la cella «a» ${ }^{22}$.

\section{LE MOBILIER}

Il était dispersé à l'intérieur de l'enceinte, avec une densité particulière de la céramique dans la zone sud-ouest, à l'ouest de la cella $n^{\circ} 6$, également dans et devant l'"abri", où se concentrent $80 \%$ des fragments. Les monnaies les plus anciennes se trouvaient dans la cella $\mathrm{n}^{\circ} 7$ et dans ses abords immédiats, et les plus récentes, du $\mathrm{IV}^{\mathrm{e}}$ et du début $\mathrm{du} \mathrm{v}^{\mathrm{e}} \mathrm{s}$., étaient pour la plupart dans l'angle nord-est de l'enclos (infra). On soulignera l'absence de lampes.

20 Comme à Lioux (voir la note 19).

21 Voir D.S., article favissa : en temps normal il s'agit d'un dépotoir sacré pour tous les objets et offrandes devenus inutiles qu'il est interdit de réutiliser. On en connaît quelques exemples dans le monde romain au moment du triomphe du christianisme, où l'on a caché les témoignages de la foi païenne pour les soustraire aux destructions. Ici la seconde fosse peut avoir joué ce rôle à la fin du ${ } \mathrm{v}^{\mathrm{e}} \mathrm{s}$., alors que la cella «a» était déjà détruite.

22 Il s'agit de la pièce $n^{\circ} 309$ (inv. 261) datée entre 364 et 375 , sous le règne de Valentinien I $^{\text {er }}$ (infra, p. 178).

\section{La céramique}

La céramique sigillée provient exclusivement de La Graufesenque, ce qui n'a rien d'étonnant puisque ce centre de production est à une vingtaine de kilomètres de là. Les fragments sont très souvent délités et, attaqués par le gel et l'acidité du sol, vernis et décors sont très détériorés. Malgré un tamisage systématique, on est surpris par le nombre de tessons absents : un seul vase est restituable presque intégralement.

Les séries ${ }^{23}$ lisses présentes sont les formes banales Drag. 18, 35/36 et Hermet 24 mais aussi des objets moins répandus appartenant aux "services flaviens" $C$, $E$ et $F$ (fig. 20 , nos 1-3), datables entre le milieu du $\mathrm{I}^{\text {er }}$ et le milieu du $\mathrm{II}^{\mathrm{e}} \mathrm{s}$. (fig. 2l). Les vases ornés consistent en quelques Drag. 29 et 30 , Knorr 78 et Hermet 16, façonnés de Claude à Domitien et en une quinzaine de bols Drag. 37 (fig. 20, $\mathrm{n}^{\text {os }} 4-7$ ), échelonnés de 60 environ au milieu du II $^{\mathrm{e}} \mathrm{s}$. Il y a aussi quelques estampilles de potier (fig. 22) imprimées le plus souvent au fond de vases dont trois sont de forme indéterminable (estampilles 2,3 et 4$)^{24}$.

1. Rosette anépigraphe sur un plat du "service flavien $\mathrm{F}$, forme 2 (fig. 20 , no 2 ), datée entre 90 et 150 .

2. BIRAGIL : Biragil(lus) a été attribué par Oswald (Potters'stamps, p. 44) au centre de production de Banassac (Lozère), sous Domitien et Trajan, mais on sait maintenant qu'un potier de ce nom travaillait également à La Graufesenque puisqu'on a trouvé sa signature dans le décor de vases ornés au moule, dans le dépotoir du four trajanien découvert en 1979 (DAF 6: La terre sigillee ..., p. 280; Vernhet, Four ...).

3. OF CALVI : Calvus est situé à La Graufesenque sous Néron et Domitien par Oswald (Polters'stamps, p. 55). Mais ce cognomen très répandu est attesté aussi bien dans un dépotoir tibérien fouillé en 1980 (Informations archéologiques, Gallia, 41, 1983, p. 478) que dans celui du grand four trajanien (Vernhet, Four ..., p. 32). On le rencontre aussi sur trois gralfites d'enfournement de La Graufesenque, les $n^{\text {os }} 47$, 53 et 54 , datés du règne de Néron et en outre ce

23 Pour limiter une abondante bibliographie, voir en dernier lieu DAF 6, la terre sigillée..., p. 96-103; C. Bémont, F. Beck, A. Vernhet, La Graufesenque, village de potiers gallo-romains, Catalogue de l'exposition, 1987, qui en rappellent l'essentiel. Voir aussi VERnhet, Création flavienne...

24 Voir Oswald, Potters'stamps; - DAF 6, La lerre sigillée... : index des noms de potiers, p. 277-286. 

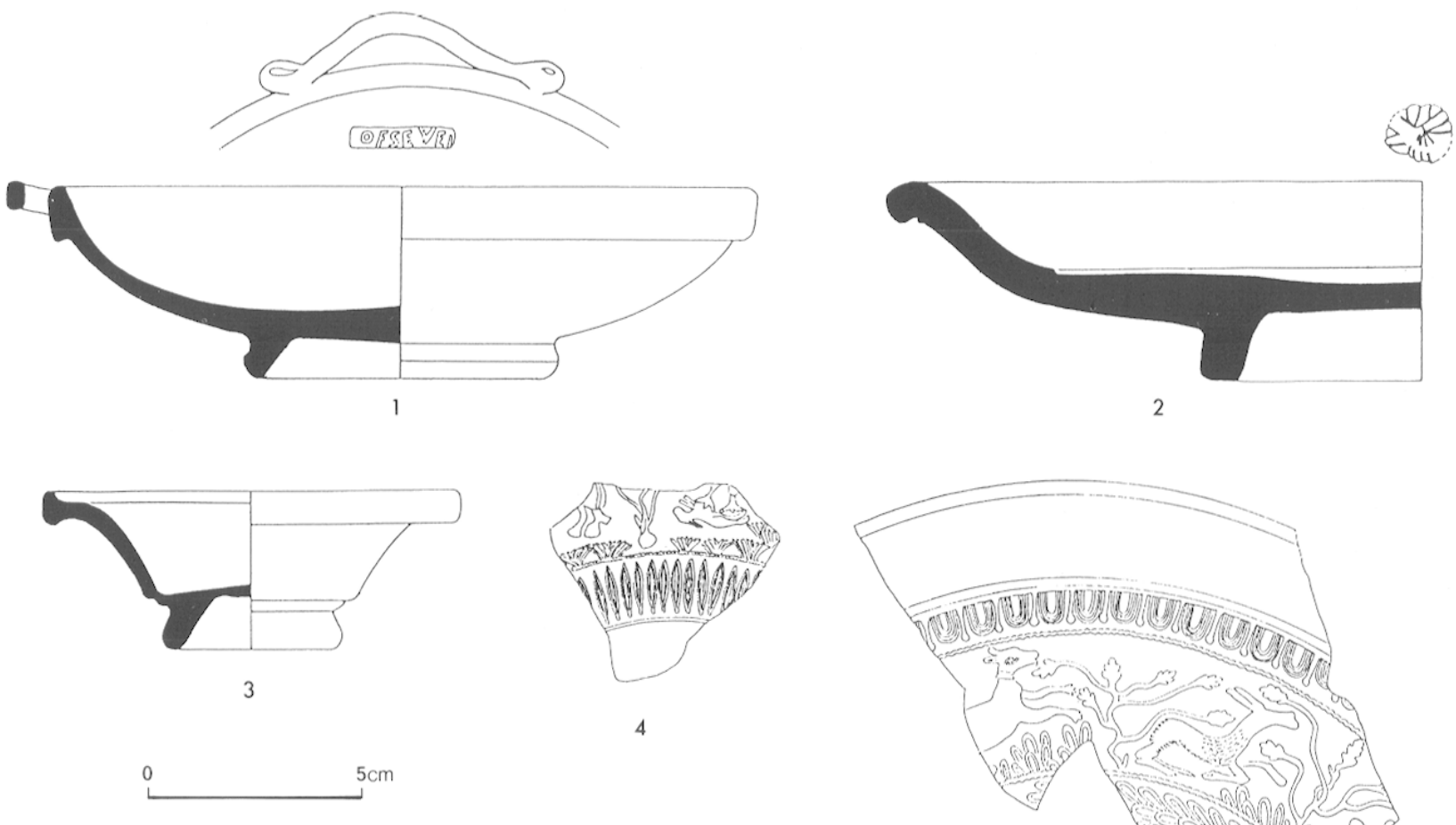

4

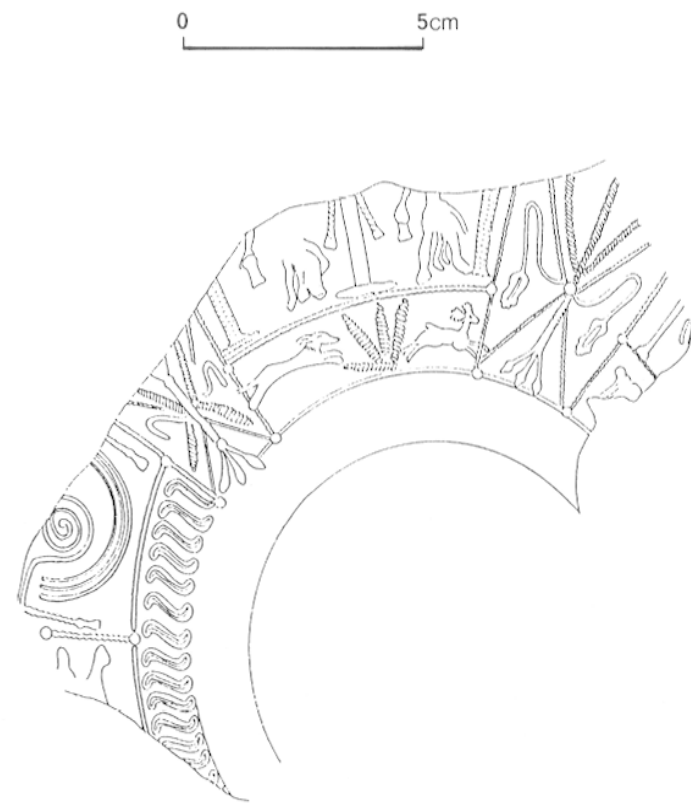

6

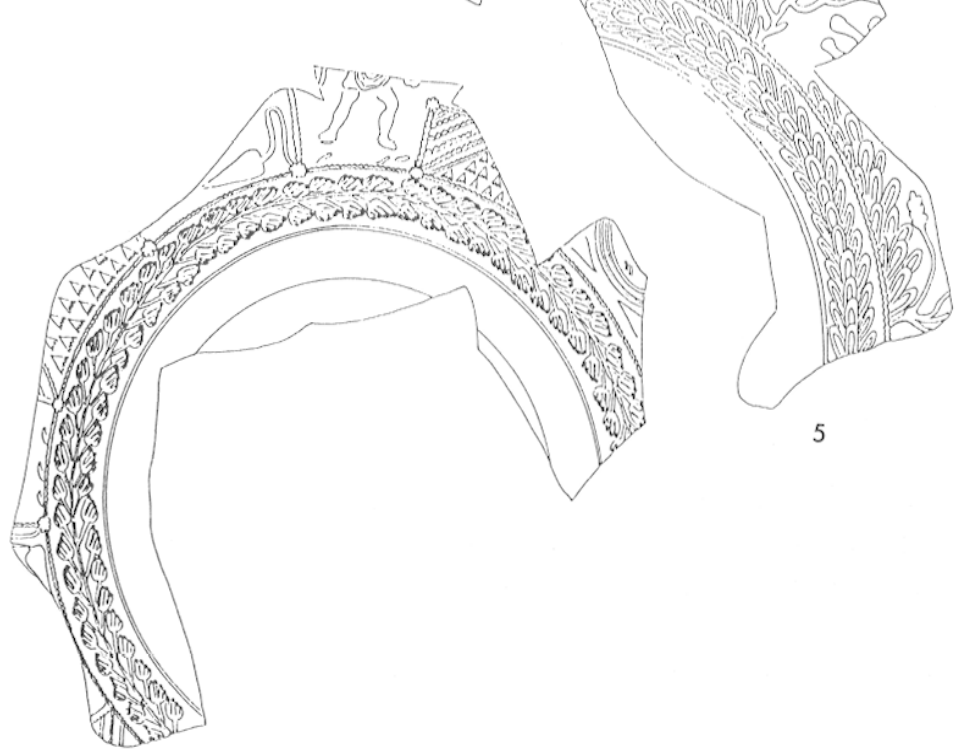

7

Fig. 20 - Sigillée des Basiols. Quelques vases lisses : 1, forme 2 du service flavien $\mathrm{F} ; 2$, forme 2 du service flavien $\mathrm{E} ; 3$, forme 1 du service flavien C; les autres formes lisses courantes n'ont pas été dessinées. Quelques vases ornés : 4-7, Drag. 37. 


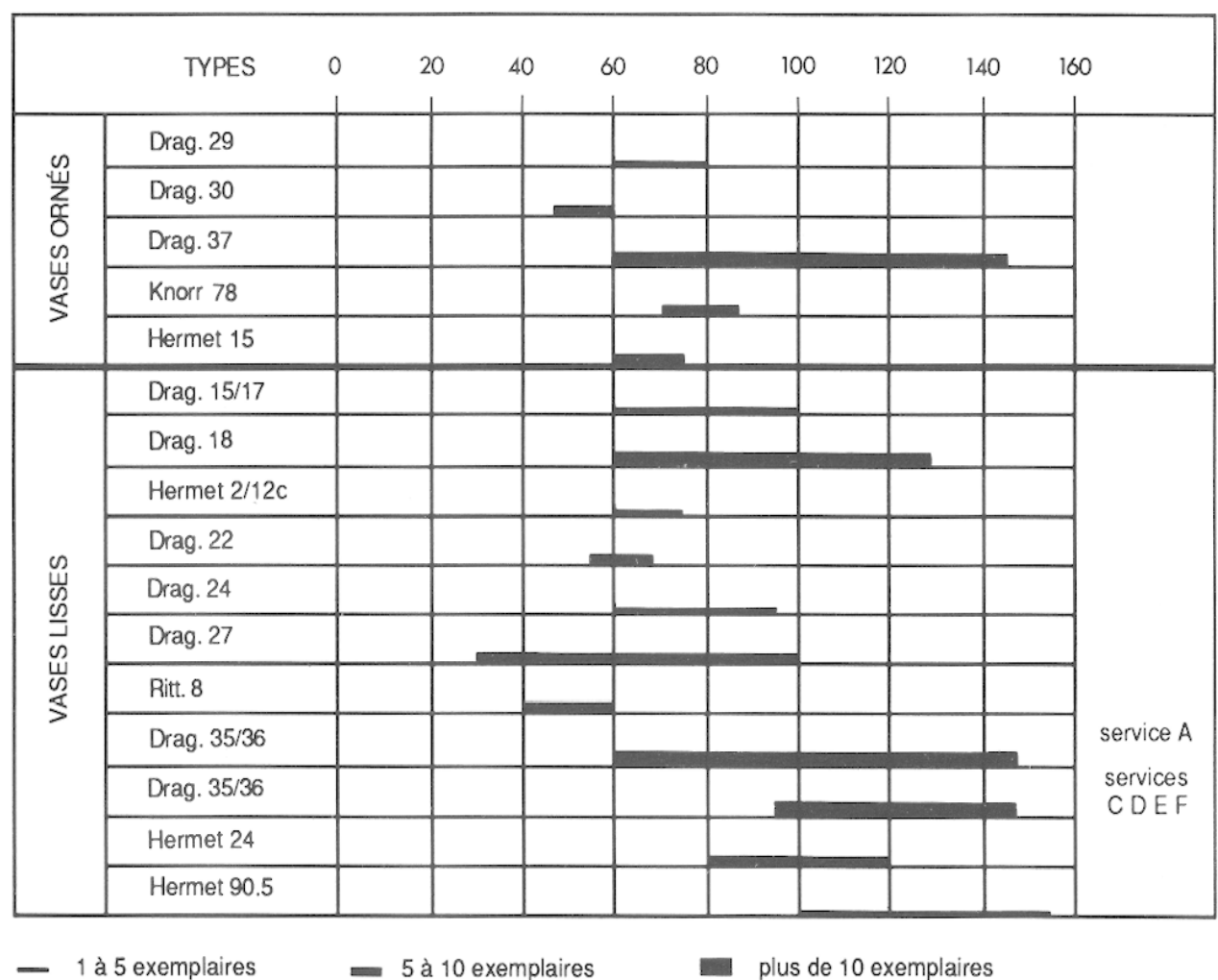

Fig. 21 -

Datation des céramiques sigillées de La Graufesenque trouvées aux Basiols (d'après A. Vernhet).
Fig. 22

Les cinq estampilles sur céramique sigillée.

1
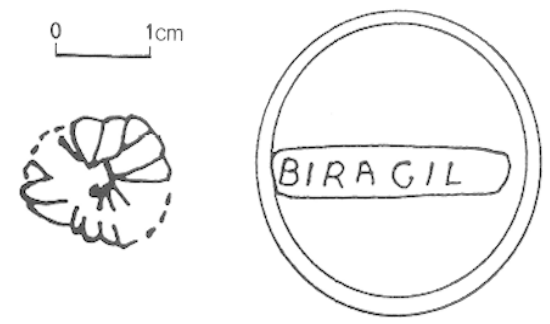

2

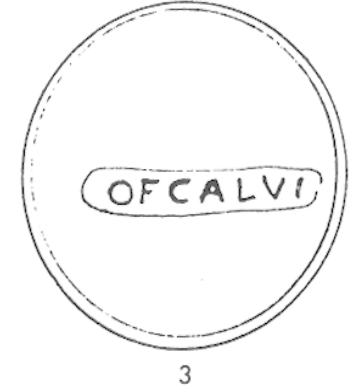

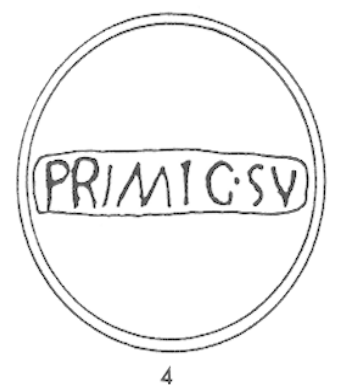

5

potier a signé l'assiette-support du graffite 96 (Marichal, Les graffites..., p. 200). Auquel des deux ou trois artisans homonymes tout au long d'une centaine d'années faut-il attribuer l'objet trouvé aux Basiols, d'autant plus que la forme ainsi marquée est indéterminable?

4. PRIMIG. SV: Oswald (Polters'stamps, p. 247) attribue cette signature abrégée à (C. Iulius) Primig (enius) Su(rius/-rus), sous Néron et Vespasien, dans un centre de production indéterminé, alors que la liste dressée par F. Hermet le mentionne à L a Graufesenque ${ }^{25}$. S'agit-il d'un potier à double cognomen

25 F. IIERMEt, La Graufesenque (Condatomago), vases sigillés, graffites, Paris, 1934, p. 205, n⿳ 130. ou alors de deux individus associés, un citoyen romain et un pérégrin, ou deux citoyens au même gentilice de lulius? Il n'est pas attesté sur les graffites ou dans une des fosses datées et on gardera donc jusqu'à nouvel ordre la datation traditionnelle.

5. OF SEVER : Sever(us) de La Graufesenque, attribué par Oswald (Potters'slamps, p. 296) à la période de Néron el Vespasien, a laissé de très nombreux témoignages signés de son activité. Si on ne rencontre pas son nom sur les bordereaux de La Graufesenque, le graffite 197 le cite et surtout on a trouvé ses estampilles près du four trajanien (Vernhet, Four ..., p. 34). Ajoutons que le support de la marque des Basiols est un vase du "service flavien E», f. 2 (fig. 20, no 1), daté entre 70 et 100 après J.-C. 
Tabl. III - Chronologie des estampilles.

\begin{tabular}{|l|l|l|}
\hline & selon Oswald & chronologie proposée \\
\hline $\begin{array}{l}\text { Biragillus } \\
\text { Calvus }\end{array}$ & Domitien-Trajan & Trajan \\
Néron-Domitien & $\begin{array}{l}30 / 40 ? \text { Néron-Vespasien? } \\
\text { Trajan? }\end{array}$ \\
$\begin{array}{l}\text { Primig( ) Su( ) } \\
\text { Néron-Vespasien }\end{array}$ & Néron-Vespasien & $\begin{array}{l}\text { Vespasien-Trajan } \\
\text { (ici Vespasien-Domitien) }\end{array}$ \\
anépigraphe & $?$ & 90 à 150 environ (datation du \\
(rosette) & & support) \\
\hline
\end{tabular}

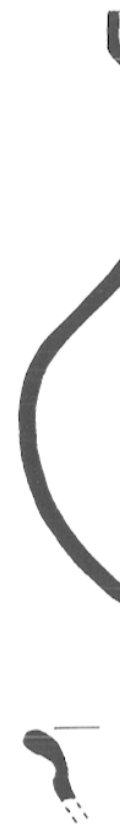

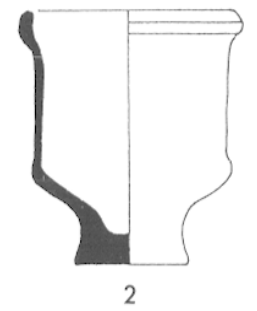
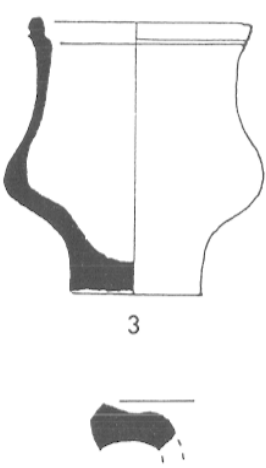

On déduit des quatre noms relevés que malgré quelques incertitudes de datation, pour Calvus par exemple, deux ou trois potiers sont en activité à l'époque de Trajan, la période de production de Primigenius $\mathrm{Su}$ ( ) restant peut-être à modifier. Les données chronologiques sont résumées dans le tableau III.

Bien que très rares, on a aussi quelques objets de sigillée claire $B$, fabriquée après la sigillée rouge dans les officines de La Graufesenque même et dans deux quartiers de Millau sur la rive droite du Tarn, vers 150 et jusqu'à 300 environ. Il s'agit d'une vaisselle de médiocre qualité, à couverte rouge orangé (fig. 23, $\left.\mathrm{n}^{\circ} 1\right)^{26}$.

26 Voir A. Vernhet, Les dernières productions de La Graufesenque et la question des sigillées claires B, Figlina, 2, 1978 , p. 33-49.
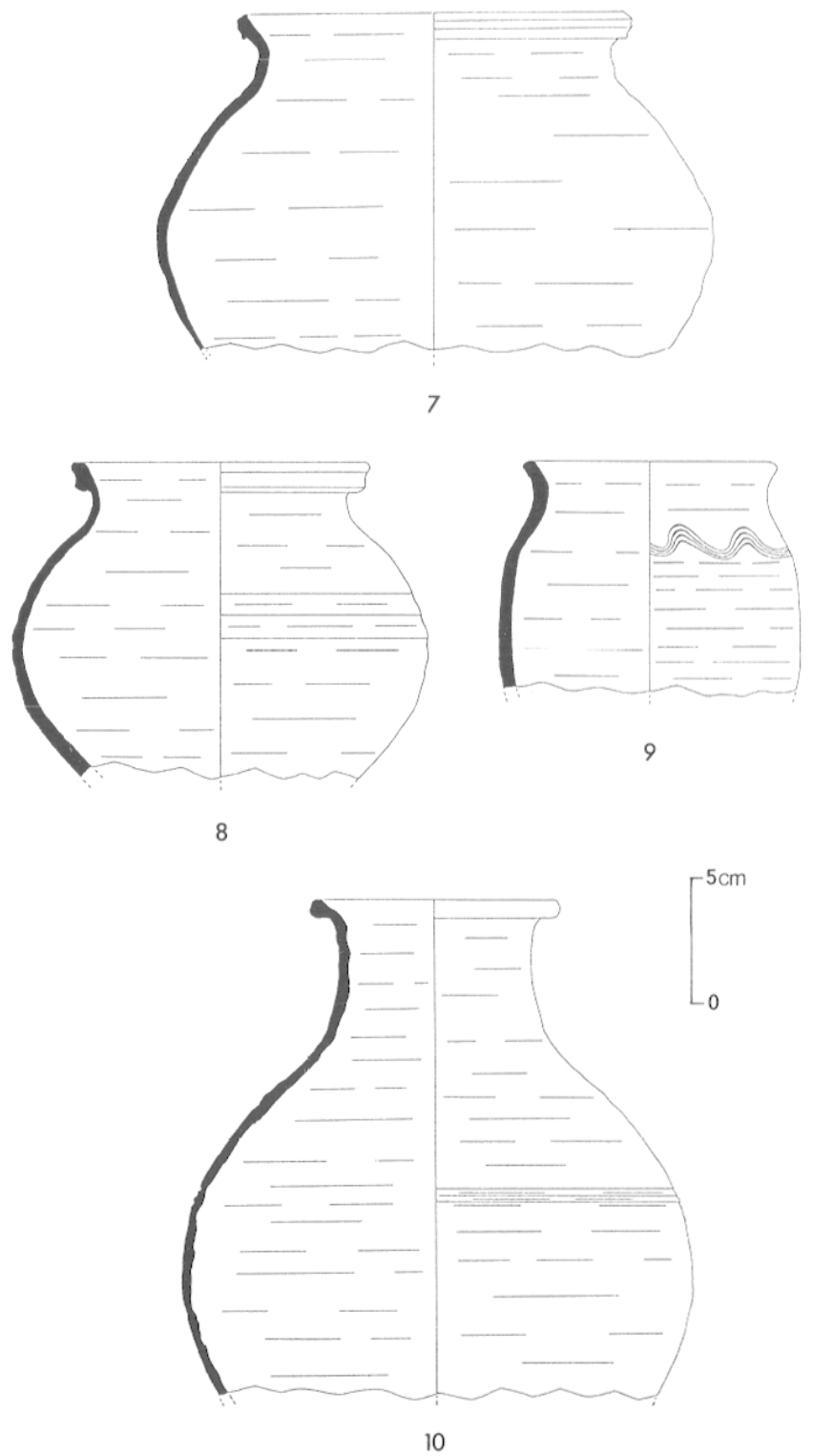

Fig. 23 - Céramique des Basiols : 1, flacon de sigillée claire B; 2-6, vases de céramique commune; 7-10, grands vases de céramique commune. 
Ajoutons à ces vaisselles fines de la céramique commune et de la céramique modelée, bien difficiles à situer dans le temps.

La première est largement représentée par des fragments d'urnes ovoïdes (fig. 23, nos 7-9), d'assiettes, de jattes, de cruches aux tailles variables, d'écuelles, de vases tripodes, à la teinte grise ou noire, d'origine locale, mais également par quelques petits vases à offrande à engobe blanc (fig. 23, $\mathrm{n}^{\text {os }} 2-3$ ), très courants dans les autres sancluaires rutènes ${ }^{27}$, temples ruraux (fanum du Combalou à Roquefort) ou urbains (fana de La Graufesenque et du quartier du Rajol à Millau), grotles-sanctuaires du Larzac (Le Rajal del Guorp, commune de Millau). Sans oublier un col d'amphore Dressel 20, amphore à huile de Bétique dont on trouve de si nombreux témoins dans la vallée du Rhône aux $\mathrm{I}^{\mathrm{er}}$ et $\mathrm{II}^{\mathrm{e}} \mathrm{s}$.

$\Lambda$ la seconde catégorie appartiennent deux ou trois vases de taille moyenne, à pâte grossière et à panse brossée, ornés au peigne sous le col (fig. 23, $\mathrm{n}^{\mathrm{o}}$ 9). Ils sont peut-être du I $\mathrm{I}^{\mathrm{er}} \mathrm{s}$. avant J.-C., mais il est bien difficile de dater la céramique modelée, sans doute toujours fabriquée sous l'Empire, concurremment à la vaisselle tournée.

\section{Statuettes en terre cuite}

Quelques petits fragments de statuettes à pâte blanche fabriquées dans l'Allier ont été récoltés dans toutes les cellae, figurines représentant poule, pigeon, cheval, figure humaine grotesque...

\section{Le verre}

On trouve quelques morceaux de verre, verdâtres ou bleutés, de forme indéterminée. Il ne semble pas y avoir de verre à vitre. On note toutefois des fragments d'un flacon de teinte verte, avec une anse fixée sous la lèvre de type Isings 52 (fig. 24, $\left.n^{0} 1\right)$. Il y a surtout un chaton de bague, de couleur bleue et de forme convexe et ovale $(13,5$ sur $11 \mathrm{~mm})$, trouvé à l'extérieur de l'angle nord-est de la cella $\mathrm{n}^{0} 6$. Sur l'intaille, très abimée, on reconnaît Mercure, seule figure divine identifiable explicitement dans ce sanctuaire. Il est représenté de manière classique, nu, de face et un peu déhanché, tenant une bourse de la main droite (fig. 24, $\mathrm{n}^{\circ} 2$ ). Mercure est le dieu le plus honoré des Gaulois, si l'on en croit César, et son succès continuera à l'époque impériale, à en juger par d'innombrables témoignages épigraphiques et figurés. Son rôle de guide des voyageurs justifie sa

27 Histoire du Rouergue, Rodez, 1979, p. 65-67; J.-P. Senkes, Trente ans de recherches archéologiques autour de Roquefort, 1947-1976, 1977, p. 28-35. présence dans un sanctuaire comme le nôtre, localisé sur une route franchissant un $\mathrm{col}^{28}$. La datation de cet objet est impossible.

\section{Les ossements}

En quantité restreinte, ils sont très fragmentés et en très mauvais état. Il s'agit d'os d'animaux, déchets alimentaires localisés surtout dans et devant l'abri au sud-ouest. Ils n'ont pas encore été étudiés.

\section{Les objets métalliques}

On signalera des fragments de tôle de bronze, un bouton à bélière en tôle repoussée et une boucle de ceinture à ardillon de fer, celle-ci trouvée à l'extérieur de l'angle nord-est de la cella $\mathrm{n}^{\circ} 6$ (fig. $24, \mathrm{n}^{\circ} 3$ ).

Les objets en fer sont beaucoup plus abondants avec de très nombreux clous de charpente ou de fixation des tuiles dont certains encore en place dans les trous prévus à cet effet. Il y a aussi quelques clous de chaussure ${ }^{29}$ et des fragments interprétés, sous toutes réserves, comme une plaque de serrure et son loquet, trouvés dans la cella n $^{\circ} 4$. Enfin avec la même prudence, on proposera d'identifier un dernier fragment de fer, récolté à l'extérieur et au sud de la cella $\mathrm{n}^{0} 6$, comme une marra, c'est-à-dire une sorte de houe dentée, de 201 sur $75 \mathrm{~mm}$, employée pour arracher les mauvaises herbes (fig. 24, no 4).

Ajoutons 316 monnaies de bronze, 2 d'argent, antiques, et 2 d'argent du XvII ${ }^{\mathrm{e}}$ s. (voir infra, p. 168179).

\section{REMARQUES}

Le site des Basiols a été sans nul doute un lieu où, dans des édifices groupés à l'intérieur d'une enceinte sacrée, se sont déroulés des rites et cérémonies de cultes ruraux. En l'absence d'inscriptions ou de représentations divines, sauf l'intaille à l'image de

28 Rappelons le culte, sur les sommets, du Mercure gallo-romain : P.-M. Iuvar, Les dieux de la Gaule, Paris, 1976, p. 67-70 [p. 69]; - Dictionnaire des Mythologies, articles: Divinités gallo-romaines (P.-M. Duval) et Mercurius (R. Schilling). César décrit le Mercure gaulois comme celui "qui indique la route à suivre, qui guide le voyageur" (...viarum atque itinerum ducem, B.G., VII, XVII, C.U.F.). Ce devait ètre un rôle divin particulièrement apprécié dans ce sanctuaire très isolé en bordure d'une grande route! Par ailleurs voir les statuettes de bronze du dieu répertoriées dans les XviII' et $\mathrm{XLIII}^{\mathrm{e}}$ suppl. à Gallia: II. Rolland, Bronzes antiques de Haule Provence, Paris, 1965;-H. Oggiano-Bitar, Bronzes antiques des Bouches-du-Rhône, 1984.

29 Sur la présence desquels on peut s'interroger, tout comme sur celle de la boucle de ceinture qu'il serait intéressant de dater. Rappelons qu'un habitat permanent nous paraît très improbable dans le sanctuaire, faute d'un local approprié. Il peut s'agir d'offrandes. 


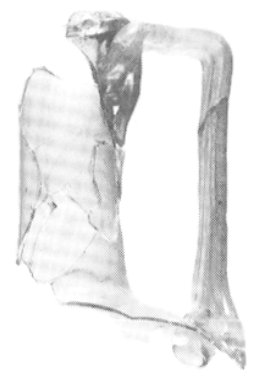

1

3

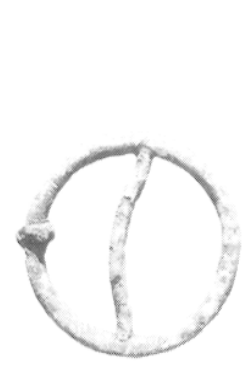

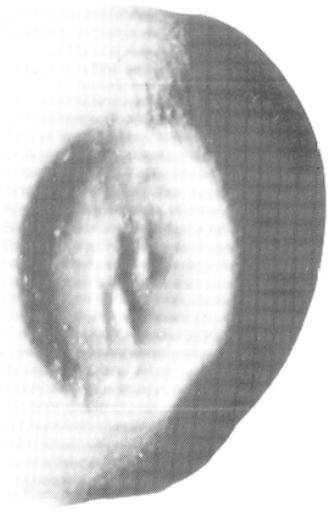
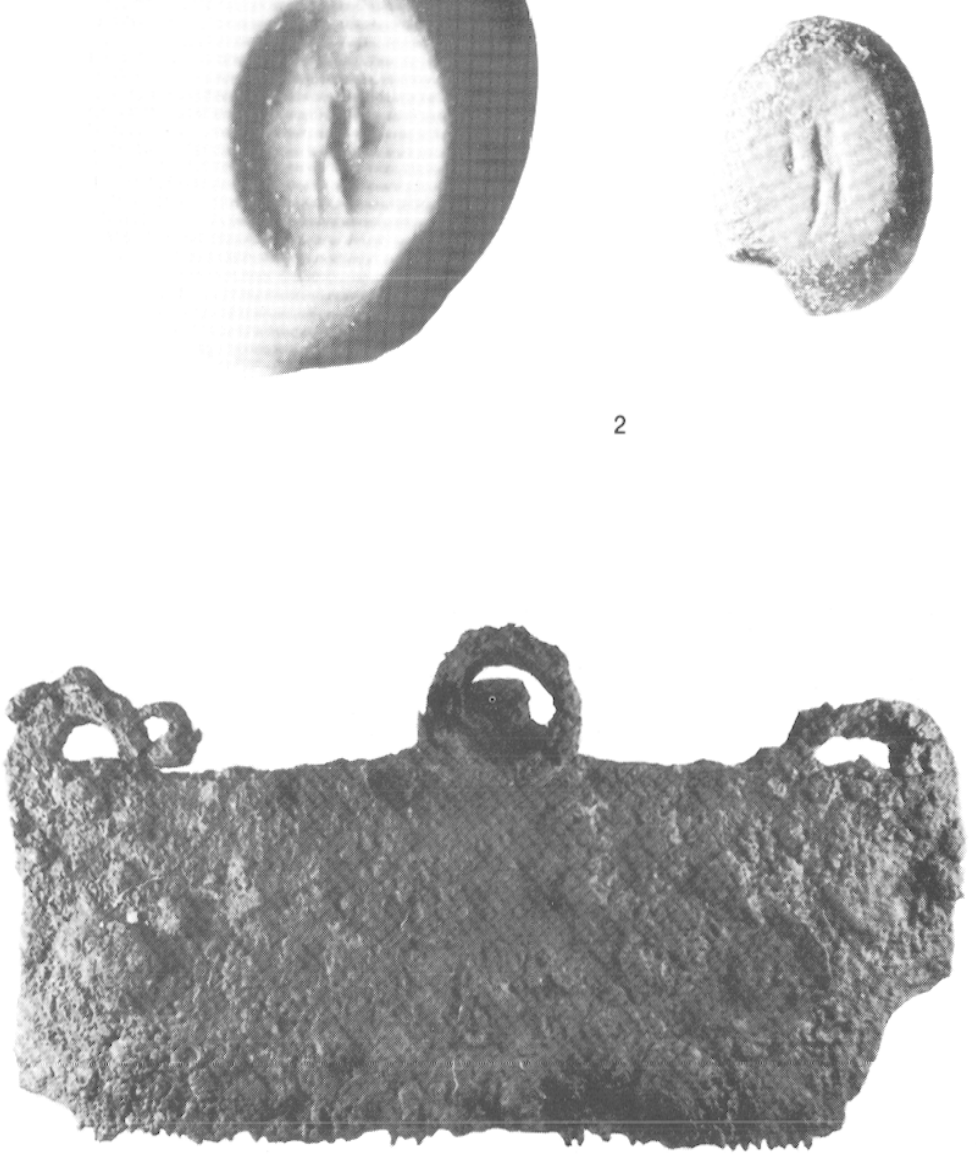

Fig. $24-$ Mobilier divers.

1 , col de flacon en verre (hauteur de l'anse : $65 \mathrm{~mm}) ; 2$, intaille ovale à l'image de Mercure trouvée à l'extérieur de l'angle nord-est de la cella $\mathrm{n}^{\circ} 6$ (à droite, l'original; à gauche, le moulage; dimensions : $13,5 \times 11 \mathrm{~mm}$ ); 3 , boucle de ceinture trouvée à l'extérieur de l'angle nord-est de la cella $\mathrm{n}^{\circ} 6$ (diamètre $: 44 \mathrm{~mm}$ ); 4 , marra? trouvée hors de la cella $\mathrm{n}^{\circ} 6$, côté sud (dimensions : $201 \times 75 \mathrm{~mm}$ ).

Mercure ${ }^{30}$, on ne peut dire à quelles divinités du panthéon celtique et gallo-romain étaient dédiées les neuf cellae, ni quels étaient au juste les rites pratiqués. On entrevoit tout juste la piété de gens pauvres, rares habitants des environs et voyageurs, grâce à leurs modestes offrandes, une monnaie ou un petit vase, en général peu luxueux.

30 Rien qui ressemble à des restes de statues comme dans le sanctuaire de Camp Ferrus (M. Bessov, Le Fanum de Camp Ferrus à Loubers (Tarn), Gallia, 36, 1978, p. 187-218) ou de Lioux (supra note 19). Les statues de cultes étaient peutatre tout simplement en bois ou en pierre fruste, peinte à la rigueur.
Chacune des cellae était-elle dédiée à une sculc divinité ? Pourquoi a-t-on vite abandonné les chapelles 7 et 8 ? Elles sont d'ailleurs bizarrement positionnées par rapport au péribole qui, s'il existait déjà, laissait un espace suffisant pour édifier les sept autres. En tout cas les nouvelles constructions, un peu plus grandes et mieux construites, sans doute bâties en partie avec les matériaux des deux plus anciennes, n'ont pas empiété sur ou réutilisé leurs fondations. En outre, de quelle époque dater chacun de ces neuf édifices? Grâce aux monnaies (infra, p. 162, tabl. VII), les plus anciens, notamment le $n^{0} 7$, paraisscnt ètre du règne d'Auguste, contemporains de sa politique de restauration religieuse à 
Rome (voir les Res Gestae Divi Augusti. 20, 21), mais surtout du moment où la Gaule Chevelue commence à adopter les méthodes de construction romaines. Les autres sont plus tardifs, peut-être du milieu du rer $^{\mathrm{e}}$. de notre ère. I.es similitudes architecturales suggèreraient que les cellae nos 1 à 6 sont plus ou moins contemporaines, et que l'enceinte a été construite pour elles. Mais quel sens attribuer à la présence ou à l'absence d'auvent qui donne à trois des édifices l'allure d'un temple classique sommaire (supra note 13)? Pourquoi ces variations d'orientation, légères mais visibles sur le plan? A quoi servaient au juste les socles et de quand datent-ils?

Quand on regarde le plan de ce sanctuaire à chapelles multiples, on est étonné de la difficulté à trouver des parallèles proches ou lointains. Une comparaison avec l'enclos de Camp Ferrus ${ }^{31}$ est peu satisfaisante car, si la fouille a révélé l'existence de deux ou trois temples avec une annexe, ils se sont succédé dans le temps, et il s'agit d'un fanum traditionnel à galerie et porche. Dans le Vaucluse, le sanctuaire gallo-romain de Verjusclas à Lioux ${ }^{32}$, isolé dans la garrigue, présente à première vue plus de ressemblance, avec une enceinte dont la porte se trouve à l'est, enfermant trois cellae ouvertes à l'orient. Avec environ $4 \mathrm{~m}$ de côté, ces petites pièces carrées sans auvent sont très proches de celles des Basiols par leur plan et leurs dimensions, leurs murs en moellons grossiers liés à l'argile et leur toit en tuile. La chronologie de cet ensemble est également comparable, avec un premier état peu perceptible sous Auguste, un réaménagement au milieu du $\mathrm{I}^{\mathrm{er}} \mathrm{s}$. et, au début $\mathrm{du} \mathrm{IV}^{\mathrm{c}} \mathrm{s}$., un abandon des chapelles enfermées dans le péribole, mais au profit d'une cella nouvelle située à l'extérieur et orientée au sud, ce qui n'a pas été trouvé aux Basiols. Nous ne pouvons pas donner d'autres références car les exemples de sanctuaires à deux ou trois temples dans une enceinte, connus ailleurs, nous ont paru différents, avec surtout des fana à galerie de type traditionnel, juxtaposés ${ }^{33}$.

31 Supra note 30.

32 Supra note 19.

33 C. Ballester (Les sancluaires ...) n'en mentionne aucun dans la région sinon celui de Camp Ferrus. Signalons tout de même le sanctuaire rural ou de vicus, aux trois temples de type romain, de Roujan dans l'Ilérault (Gallia Informations, 1987-1988, 2, p. 256); - celui du Gué de Sciaux à Antigny, avec trois fana à galerie et un long bâtiment le long de l'enceinte à l'est, interprété comme des propylées (C. RichaRd, Lieux cultuels gallo-romains du sud de la Vienne : apports de la prospection aérienne, Aquitania, 5, 1987, p. 133-148, plus particulièrement p. 137-138: "A 1, zone 1»). Quant au sanctuaire d'Argenton-sur-Creuse, il aligne deux enclos avec trois

\section{LES MONNAIES DU SANCTUAIRE}

\section{PréSENTATION DES MONNAIES}

En 1987, le sanctuaire des Basiols a livré 320 monnaies dont 2 du xvile s. (nos $319-320)$ qui n'ont évidemment aucun rapport avec les 318 pièces romaines que nous allons étudier ${ }^{34}$. Elles résultent d'une perte récente sur un site qui ne devait alors plus rien évoquer pour personne, à imaginer qu'on ait pu encore voir les vestiges des constructions antiques.

Les monnaies romaines sont dans un état de conservation très inégal. Beaucoup ont longtemps circulé avant d'être offertes dans le sanctuaire - il suffit de mentionner la centaine d'as lisses ou presque ( $n^{\text {os }} 177-184$ et 192-278), dont les poids sont parfois si faibles ${ }^{35}$ qu'il faudrait peut-être voir dans certains des semisses. D'autres monnaies sont très corrodées, en particulier les as de Lyon, à cause de la nature chimique du sol ${ }^{36}$. Enfin les dernières pièces du catalogue ( $\left.\mathrm{n}^{\text {os }} 311-318\right)$ sont en si médiocre état qu'il est impossible de déterminer s'il s'agit d'antoniniani de la seconde moitié du $\operatorname{III}^{\mathrm{e}} \mathrm{s}$. ou bien de piècettes de la fin du Ive et du début du ve $\mathrm{s}$. Il serait intéressant de le déterminer car, concentrées dans l'angle nord-est, elles seraient les pièces les plus tardives des Basiols, ultimes témoins de la fréquentation du sanctuaire. Au contraire, d'autres monnaies sont en bon état, par exemple le denier d'argent $n^{\circ} 1$ et la plupart des as de Nîmes.

Les 318 monnaies antiques s'échelonnent de la fin du ${ }^{\mathrm{e}}{ }^{\mathrm{e}}$ s. avant J.-C. au ve $\mathrm{v}^{\mathrm{e}}$. de notre ère (tabl. IV

temples en enfilade, tous ouverts à l'est: deux fana galloromains et une cella carrée de $4,90 \mathrm{~m}$ de côté, décorée de peintures, à couverture de tuile et protégée sans doute par un auvent. Elle est datée de la première moitié du $\mathrm{I}^{\mathrm{er}} \mathrm{s}$. de notre ère et paraît avoir été abandonnée après la fin du $\mathrm{m}^{\mathrm{c}} \mathrm{s}$. ou le début $\mathrm{du}_{\mathrm{IV}} \mathrm{s}$. Des offrandes ont été retrouvées en grande quantité, mais il y avait seulement 25 monnaies dans la cella et son enclos (13,40 sur $13 \mathrm{~m})$ : voir G. Covlon, S. Deyts, G. LinTz et alii, L'aire cultuelle des Mersans à Argentomagus (Saint-Marcel, Indre) : l'apport des fouilles de 1982, Cahiers d'Archéologie et d'Histoire du Berry, $\mathrm{n}^{\circ}$ spécial de 9/1991. Beaucoup plus loin encore, le sunctuaire a cellae multiples de tradition romaine ou indigène de l'Altbachtal de Trèves ne nous parait pas convenir pour comprendre celui des Basiols car il s'agit du très grand sanctuaire péri-urbain d'une capitale de cité et il est surtout très éloigné sur le plan géographique.

34 A l'aide des ouvrages suivants : $R R C$ et $R I C$ I (éd. de 1984) à VII ; - El.mrr, 1941 ; - Giard, Catalogue...

35 Voir en particulier les nos 193 et 195-208.

36 La céramique sigillée est également très abîmée, comme rongée par la terre (supra). 
Tabl. IV - Monnaies, répartition par règne, métaux et espèces.

\begin{tabular}{|c|c|c|c|c|c|c|c|c|c|c|c|}
\hline \multirow[b]{2}{*}{ règnes } & \multirow[b]{2}{*}{$\begin{array}{l}\text { nbre } \\
\text { d'ex. }\end{array}$} & \multirow[b]{2}{*}{$\%$} & \multicolumn{2}{|c|}{ argent } & \multicolumn{7}{|c|}{ «bronze», orichalque et billon } \\
\hline & & & denier & quinaire & quadrans & as & dupondii & sesterces & antoniniani & nummi & aes $3 / 4$ \\
\hline $\mathrm{II}^{\mathrm{e}}$ s. avant J.-C. & 1 & 0,31 & 1 & & & & & & & & \\
\hline${ }^{\mathrm{Ir}} \mathrm{S}$. avant J.-C. & 1 & 0,31 & & 1 & & & & & & & \\
\hline Auguste & 21 & 6,60 & & & & 21 & & & & & \\
\hline Caligula & 12 & 3,77 & & & & 12 & & & & & \\
\hline Claude I & 19 & 5,97 & & & & 19 & & & & & \\
\hline Néron & 2 & 0,62 & & & & 2 & & & & & \\
\hline Julio-Claudiens & 7 & 2,20 & & & 1 & 6 & & & & & \\
\hline Vespasien & 3 & 0,94 & & & & 2 & 1 & & & & \\
\hline Titus & 2 & 0,62 & & & & 2 & & & & & \\
\hline Domitien & 14 & 4,44 & & & & 13 & 1 & & & & \\
\hline Ir $\mathrm{s}$ & 9 & 2,83 & & & & 9 & & & & & \\
\hline Nerva & 3 & 0,94 & & & & 3 & & & & & \\
\hline Trajan & 15 & 4,72 & & & & 10 & 5 & & & & \\
\hline Hadrien & 18 & 5,66 & & & & 17 & & 1 & & & \\
\hline Antonin & 26 & 8,18 & & & & 23 & & 3 & & & \\
\hline Marc-Aurèle & 19 & 5,97 & & & & 14 & 1 & 4 & & & \\
\hline Commode & 4 & 1,27 & & & & 3 & & 1 & & & \\
\hline $\mathrm{II}^{\mathrm{c}} \mathrm{s}$ & 8 & 2,54 & & & & 8 & & & & & \\
\hline Septime Sévère & 1 & 0,31 & & & & 1 & & & & & \\
\hline Sévère Alexandre & 1 & 0,31 & & & & & & 1 & & & \\
\hline Gordien III & 1 & 0,31 & & & & & & 1 & & & \\
\hline Philippe & 1 & 0,31 & & & & & & 1 & & & \\
\hline Gallien & 3 & 0,94 & & & & & & & 3 & & \\
\hline Claude II & 3 & 0,94 & & & & & & & 3 & & \\
\hline empire gaulois & 4 & 1,27 & & & & & & & 4 & & \\
\hline imitations & 3 & 0,94 & & & & & & & 3 & & \\
\hline Tacite & 1 & 0,31 & & & & & & & 1 & & \\
\hline Probus & 1 & 0,31 & & & & & & & 1 & & \\
\hline Constantin & 5 & 1,57 & & & & & & & & 5 & \\
\hline Valentinien I & 1 & 0,31 & & & & & & & & & 1 \\
\hline indéterminables & 109 & 34,31 & & & & 87 & 1 & 3 & 9 & & 9 \\
\hline $\begin{array}{l}\text { Total } \\
\text { Pourcentage }\end{array}$ & 318 & 100 & $\begin{array}{c}1 \\
0.3\end{array}$ & $\begin{array}{l}1 \\
0 \\
03\end{array}$ & $\begin{array}{c}1 \\
0.3\end{array}$ & $\begin{array}{lll}2 & 5 & 2 \\
7 & 9 & 2\end{array}$ & $\begin{array}{c}9 \\
28\end{array}$ & $\begin{array}{l}15 \\
4.7\end{array}$ & 24 & 5 & $\begin{array}{ll}10 \\
3 & 2\end{array}$ \\
\hline
\end{tabular}

et fig. 25). L'époque républicaine est représentée par un exemplaire, soit $0,31 \%\left(n^{\circ} 1\right)$, la fin du second triumvirat par un autre ( $\left.\mathrm{n}^{\circ} 2\right)$. L'essentiel couvre les deux premiers siècles du Haut-Empire avec 264 monnaies $(86 \%)$. En prenant en compte seulement les pièces identifiables, le $\mathrm{I}^{\text {er }} \mathrm{s}$. a livré 91 exemplaires $(28,4 \%)$ et le II $^{\mathrm{e}}$ s. $88(27,5 \%)$, soit des quantités très proches. Le règne d'Antonin est le mieux représenté avec 26 exemplaires $(8,2 \%)$. Contrastant avec cette période, les $\mathrm{III}^{\mathrm{e}}$ et $\mathrm{IV}^{\mathrm{e}} \mathrm{s}$. ne sont plus illustrés que par 44 trouvailles (n ${ }^{\text {os }} 185$ à 188 et 280 à 318 , soit $13 \%$ ), et en fait l'essentiel se rattache au $\mathrm{III}^{\mathrm{e}} \mathrm{s}$. (28 ex., soit 8,8\%); le $\mathrm{IV}^{\mathrm{e}}$ et le début du $\mathrm{V}^{\mathrm{e}} \mathrm{s}$. ont donné simplement 6 pièces sur 22 attribuables à un règne donné $(1,9 \%$ sur $6,9 \%)$.

Dans cet ensemble constitué au fil du temps, sans tri initial au contraire d'une thésaurisation, les espèces sont très variées. Les deux pièces les plus 


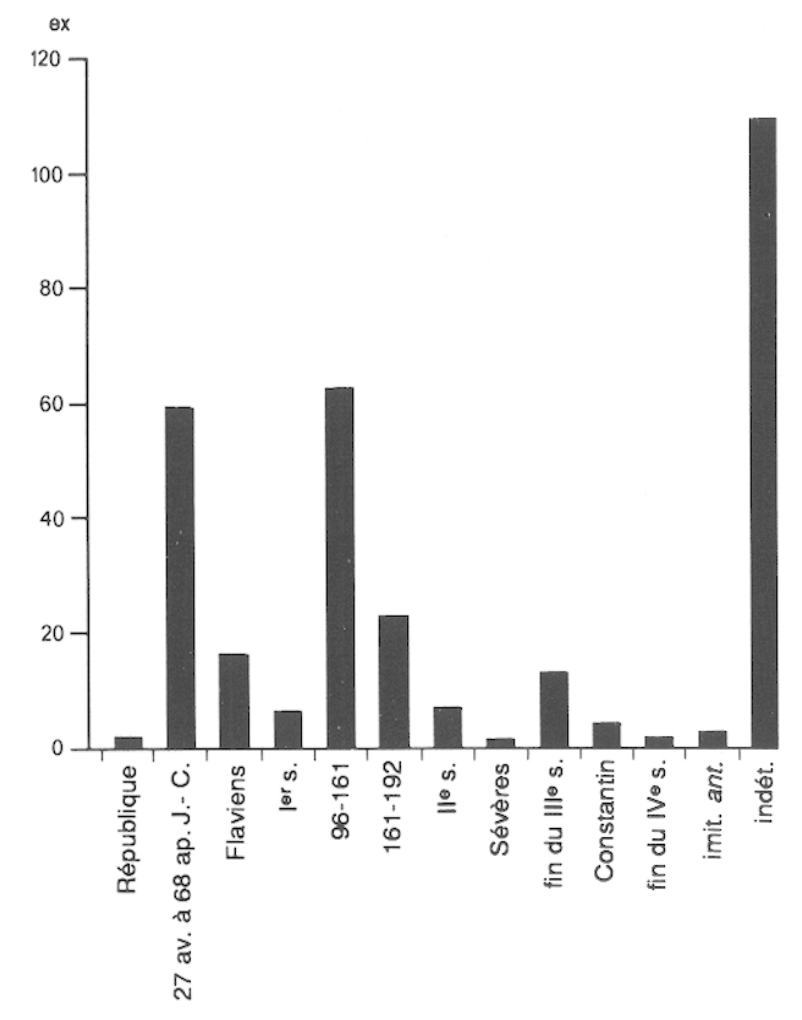

Fig. 25 - Répartition des monnaies suivant les dynasties et les règnes des empereur's romains.

anciennes, les seules en argent, un denier $\left(n^{\circ} 1\right)$ et un quinaire ( $\left.n^{\circ} 2\right)$, sont de belle qualité et bonne conservation. Le «bronze» est illustré par ses variétés courantes du Haut-Empire, sesterces et as, mais aussi par 9 dupondii $(2,8 \%)$ et par une petite division (quadrans, $\mathrm{n}^{0} 57$ ). Les as sont évidemment les plus nombreux pour le Haut-Empire, avec 252 exemplaires $(79,2 \%)$ dont 95 indéterminables. Les dupondii, équivalant à 18 as, vont des Flaviens à Lucius Verus, et les 15 sesterces $(4,7 \%)$, soit 60 as, appartiennent exclusivement au $1^{\text {e }}$ et à la première moitié du III $^{\mathrm{e}}$ s. Plus tard, entre Gallien et Probus, ont été offerts 24 antoniniani de billon $(7,5 \%)$, puis au IV s., 5 nummi $(1,6 \%)$ et 2 aes 3 ou $4(0,6 \%)$. Cent neuf objets illisibles $(34,5 \%)$ sont attribuables à une espèce donnée, sauf quelques exemplaires très usés pour lesquels on peut hésiter entre as et dupondii pour certains et entre antoniniani et aes 3 ou 4 pour d'autres.

La plupart de ces pièces ont été émises à Rome, 260 exactement, soit plus des quatre cinquièmes (tabl. V). Cette prééminence est d'autant plus explicable que la capitale de l'Empire a été la seule à frapper monnaie sous Domitien et au II $^{\mathrm{e}} \mathrm{s}$. De l'acti- vité des autres ateliers nous avons très peu de témoins : pour le $\mathrm{I}^{\mathrm{er}} \mathrm{s}$., Nîmes (14 ex. : $\mathrm{n}^{\mathrm{os}} 3$ à 16) el Lyon (10 ex. : $\mathrm{n}^{\circ \mathrm{s}} 17$ à 23 et $\left.57,64,66\right)$ ont été favorisés par leur relative proximité du Lévézou, et la quantité des pièces récoltées $(7,54 \%)$ correspond à leur fréquence en Gaule sous Auguste et Tibère. Les centres de production monélaire du $\|^{\mathrm{e}} \mathrm{s}$. comme Milan (2 ex. : $n^{\text {os }} 281$ et 285), Siscia (1 ex. : no 294) et Ticinum (1 ex. : no 293) ont frappé des antoniniani pour les empereurs de Rome, tout comme celui de Cologne (4 ex. : nos 286 à 289) pour les empereurs gaulois. Pour le rve s., seule la monnaie de Valentinien I est attribuable à l'atelier d'Arles ( $\left.n^{\circ} 309\right)$, par ce qui reste de sa marque. Enfin, signalons qu'une douzaine d'antoniniani proviennent d'officines locales, ainsi que quelques pièces indéterminables $\mathrm{du}$ Ive s. et du début $d u v^{e} s$.

Quand il s'agit de monnaies de fouilles, dispersées dans le temps et reflet de la circulation monétaire, une étude systématique des poids et notamment des poids moyens (= p.m.) paraît assez aléatoire. Nous l'avons cependant tentée, en particulier pour les séries les plus importantes, soit par règne soit par siècle (tabl. VI). Nous avons constaté en les pesant, et confirmé ainsi l'impression ressentie en regardant ces pièces si souvent usées et peu lisibles, qu'elles sont particulièrement légères comparées à celles d'autres sites. On pourrait s'interroger sur ce point mais nous croyons que les réponses possibles risqueraient d'être fantaisistes et peu fondées (psychologie des donateurs? Etat de la circulation monétaire dans un coin reculé du sud du Massif central ? Long décalage entre la date d'émission et l'utilisation des pièces...?).

Les as augustéens de Nîmes et de Lyon sont très différenciés. Autant les premiers ont belle allure (voir infra, fig. $27, \mathrm{n}^{\text {os }} 3,9$ et 16 ), avec un p.m. de $11,46 \mathrm{~g}$, peu éloigné du poids théorique indiqué par le $R I C$, autant les seconds sont trop souvent usés et pulvérulents, d'un p.m. de 7,51 g très inférieur aux 9-11 g attendus ${ }^{37}$. Pour les as émis à Rome, on constate un renforcement du p.m. entre le $\mathrm{I}^{\mathrm{er}}$ et le $\mathrm{II}^{\mathrm{e}} \mathrm{s}$. : en moyenne les 64 as du r $^{\text {er }}$ s. font $7,83 \mathrm{~g}$ et les 78 frappés par les Antonins, $8,36 \mathrm{~g}^{38}$. Pour ces derniers, on remarquera le p.m. record de $9,15 \mathrm{~g}$ des 13 pièces attribuables à Nerva et à Trajan, mais elles sont trop

$37 \quad R I C$ I, p. 51 (Nîmes) et 57 (Lyon).

38 A titre de comparaison, à Belo dans le sud de l'Espagne, 26 as de Vespasien à Commode font en moyenne 7,90 $\mathrm{g}$ (Belo IV, p. 61). A Bordeaux, dans le Trésor de Garonne, 16 as de Vespasien à Hadrien ont un p.m. de $10,87 \mathrm{~g}$. Le RIC $I$, p. 26, parle d'un p.m. d'environ $11 \mathrm{~g}$. 
Tabl. V - Monnaies, répartition par règne et par atelier.

\begin{tabular}{|c|c|c|c|c|c|c|c|c|c|}
\hline Règnes & Rome & Nîmes & Lyon & Milan & Siscia & Ticinum & Cologne & Arles & intéderminés \\
\hline $\begin{array}{l}\mathrm{II}^{\mathrm{e}} \text { s. avant J.-C. } \\
\mathrm{I}^{\mathrm{er}} \text { s. avant J.-C. } \\
\text { Auguste } \\
\text { Caligula } \\
\text { Claude I } \\
\text { Néron } \\
\text { Vespasien } \\
\text { Titus } \\
\text { Domitien } \\
\mathrm{I}^{\text {er }} \text { s. } \\
\text { Nerva } \\
\text { Trajan } \\
\text { Hadrien } \\
\text { Antonin } \\
\text { Marc-Aurèle } \\
\text { Commode } \\
\text { II }{ }^{\mathrm{e}} \text { s. } \\
\text { Septime Sévère } \\
\text { Sévère Alexandre } \\
\text { Gordien III } \\
\text { Philippe } \\
\text { Gallien } \\
\text { Claude II } \\
\text { empereurs gaulois } \\
\text { Tacite } \\
\text { Probus } \\
\text { Constantin } \\
\text { Valentinien I } \\
\text { "petits bronzes» } \\
\text { «grands bronzes» }\end{array}$ & 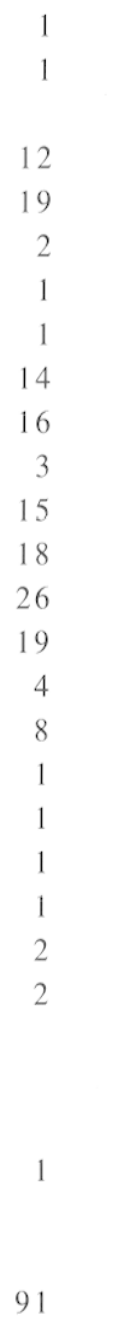 & 14 & $\begin{array}{l}7 \\
\\
2\end{array}$ & $\begin{array}{l}1 \\
1\end{array}$ & 1 & 1 & 4 & 1 & $\begin{array}{r}4 \\
20\end{array}$ \\
\hline $\begin{array}{l}\text { total } \\
\text { pourcentage }\end{array}$ & $\begin{array}{l}260 \\
81,8\end{array}$ & $\begin{array}{l}14 \\
4,4\end{array}$ & $\begin{array}{l}10 \\
3,1\end{array}$ & $\begin{array}{c}2 \\
0,6\end{array}$ & $\begin{array}{c}1 \\
0,3\end{array}$ & $\begin{array}{c}1 \\
0,3\end{array}$ & $\begin{array}{c}4 \\
1,3\end{array}$ & $\begin{array}{c}1 \\
0,3\end{array}$ & $\begin{array}{l}25 \\
7,9\end{array}$ \\
\hline
\end{tabular}

* A supposer que tous les as lisses soient de Rome

peu nombreuses pour étayer une certitude. A l'inverse, après la série la plus fournie d'Antonin avec $8,56 \mathrm{~g}$ de p.m. pour 23 exemplaires, les 14 as de Marc Aurèle retombent au p.m. du $\mathrm{I}^{\mathrm{er}} \mathrm{s}$. avec $7,76 \mathrm{~g}^{39}$.

39 Nous n'avons pas calculé le p.m. des 87 as indéterminables : très usés, ils feraient certainement baisser la moyenne et de plus, s'ils ont vraiment été offerts dans la première moitié du III $^{\mathrm{e}} \mathrm{s}$. (infra, note 57 ), ils ne sont pas représentatifs de cette période.
Les 9 dupondii font en moyenne $9,93 \mathrm{~g}$ et les 15 sesterces 17,66 g. Mais pour le seul II $^{\mathrm{e}} \mathrm{s}$., ces derniers atteignent $19,33 \mathrm{~g}$, ce qui est un peu plus proche du poids officiel ${ }^{40}$. Quant aux monnaies des $\mathrm{III}^{\mathrm{e}}$ et $\mathrm{IV}^{\mathrm{e}} \mathrm{s}$.,

40 Ils sont bien inférieurs aux résultats de Belo IV (p. 61 et note 110) et du Trésor de Garonne (p. 346) (p.m. des sesterces de Trajan : de 24,48 à 24,94 g; d'Hadrien : 24,94 à $25,64 \mathrm{~g}$; d'Antonin : 25,15 à $25,41 \mathrm{~g}$ ). Mais surtout du poids "officiel" de 26,83 à $27,25 \mathrm{~g}$ (voir le RIC). 
Tabl. VI - Variation des poids moyens (p.m. en gramme) par espèces et par règnes (seules monnaies identifiables).

\begin{tabular}{|c|c|c|c|c|c|c|}
\hline règnes & $\begin{array}{l}\text { p.m. } \\
\text { par règnes }\end{array}$ & $\begin{array}{l}\text { p.m. } \\
\text { par périodes }\end{array}$ & $\begin{array}{l}\text { p.m. } \\
\text { par règnes }\end{array}$ & $\begin{array}{l}\text { p.m. } \\
\text { par règnes }\end{array}$ & $\begin{array}{l}\text { p.m. } \\
\text { par règnes }\end{array}$ & p.m. \\
\hline & & as & dupondius & sesterces & antoniniani & numm \\
\hline $\begin{array}{c}\text { Auguste, Nîmes } \\
\text { L y o n }\end{array}$ & $\begin{array}{r}11,46 \\
7,51\end{array}$ & & & & & \\
\hline Caligula & 7,56 & & & & & \\
\hline Claude I & 7,22 & 7,42 & & & & \\
\hline Néron & $(8,41: 2$ ex. $)$ & $(33$ ex. $)$ & & & & \\
\hline Julio-Claudiens & $8,42 \quad(6$ ex. $)$ & $\begin{array}{l}7,83 \\
(64 \text { ex.) }\end{array}$ & & & & \\
\hline $\begin{array}{l}\text { Flaviens } \\
\text { I }^{\text {er }} \mathrm{s}\end{array}$ & $\begin{array}{ll}8,00 & \text { (16 ex.) } \\
7,61 & (1.5 \mathrm{ex} .)\end{array}$ & & 9,59 (2 ex.) & & & \\
\hline Nerva-Trajan & 9,15 (13 ex.) & & 10,42 (5 ex.) & & & \\
\hline Hadrien & 8,23 (17 ex.) & & & $(20,20: 1$ ex. $)$ & & \\
\hline Antonin & 8,56 (23 ex.) & 8,36 & & 18,93 (3 ex.) & & \\
\hline Marc-Aurèle & 7,76 (14 ex.) & (78 ex.) & $(9,12: 1$ ex.) & 18,72 (4 ex.) & & \\
\hline Commode & $(8,76: 3$ ex. $)$ & & & $(21,19: 1$ ex. $)$ & & \\
\hline $\mathrm{II}^{\mathrm{e}} \mathrm{s}$ & 7,68 (8 ex.) & & $(10,01: 1$ ex. $)$ & & & \\
\hline $\begin{array}{l}\text { Septime Sévère } \\
\text { Sévère Alexandre } \\
\text { Gordien III } \\
\text { Philippe }\end{array}$ & $(9,62: 1$ ex. $)$ & & & $\begin{array}{ll}(20,63: & 1 \text { ex. }) \\
(18,93: & 1 \text { ex. }) \\
(14,07: & 1 \text { ex. })\end{array}$ & & \\
\hline \multirow[t]{2}{*}{$\begin{array}{l}24 \text { antoniniani } \\
5 \text { nummi }\end{array}$} & & & & & 1,28 & 1,06 \\
\hline & & & p.m. $=9,93 \mathrm{~g}$ & p.m. $=17,66 \mathrm{~g}$ & & \\
\hline
\end{tabular}

elles sont particulièrement usées et légères avec, pour les 24 antoniniani, un p.m. de 1,28 g, soit la moitié de ce à quoi on s'attendrait ${ }^{41}$, et à peine $1,06 \mathrm{~g}$ pour les pièces du Ives.

Dernière remarque sur la banalité ou la rareté de notre matériel : toutes les monnaies lisibles sont déjà connues et donc répertoriées. Signalons tout de même les particularités que représentent les contremarques ou les poinçons ajoutés sur les pièces d'argent $n^{\text {os }} 1$ et $2^{42}$. L'exemplaire $n^{\circ} 38$ a un droit et

41 J.-P. CALlu, La politique monétaire des empereurs romains de 238 à 311 , Paris, 1966, p. $238 s q$, en particulier p. 243 , fig. de la courbe des poids.

42 Les poinçons ajoutés après coup sur le denier $n^{\circ} l$ ne sont pas répertoriés par le $R R C$, pas plus que le $R I C$ ne mentionne de signes identiques à ceux du quinaire $n^{\circ} 2$. Pour ce dernier, on peut tout de même faire un rapprochement avec Giard, Catalogue ..., p. 40 et 143 (infra note 51). un revers associés ${ }^{43}$ sur un sesterce mais aux Basiols il ne peut s'agir que d'un as, avec son poids de $7,28 \mathrm{~g}$; il est vrai que la disparition des légendes complique l'identification ${ }^{\mathbf{4 4}}$.

\section{Distribution DES MONNAIES DANS LE SANCTUAIRE}

La répartition des 318 pièces antiques dans l'enclos sacré est significative (fig. 26). Il faut distinguer de l'ensemble ce qui a été récolté dans les structures construites : les cellae, le local de l'angle sud-ouest et

43 RIC $I, \mathrm{n}^{\circ} 102$.

44 Cet as pourrait être le témoin d'une émission de sesterces et d'as à l'effigie d'Agrippine, avec la même figure au revers. L'usure de notre pièce empêche de dire si les légendes différaient ou nun sur les deux espèces. Son absence dans le $R I C$ indiquerait qu'il est fort rare. 


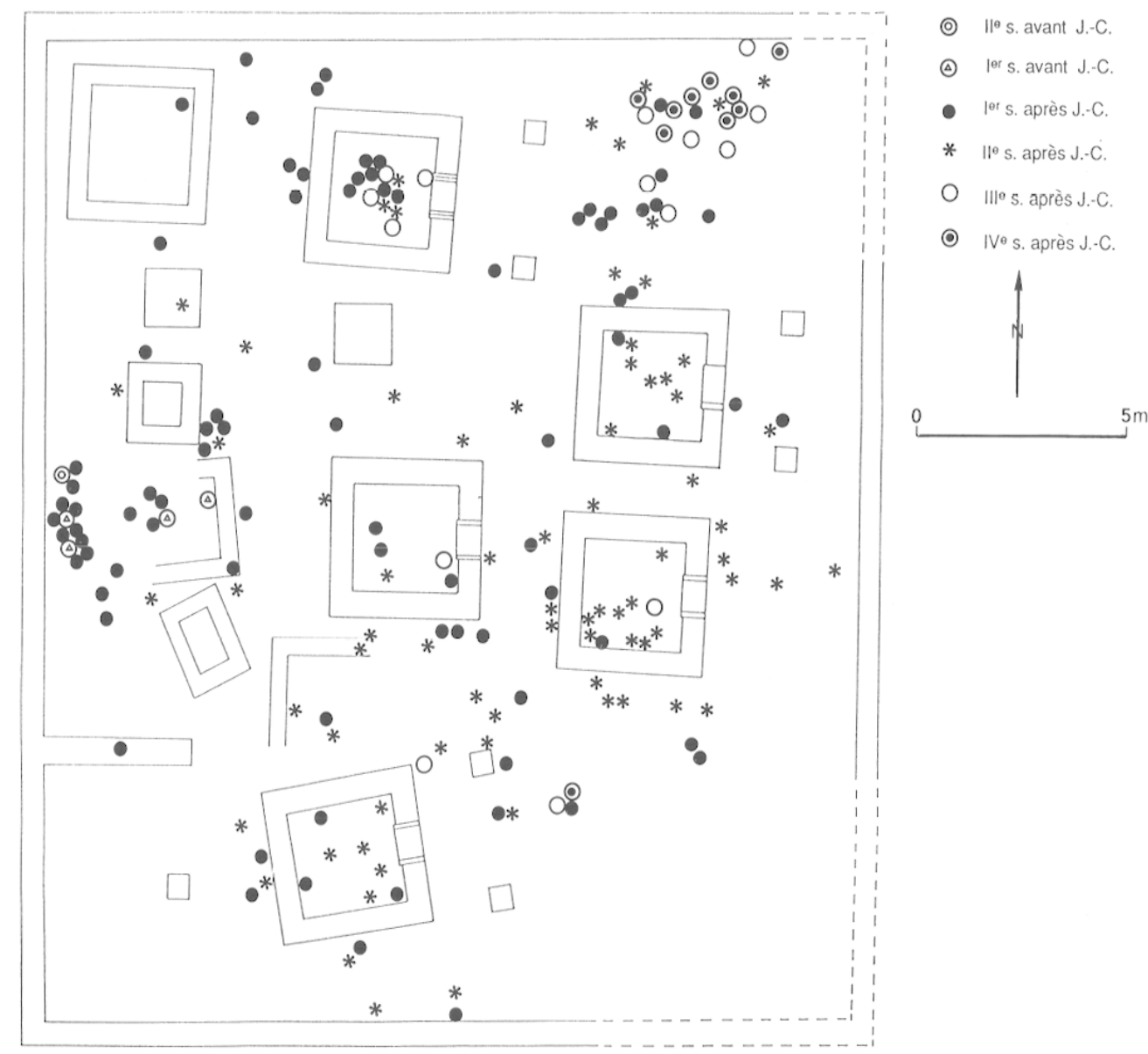

Fig. 26 - Localisation des monnaies sur le site (avec l'indication sommaire de leur chronologie). Les pièces indéterminées et celles recueillies dans la cella «a» de l'angle sud-est en 1991 ne figurent pas sur ce plan.

également dans la fosse postérieure à la cella «a». Le tableau VII classe les monnaies selon les édifices à l'intérieur desquels elles ont étė trouvées, des plus anciennes aux plus récentes, et permet de réfléchir sur le moment éventuel de la construction ou l'aménagement, et la durée d'utilisation des cellae ${ }^{45}$.

Les cellae 1 et 7 ont livré des monnaies du $\mathbf{I}^{\text {er }} \mathrm{s}$. Pour la première, notre remarque est très discutable car il y a seulement 2 as dont un seul est lisible (no 52, de Claude). Dans la cella 7, détruite dès l'Antiquité, 4 des 5 pièces identifiables jalonnent la période qui va du second Triumvirat à Claude, la cinquième étant de Domitien. Il est vrai que 3 as lisses auraient peut-être modifié cette impression, notamment s'ils ont été offerts au $\mathrm{II}^{\mathrm{e}} \mathrm{s}^{46}$.

45 On comparera avec le matériel non monétaire (supra, p. 150).

46 Infra texte et notes 57,58 et 59 .
Les cellae 3 et 6 ont un mobilier monétaire surtout du $\mathrm{II}^{\mathrm{e}} \mathrm{s}$. Pour la cella 3 , il s'agit de 11 as et 1 sesterce, dont le plus ancien remonte à Claude (no 47) et les plus récents à Marc Aurèle et Faustine II avant 176 . Il n'y a aucune monnaie postérieure. Sans chercher à l'interpréter, on signalera la présence de 3 as et 1 sesterce à l'effigie des impératrices Faustine I et II, soit le tiers des trouvailles. La cella 6 , elle aussi, contenait 10 as, 1 dupondius et 1 sesterce, échelonnés de Claude au début du règne de Marc Aurèle, en 162-163, mais aucun antoninianus. Dans les deux cas, les dernières monnaies sont du règne de Marc Aurèle.

Les cellae 2, 4 et 5 ont toutes les trois livré des antoniniani datables de la seconde moitié du $\mathrm{II}^{\mathrm{e}} \mathrm{s}$. Dans la chapelle 2 , l'échantillonnage de 18 pièces va d'un as de Nîmes $\left(n^{\circ} 3\right)$ à 4 antoniniani, de Claude II, Postume, Tetricus et Probus, émis dans un laps de temps d'une quinzaine d'années entre 268 
Tabl. VII - Ensembles monétaires des cellae (les as sont indiqués en caractères romains, les sesterces en gras, les dupondii en caractères italiques et les antoniniani sont signalés par un astérisque).

\begin{tabular}{|c|c|c|c|c|}
\hline cellae & espèce & $\mathrm{n}^{\circ}$ du catalogue & identification & datation \\
\hline 1 & 2 & $\begin{array}{l}52 \\
208\end{array}$ & $\begin{array}{l}\text { Claude I } \\
\text { as indéterminé }\end{array}$ & Ier s. après J.-C. \\
\hline 2 & $\begin{array}{l}4 \\
4 *\end{array}$ & $\begin{array}{l}3 \\
26,48,51 \\
67,69,75 \\
83,86 \\
149 ; 159,163 ; 190 \\
192,232 \\
284^{*}, 286^{*}, 289^{*} \\
294^{*}\end{array}$ & $\begin{array}{l}\text { as de Nîmes } \\
\text { Caligula et Claude } \\
\text { Flaviens } \\
\text { peu déterminables } \\
\text { Faustine I; Marc Aurèle; indét. } \\
\text { as indéterminés } \\
\text { Claude II, Postume, Tetricus I } \\
\text { Probus }\end{array}$ & $\begin{array}{l}\text { Auguste } \\
1^{\text {ère }} \text { moitié du I }{ }^{\text {er }} \mathrm{s} \text {. } \\
2^{\mathrm{e}} \text { moitié du I } \mathrm{I}^{\mathrm{er}} \mathrm{s} \text {. } \\
\mathrm{I}^{\mathrm{er}} \mathrm{s} . \\
\mathrm{II}^{\mathrm{e}} \mathrm{s} . \\
\text { Haut-Empire } \\
3^{\mathrm{e}} \text { quart du } \mathrm{III}^{\mathrm{e}} \mathrm{s} \text {. } \\
276-282\end{array}$ \\
\hline 3 & 11 & $\begin{array}{l}47 \\
76 \\
132,152,153,243 \\
154,160,170 \\
261,264,278\end{array}$ & $\begin{array}{l}\text { Claude } \\
\text { Domitien } \\
\text { Antonin et Faustine I } \\
\text { Marc Aurèle et Faustine II } \\
\text { as indéterminés }\end{array}$ & $\begin{array}{l}1^{\text {ère }} \text { moitié du I }{ }^{\mathrm{er}} \mathrm{s} . \\
2^{\mathrm{e}} \text { moitié du } \mathrm{I}^{\mathrm{er}} \mathrm{s} \text {. } \\
\mathrm{II}^{\mathrm{e}} \mathrm{s} . \\
\text { avant } 176 \\
\text { Haut-Empire }\end{array}$ \\
\hline 4 & $1 *$ & $\begin{array}{l}33 ; 84 \\
93 \\
175 \\
276 \\
285^{*}\end{array}$ & $\begin{array}{l}\text { Caligula et as du } \mathrm{I}^{\mathrm{er}} \mathrm{s} \text {. } \\
\text { Nerva } \\
\text { Commode } \\
\text { as indéterminé } \\
\text { antoninianus indéterminé }\end{array}$ & $\begin{array}{l}\mathrm{I}^{\text {er }} \mathrm{s} . \\
96-98 \\
183-184 \\
2^{\mathrm{e}} \text { moitié du III }{ }^{\mathrm{e}} \mathrm{s} .\end{array}$ \\
\hline 5 & $\begin{array}{l}12 \\
1 \\
1 *\end{array}$ & $\begin{array}{l}24,58,60 \\
107,109 ; 111,120,121,125 \\
184 ; 172 \\
209,259 \\
302 *\end{array}$ & $\begin{array}{l}\text { Caligula et Julio-Claudiens } \\
\text { Trajan, Hadrien } \\
\text { Antonin? Lucille } \\
\text { as indéterminés } \\
\text { antoninianus indéterminé }\end{array}$ & $\begin{array}{l}\mathrm{I}^{\mathrm{er}} \mathrm{s} . \\
1^{\mathrm{ère}} \text { moitié du II }{ }^{\mathrm{e}} \mathrm{s} . \\
2^{\mathrm{e}} \text { moitié du } \mathrm{II}^{\mathrm{e}} \mathrm{s} . \\
\text { Haut-Empire } \\
2^{\mathrm{e}} \text { moitié du III }{ }^{\mathrm{e}} \mathrm{s} .\end{array}$ \\
\hline 6 & $\begin{array}{l}10 \\
1+1\end{array}$ & $\begin{array}{l}43,49 \\
80 \\
101,105 \\
137,144 ; 157 \\
227 ; 230 ; 256,258\end{array}$ & $\begin{array}{l}\text { Claude I } \\
\text { Domitien } \\
\text { Trajan } \\
\text { Antonin; Marc Aurc̀lc } \\
\text { as indéterminés }\end{array}$ & $\begin{array}{l}1^{\text {ère }} \text { moitié du } \mathrm{I}^{\mathrm{er}} \mathrm{s} . \\
2^{\mathrm{e}} \text { moitié du } \mathrm{I}^{\mathrm{er}} \mathrm{s} \text {. } \\
1^{\text {ère }} \text { moitié du II } \mathrm{I}^{\mathrm{e}} \mathrm{s} . \\
2^{\mathrm{e}} \text { moitié du II } \mathrm{s} \text {. } \\
\text { Haut-Empire }\end{array}$ \\
\hline 7 & $\begin{array}{l}\mathrm{AR} \\
8\end{array}$ & $\begin{array}{l}2 \text { (quinaire) } \\
5,16 \\
202 \\
77 \\
222,244,247\end{array}$ & $\begin{array}{l}\text { Octave } \\
\text { as de Nîmes } \\
\text { Claude I? } \\
\text { Domitien } \\
\text { as indéterminés }\end{array}$ & $\begin{array}{l}\text { 29-27 avant J.-C. } \\
\text { Auguste } \\
41-54 \\
81-96 \\
\text { Haut-Empire }\end{array}$ \\
\hline 8 & 5 & $\begin{array}{l}73 \\
270 \\
143 \\
236,269\end{array}$ & $\begin{array}{l}\text { Domitien } \\
\text { as du Ir s. ou de Trajan } \\
\text { Antonin } \\
\text { as indéterminés }\end{array}$ & $\begin{array}{l}87-89 \\
138-161 \\
\text { Haut-Empire }\end{array}$ \\
\hline
\end{tabular}


Tabl. VIII - Monnaies de la fosse devant la cella 6 (les as sont indiqués en caractères romains, les sesterces en gras, les dupondii en caractère italiques et les antoniniani sont signalés par un astérisque).

\begin{tabular}{|l|l|l|l|}
\hline espèce & $\mathrm{n}^{\circ}$ du catalogue & identification & datation \\
\hline 9 & 40,41 & Claude & moitié du I ${ }^{\text {er }} \mathrm{s}$. \\
& 98 & Trajan & $\mathrm{II}^{\mathrm{e}} \mathrm{s}$. \\
& 179,$180 ; 156,165 ; 176$ & Antonin; Marc Aurèle; Commode & $\mathrm{II}^{\mathrm{e}} \mathrm{s}$. \\
2 & 187 & Gordien III & $241-243$ \\
& $191 ; 263$ & indéterminés & Haut-Empire $^{*}$ \\
2 aes 3 & $281^{*} ; 291^{*}$ & Gallien ; Tetricus & $3^{\text {e }}$ quart du III $\mathrm{s}$. \\
\hline
\end{tabular}

et 282. Entre ces deux extrêmes il y a une dizaine d'as du $\mathrm{I}^{\mathrm{er}} \mathrm{s}$. et 4 sesterces du $\mathrm{II}^{\mathrm{e}} \mathrm{s.}^{\mathrm{4} 7}$. Évidemment les monnaies les plus anciennes et les plus tardives n'indiquent pas assurément la date de la construction puis de l'abandon de l'édifice, mais elles donnent tout au moins sa période principale de fréquentation. Le mobilier monétaire de la cella 4 , avec seulement 6 pièces dont 4 as, va de Caligula au ${ }_{11}{ }^{\circ}$ s., avec 1 antoninianus indéterminable; dans la cella 5, la même apparente durée est marquée par 12 as, 1 dupondius et 1 antoninianus.

Quant à la cella 8 , apparemment abandonnée et détruite au profit de la cella 6 , les 5 ou 6 monnaies trouvées à l'intérieur posent un problème : seules 2 sont identifiables, l'une de Domitien, l'autre d'Antonin, c'est-à-dire à peine plus tôt que la dernière pièce de la cella 6 . Ou alors il faudrait apparenter cet ensemble de monnaies à celles trouvées éparses dans les diverses zones de circulation du sanctuaire. La cella 8 en cela se distinguerait de la cella 7 (supra), elle aussi détruite tôt dans l'Antiquité et au contraire datée par des pièces parmi les plus anciennes.

Le bâtiment au sud-ouest du sanctuaire n'a presque rien donné, un as de Titus, sous le règne de Vespasien en 77-78, et un autre apparemment $d u$ I $^{\text {er }}$ s. ou de Trajan. Cies monnaies ne suffisent pas pour proposer une chronologie de la fréquentation.

La fosse entre les cellae 6 et "a" contenait une quinzaine de pièces, intéressantes par leur réparti-

47 Sur les 15 sesterces du sanctuaire, les 4 de la cella 2 sont de Faustine I et Marc Aurèle ( 2 ex.), de Trajan ou Marc Aurèle César avec un visage imberbe ( $\left.{ }^{\circ} 190\right)$. Ajoutons une remarque faite lors de la fouille de la fosse (volontaire ou non?, supra, p. 149-150) : à une profondeur de 20 à $30 \mathrm{~cm}$, on a trouvé ensemble trois antoniniani $d u{ }_{\mathrm{III}^{\mathrm{e}}} \mathrm{s}$. et six as du $\mathrm{I}^{\mathrm{er}} \mathrm{s}$. Du fond de la fosse (a $30 / 40 \mathrm{~cm}$ ), proviennent deux as de la première moitié du ier $s$., les $n^{\text {os }} 3$ et 26 . tion chronologique. La plus ancienne date de Claude, mais si l'essentiel consiste en 9 as et sesterces du $\mathrm{II}^{\mathrm{e}}$ s., auxquels s'ajoutent deux antoniniani de Callien et Tetricus, la plus récente de toutes est un petit bronze de Valentinien I trouvé au fond ( $\left.n^{\circ} 309\right)$. Ce n'est sans doute pas la monnaie antique la plus tardive du sanctuaire (voir les nos 310 à 318 ) et elle suggère simplement que la fosse, aménagée tardivement après la destruction des murs ouest et nord de la cella "a», mêlant ainsi le mobilier récent à celui plus ancien de l'édicule, n'a èté creusée qu'à la fin du IV e s. au plus lôt (tabl. VIII).

Deux secteurs non construits ont retenu notre attention, l'un, ancien, est daté de la première moitié du $\mathbf{I}^{\text {er }} \mathrm{s}$. après J.-C. ; l'autre, très tardif, correspond à la période finale de la fréquentation du lieu.

- Le premier se situe entre la cella 7 et le mur occidental du sanctuaire : comme à l'intérieur de l'édifice à moitié disparu, les 25 monnaies trouvées sont le denier émis en 109-108 avant notre ère, le quadrans de la première moitié du $\mathbf{1}^{\mathrm{er}} \mathrm{s}$. de notre ère, 10 as de Nîmes, 5 as de Lyon et 2 de Caligula (tabl. IX). Peut-on supposer que les 6 as illisibles sont aussi de cette époque?

- Le second, dans l'angle nord-est, a livré un ensemble remarquable par la quantité des pièces, une soixantaine sur une superficie de 16 à $20 \mathrm{~m}^{2}$, et par leur dispersion chronologique (tabl. X). Le $\mathrm{I}^{\mathrm{er}} \mathrm{s}$. est représenté par une dizaine d'as dont les plus anciens sont de Caligula. Deux dupondii, 3 sesterces et 5 as sont $d u I^{e} s$. Pour la première moitié du ${ }_{\text {III }}{ }^{\mathrm{e}}$ s., il y a seulement 2 sesterces, et pour la seconde moitié, 14 antoniniani dont le plus récent est de Tacite. Mais le plus intéressant est l'existence à cet endroit de 11 petits bronzes du IV s. et du début du $v^{e}$ s., dont nous ne connaissions jusqu'à présent qu'un unique exemplaire découvert dans la fosse devant la cella 6 . Cinq sont du temps de Constantin, 2 de l'extrême fin du $\mathrm{IV}^{\mathrm{e}} \mathrm{s}$. ou plus tardifs, et pour 4 
Tabl. IX - Entre la cella 7 et le mur ouest (les as sont indiqués en caractères romains, les sesterces en gras, les dupondii en caractères italiques et les auloniniani sont signalés par un astérisque).

\begin{tabular}{|l|l|l|c|}
\hline espèce & $\mathrm{n}^{\circ}$ du catalogue & identification & datation \\
\hline 1 denier & 1 & la plus ancienne monnaie du site & 109-108 avant J.-C. \\
23 & $4,6-11,13-16$ & as de Nîmes & Auguste \\
& $19,21-23$ & Caligula de Lyon & Auguste \\
& $17,27,29$ & as indéterminés & Haut Empire \\
1 quadrans & $91,197,246,248,251,272$ & Augre moitié du I Ier s. \\
\hline
\end{tabular}

Tabl. X - Monnaies de l'angle nord-est. (les as sont indiqués en caractères romains, les sesterces en gras, les dupondii en caractères italiques et les antoniniani sont signalés par un astérisque).

\begin{tabular}{|c|c|c|c|}
\hline espèce & $n^{\circ}$ du catalogue & identification & datation \\
\hline 27 & $\begin{array}{l}31,34,38 ; 54 ; 55 ; 56 \\
70,72,82 \\
89\end{array}$ & $\begin{array}{l}\text { Caligula; Claude ; Néron } \\
\text { Domitien } \\
\text { as }\end{array}$ & $\begin{array}{l}1^{\text {ère }} \text { moitié du I }{ }^{\mathrm{er}} \mathrm{s} \text {. } \\
2^{\mathrm{e}} \text { moitié du } \mathrm{I}^{\mathrm{er}} \mathrm{s} \text {. } \\
\mathrm{I}^{\mathrm{er}} \mathrm{s} \text {. }\end{array}$ \\
\hline 1 & 100,103 & Trajan & $\mathrm{II}^{\mathrm{e}} \mathrm{s}$ \\
\hline 5 & $\begin{array}{l}121,123,177 \\
135 ; 155,158,171 \\
174 \\
186 ; 188 \\
200,207,214,215,231,235,239 \\
245,249,257,275,278\end{array}$ & $\begin{array}{l}\text { Hadrien } \\
\text { Antonin; Marc Aurèle } \\
\text { Commode } \\
\text { Sévère Alexandre ; Philippe } \\
\text { as indéterminés }\end{array}$ & $\begin{array}{l}\mathrm{II}^{\mathrm{e}} \mathrm{s} . \\
\mathrm{II}^{\mathrm{e}} \mathrm{s} . \\
\mathrm{II}^{\mathrm{e}} \mathrm{s} . \\
1^{\text {ère }} \text { moitié du III } \mathrm{s} \text {. } \\
\text { Haut-Empire }\end{array}$ \\
\hline $14 *$ & $\begin{array}{l}280^{*}, 282^{*} ; 287^{*} ; \\
288^{*}, 290^{*}, 292^{*} ; 293^{*} \\
295^{*}, 296^{*}, 298^{*}-301^{*}, 303^{*}\end{array}$ & $\begin{array}{l}\text { Gallien; Victorin } \\
\text { Tetricus; Tacite } \\
\text { antoniniani indéterminés }\end{array}$ & $\begin{array}{l}2^{\mathrm{e}} \text { moitié du } \mathrm{III}^{\mathrm{e}} \mathrm{s} \\
2^{\mathrm{e}} \text { moitié du } \mathrm{III}^{\mathrm{e}} \mathrm{s} \text {. } \\
\mathrm{III}^{\mathrm{e}} \mathrm{s} \text {. }\end{array}$ \\
\hline 5 nummi & $304-308$ & Constantin & $1^{\text {ère }}$ moitié du IV $\mathrm{s}$ \\
\hline 1 aes 4 & 310 & aes 4 indéterminable & fin du IV $\mathrm{IV}^{\mathrm{e}}$ - début du $\mathrm{V}^{\mathrm{e}} \mathrm{s}$. \\
\hline $4 \mathrm{ex}$ & $312-315$ & 4 antoniniani ou aes 4 indéterminés & \\
\hline $1 \mathrm{ex}$ & 316 & monnaie coulée indéterminable & fin du IV $V^{\mathrm{e}}$ - début du V $\mathrm{V}^{\mathrm{e}} \mathrm{s}$. \\
\hline
\end{tabular}

autres, en très piteux état, nous hésitons à les idcntifier comme des antoniniani ou des aes 3 ou 4 : dans ce dernier cas, cela renforcerait la place des monnaies de la fin $d u \mathrm{IV}^{\mathrm{e}} \mathrm{s}$. et du $\mathrm{v}^{\mathrm{e}} \mathrm{s}$. dans cette zone et aussi dans tout le sanctuaire. Ces 11 pièces sont groupées le long du mur nord ${ }^{48}$, les autres étant un peu plus éparpillées.

48 Les carrés E $18-19$ rassemblent les 14 antoniniani, les 5 nummi et les 6 piécettes de la fin du Iv ou du début du $v^{e}$ s., soit 25 des 40 monnaies émises après 250 .
49 Sur la difficulté de trouver des sanctuaires proches de celui des Basiols, voir supra, p. 156 et notes 31 à 33 .

$50 \mathrm{Au}^{\prime \prime} \mathrm{I}^{\prime}$ s. au moins les cellae $2,3,4,5$ et 6 ; pour le III $^{\mathrm{e}}$ s., les cellae 2,4 et 5 . 


\section{L'origine du sanctuaire}

On se demandera quand commence la fréquentation du sanctuaire, situé à un col dont la montée difficile devait inciter à un peu de répit en arrivant au sommel, occasion de pénétrer dans le lieu sacré. Si la monnaie $n^{\circ} 1$, de la fin du II $^{\mathrm{e}}$ s. avant J.-C., peu usée et contremarquée sur les deux faces, a été offerte peu après son émission ou quelques décennies plus tard ${ }^{51}$, cela indique simplement que, peut-être pendant le dernier siècle de la République romaine, il y avait déjà quelque chose aux Basiols ${ }^{52}$. Depuis quand? La fouille ne permet pas de le dire ${ }^{53}$. La proximité des deux plus anciennes monnaies, $\left(\mathrm{n}^{0} \mathrm{l}\right.$ près du mur ouest et $\mathrm{n}^{\circ} 2$ dans la cella 7 ) situerait apparemment dans les parages l'endroit occupé en premier. Si nous avions ici déjà un sanctuaire gaulois, dans cette région indépendante jusqu'en $51^{54}$, il était dédié à des divinités celtiques que nous ne pouvons déterminer. Mais il est tout aussi difficile de dire qui sous l'Empire fut honoré dans l'enclos aux 9 cellae, dieux indigènes ou issus du syncrétisme galloromain ${ }^{55}$ et/ou empereurs divinisés ${ }^{56}$.

\section{Vie et déclin du sanctuaire}

Une réflexion sur la période de fréquentation du sanctuaire est plus satisfaisante. Durant quatre ou cinq siècles, jalonnés par les 318 monnaies offertes, des fidèles sont venus en ce lieu. Ils semblent avoir été particulièrement nombreux aux $\mathrm{I}^{\mathrm{er}}$ et $\mathrm{II}^{\mathrm{e}} \mathrm{s}$., chacun représenté par près de $30 \%$ des pièces identi-

51 Giard, Calalogue..., p. 40, envisage cependant la possibilité d'une "actualisation" de monnaies d'argent de bon aloi de la fin de la République et du début de l'Empire, sous les Julio-Claudiens et jusqu'à Vespasien.

52 La route (cf. notes 3 et 61 ) qui continue celle-ci au sud de Millau existait avant la conquête césarienne: voir P. Sillimeres et A. Vernhet, La voie romaine Segodunum-Cessero à l'Hospitalet du Larzac, Aquitania, 3, 1985, p. 63-71. En ètait-il ainsi au nord de Condalomagus? Les deux pièces d'argent républicaines pourraient en être un indice.

53 On a trouvé cependant quelques vases modelés, peut-être du $\mathrm{i}^{\mathrm{er}} \mathrm{s}$. avant notre ère (supra, p. 154), mais l'ancienneté du sanctuaire pourrait remonter beaucoup plus haut, les éventuelles installations en bois et matériaux périssables n'ayant alors laissé aucune trace. Il est d'ailleurs possible que comme dans beaucoup d'autres lieux sacrés préromains il n'y ait eu aucun aménagement.

54 On remarquera qu'aucune monnaie n'est contemporaine de la conquête césarienne.

55 Voir supra, p. 154 et la note 28 sur Mercure dont nous avons une représentation sur une intaille de verre bleu (fig. 24, $\mathrm{n}^{\circ} 2$ ).

56 Il faut sans doute voir un hasard dans la présence de quatre monnaies à l'effigie des impératrices Faustine I (3 ex.) et II (1 ex.) dans la cella 3 . fiables: ces deux lots totalisent entre les trois et quatre cinquièmes des monnaies. La grande rupture se situe en apparence après les Antonins, ou plutôt. Marc Aurèle : dès 180, pour les sept décennies de Commode à Philippe l'Arabe, pendant lesquelles sont frappés les derniers "grands bronzes" avant la généralisation de l'antoninianus, le sanctuaire semble n'avoir plus reçu qu'une dizaine de pièces, et même 4 entre Septime Sévère et Philippe. Il serait abusif de relier cette constatation à des événements historiques précis ou à une crise économique, notamment en Occident., aboutissant à l'arrêt de la circulation sur le réseau routier et donc des offrandes monétaires par les fidèles du sanctuaire, ou enfin à une improbable désaffection à l'égard des cultes galloromains. Il y a plutôt une explication liée à l'histoire de la monnaie impériale ${ }^{57}$, victime de plusieurs transformations, ainsi l'abaissement du poids et du titre de l'or et l'argent, la création éphémère, avant sa reprise en 238 , de l'antoninianus ; les frappes sénatoriales du bronze sont très réduites à partir de Septime Sévère, ce qui amène à utiliser fréquemment des monnaies des $\mathrm{I}^{\mathrm{er}}$ et $\mathrm{II}^{\mathrm{e}} \mathrm{s}$. ayant beaucoup circulé et donc presque totalement usées mais tolérées à cause de la pénurie en numéraire ${ }^{58}$. Il est donc possible de suggérer, non pas la répartition à peu près équitable des as indéterminés entre les $\mathrm{I}^{\mathrm{er}}$ et $\mathrm{II}^{\mathrm{*}} \mathrm{s}$., à l'image de ceux identifiables et en quantités équivalentes pour les deux siècles (91 ex., soit $28,4 \%$ et 88 ex., soit $27,5 \%$ ), mais l'attribution de ces 91 pièces lisses $\left(28,43 \%: n^{\circ s} 189\right.$ à 279$)$ à la première moitié du uI ${ }^{\mathrm{e}} \mathrm{s}$.

A ces as lisses s'ajoutent 4 sesterces de la première moitié du $1 I^{\mathrm{e}} \mathrm{s}$. Dans la seconde moitié, on a offert seulement 24 antoniniani $(7,4 \%$ ), objets de très faible poids et de très mauvais aloi.

Ainsi, pour tout le $11 \mathrm{I}^{\mathrm{e}} \mathrm{s}$, , on aurait offert aux dieux des Basiols 95 as, sesterces et dupondii, et 24 antoniniani, soit $37 \%$ des monnaies. Il n'y aurait donc pas un effondrement brutal de la fréquentation

57 Selon Claude Brenot, à qui ce passage doit beaucoup, les as lisses, portant ainsi la preuve d'une longue circulation, ont sans doute été offerts très tardivement, dans la première moitié du $\|^{\mathrm{C}} \mathrm{s}$, peu avant la prééminence puis la dégradation rapide de l'antoninianus, les fidèles du sanctuaire n'ayant pas les moyens d'offrir cette pièce d'argent puis de billon qui valait en principe au début, suivant les débats en cours, l'équivalent d'un denier et quart, ou un et demi, ou deux deniers, donc une grosse somme pour des gens pauvres.

58 Voir A. Kunisz, Remarques sur la circulation monétaire sur les territoires européens de l'Empire romain, au cours

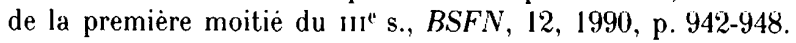
Voir aussi la note précédente. 
du sanctuaire à la fin du $11^{\mathrm{e}}$ ou au début du $1 \mathrm{I}^{\mathrm{e}} \mathrm{s}$. Pourtant il faut s'interroger sur le décalage évident entre la première et la seconde moitié du siècle : sous les Sévères, la dévotion semblerait à son apogée puisque les dieux reçoivent encore plus d'offrandes que durant chacun des deux siècles précédents ${ }^{59}$. Ainsi se pose à nouveau la question de la désaffection éventuelle des lieux dans la seconde moitié du $11^{\mathrm{e}} \mathrm{s}$., surtout si l'on songe à l'abondance des antoniniani ailleurs en Gaule.

Pendant la période finale qui dure plus d'un siècle, au $\mathrm{IV}^{\mathrm{c}} \mathrm{s}$., le déclin devient définitif.

Le succès du sanctuaire durant le Haut-Empire était sans doute lié à la proximité de la route. On sait que, sur le I arzac, un autre secteur de la même route a été aménagé par les Romains à partir d'un chemin gaulois, au début de l'Empire, et restaurć au moins deux fois dont une entre 150 et $250^{60}$ : son importance est indissociable de l'exportation massive vers le sud de la sigillée de La Graufesenque jusqu'au début du $\mathrm{II}^{\mathrm{e}} \mathrm{s}$. En outre la longue période de paix du II $^{\mathrm{e}} \mathrm{s}$. a favorisé les déplacements en tout genre et l'entretien du réseau. Peut-on étendre cette remarque au tronçon du I évézou, dont la fréquentation tout au long des trois siècles aurait assuré la renommée du sancluaire? Pourquoi alors cette désaffection à son égard, sinon dès le règne de Commode, du moins après le milieu du $\operatorname{III}^{\mathrm{c}} \mathrm{s}$. ? Une modification de l'itinéraire, pour le rendre plus facile, l'a-t-elle laissé à l'écart sur un ancien tracé ${ }^{61}$ ? Ou peut-être encore un sentiment d'insécurité assez répandu dans la seconde moitié du $\operatorname{III}^{\mathrm{e}} \mathrm{s} .{ }^{62}$, égale-

59 Rappelons que les grosses espèces de bronze disparaissent au milieu du $\mathrm{II}^{\mathrm{e}} \mathrm{s}$. par leur refonte pour frapper un billon de plus en plus médiocre (voir J.-N. Barrandon, C. Brfnot, M. Christol et S. Melky, De la dévaluation de l'antoninianus à la disparition du sesterce : essai de modélisation d'un phénomène monétaire, PACT, V, 1981, p. 381-390). Mais le trésor de Vannes enfoui vers 260 (C. BREnor, Le trésor de Vannes (Morbihan), RN, 5, 1963, p. 159-164) contenait à la fois des "grands bronzes" très usés, résultat d'une longue circulation, et des antoniniani. On rencontre d'ailleurs la même chose dans le trésor du Verdier, en Aveyron même, enfoui au plus tôt en 274 (cf. C. BÉnÉvent, Inventaire de la trouvaille monetaire du Verdier, Savignac, Vivre en Rouergue, Cahiers d'archéologie aveyronnaise, 31, nº spécial, 1989, p. 41-54.

60 Supra notes 3 et 52 .

61 La route moderne de Millau à Rodez par SaintBeauzély ne passe plus du tout par là et il n'y a plus qu'une petite route : il faudrait chercher si le changement d'itinéraire est récent ou au contraire très ancien.

62 Sentiment d'insécurité répandu à juste titre dans la Gaule du Nord et du Centre dès la fin des Sćvères. Mais le Lévézou courait apparemment peu de risques, même si cer- ment l'appauvrissement constaté des provinciaux, pour diverses raisons durant toute cette période et débutant même dans la Narbonnaise voisine à la fin du II: s. $^{63}$, ajoutés à l'isolement du lieu, ont-ils eu le même effet, aboutissant à un repliement dont nous voyons les résultats dans la rareté et la médiocrité des offrandes. Si la raison du déclin est autre, on serait tenté de la chercher dans un changement des mentalités, mais il semblerait qu'au $\mathrm{II}^{\mathrm{e}} \mathrm{s}$., à plus forte raison dans les campagnes, les cultes traditionnels soient toujours bien vivaces ${ }^{64}$, favorisés par la politique des Sévères ou des empereurs des périodes troublées qui suivirent. Quelles sont donc les raisons de la désaffection pour le sanctuaire, qu'il ne surmontera pas?

\section{L'abandon du sanctuaire}

L'ensemble cultuel survit au $\mathrm{rv}^{\mathrm{e}} \mathrm{s}$. mais nous avons signalé que l'endroit fréquenté par les fidèles se situe alors du côté nord-est, à en juger par les trouvailles monétaires. A la fin du $\mathrm{IV}^{\mathrm{e}} \mathrm{s}$., les motifs d'indifférence pour les cultes traditionnels sont plus clairs, liés aux progrès du christianisme et surtout à la politique intolérante des empereurs chrétiens contre les païens, parachevée par l'édit de Théodose Ier le 8 novembre $392^{65}$. Les ultimes piécettes non identifiables de notre catalogue sont plus ou moins de l'époque de celle polilique, menus témoignages d'une piété encore tolérée avant 392 ou bien après, bravade furtive et sans lendemain. Il est vrai aussi que la crise monétaire est plus forte que jamais

tains envisagent la possibilité d'une avancée des Alamans jusqu'à Rodez en 259-260. Néanmoins aucun trésor monétaire n'est à mettre en relation avec ce fait, mentionné par des textes et dont la datation est discutée : voir E. Demougeor, $L a$ formation de l'Europe el les invasions barbares, I, Des origines germaniques à l'avènement de Dioclélien, Paris, 1969 (p. 498; et carte XVIII A, "Incursions alamaniques,... el dépôts monétaires" de 250 à 260). Si les pillards n'ont pas alors atteint Rodez, ils ont cependant parcouru la vallée du Rhône et le bas Languedoc avant d'atteindre la Catalogne. Lors de la grande invasion de 276, le Rouergue paraît également épargné (ibid., p. 522-523 et carte XVIII B, "Incursions alamaniques, ... et dépôts monétaires " de 270 à 280), malgré le trésor du Verdier à Savignac, incomplet, signalé dans la note 59 et daté de 274 au plus tôt.

63 Petit, Histoire générale, p. 493-497.

64 Prtit, Histoire générale, p. 639, sur la vigueur du paganisme dans les campagnes dans la seconde moitié du $\mathrm{II}^{\mathrm{e}} \mathrm{s}$. Egalement dans l'Histoire du Rouergue, p. 69, on souligne $q u$ 'au $\mathbf{I V}^{\mathrm{e}}$ s., "les sanctuaires traditionnels sont aussi fréquentés que jamais".

65 Petit, Histoire générale, p. 641. 
avec des productions monétaires de très basse qualité ${ }^{66}$ et que les éventuelles offrandes ont pu être de nature périssable.

Le sanctuaire des Basiols sera alors définitivement déserté ${ }^{67}$. Malgré la destruction des murs de la cella "a" lors du creusement d'un trou profond à leurs emplacements, malgré la présence d'une colonne et de matériaux de construction jetés dedans, il ne semble pas avoir été détruit brutalement, sauf peut-être à cet endroit : il est vrai qu'on

66 Histoire du Rouergue, p. 69 confirme cela : «partout les séries monétaires s'interrompent au temps de Théodose".

67 A la différence d'autres temples et en tout cas des grottes-sanctuaires du Larzac où l'on trouve de la céramique estampée paléochrétienne rouge et orangée des $\mathrm{v}^{\mathrm{e}}-\mathrm{vI}^{\mathrm{e}} \mathrm{s}$. et une imitation d'un solidus d'Anastase Ier : Histoire du Rouergue, p. 66-69. est près d'une entrée. Il n'a pas non plus été réutilisé par les chrétiens - il n'y a aucun indice même ténu d'une éventuelle christianisation d'un lieu de culte païen, à la différence d'autres sites connus du Rouergue. Mais cet abandon ne signifie pas forcément celui de vieux cultes pratiqués en secret ni même la conversion rapide au christianisme de tous les paysans du Lévézou pour laquelle il faudra sans doute attendre quelque temps!

Sans autres destructions que celles du temps et en raison de l'altitude et de l'isolement des lieux, ce site de sommet offre ainsi l'avantage d'un ensemble resté pratiquement intact depuis le $\mathrm{IV}^{\mathrm{e}} \mathrm{s}$., avec un nombre aussi important d'édifices.

A. Bourgeois, J. Pujol et J.-P. SÉguret 


\section{CATALOGUE DES MONNAIES ${ }^{68}$}

\section{Époque républicaine}

1 ROMA - X (tête casquée de Roma à droite).

A. FLAMIN. / CILO (bige conduit par la Victoire vers la droite).

Fig. 27. Denier d'argent avec des contremarques : au droit, T sur la joue de Roma et, au revers, V (et T lié?) sous l'attelage ${ }^{69} ; 3,66 \mathrm{~g}$ (inv. d'origine $\mathrm{n}^{\circ} 126$ ) : le $R R C$, $n^{\circ} 302$ ne mentionne pas ces contremarques : atelier de Rome en 109 ou 108 avant J.-C.

2 CAESAR [imp VII ?] (tête nue (?) à droite; poinçon sur la joue ${ }^{70}$.

ASIA [recepta] (Victoire debout à gauche; autel encadré de deux grands serpents).

Fig. 27. Quinaire d'argent, très bien conservé; $1,46 \mathrm{~g}$ (inv. 176) : RIC I $\mathrm{I}, \mathrm{n}^{\circ} 276$ : Octave, atelier de Rome ou Brindisi ${ }^{71}$; 29-27 avant J.-C.

Auguste (colonie de Nîmes) : revers COL NEM (crocodile et palme) ${ }^{72}$

3 [ ]MP /[Div]I F (tête d'Auguste couronné de chène, à droite).

Fig. 27. Demi-as très bien conservé ; $7,20 \mathrm{~g}$ (inv. 54) : $R I C \mathrm{I}, \mathrm{n}^{\circ} 158$ : entre 10 avant J.-C. et 10 après J.-C.

68 Le numéro à gauche est celui du catalogue; nous transcrivons ensuite les légendes conservées et nous donnons une description sommaire des images du droit et du revers. Le numéro d'inventaire donné lors de la fouille est signalé entre parenthèses après le poids de la pièce. Les références utilisées pour l'identification et la datation sont le $R R C$ et le $R I C$ pour le monnayage officiel et l'ouvrage de G. Elmer pour les empereurs gaulois du III ${ }^{\mathrm{e}} \mathrm{s}$. (supra note 34 ).

69 Sur les contremarques, voir supra la note 42.

70 Le $R I C$ I, édition de 1984, ne signale des contremarques que sur le bronze (p. 9-11) mais pas celle-ci. Giard, Catalogue.., p. 143, mentionne les poinçons $V$ et gamma sur les quinaires d'argent du même type : ces deux lettres, contremarques ou marques de changeurs ou autres, sont dissociées sur les exemplaires qu'il reproduit, mais aux Basiols, il pourrait bien s'agir des mêmes signes, liés.

71 Giard (Calalogue ..., p. 143) attribue ces pièces à l'atelier d'Éphèse en août 29 avant J.-C., mais le RIC I, 1984, ne l'a pas suivi.

72 Pour cette série. il y a un débat entre une datation haute (elle serait frappée dès 28 avant J.-C., selon J.-M. RonDaz, Marcus Agrippa, Rome, BEFAR 253, 1984, p. 595-597) et une chronologie basse (seulement après 20 avant notre ère : en dernier lieu, voir M. Christor, et Chr. Goudineau, Nimes et les Volques Arécomiques au $\mathrm{I}^{\mathrm{er}} \mathrm{s}$. avant J.-C., Gallia, 19871988 , 45, p. 87-103, qui la justifient en disant (p. 102) : "le monnayage de Nîmes s'inscrirail donc dans la série des mesures prises vers 16 [avant J.-C.]》.
4-6 IMP/P P/ DIVI F (têtes d'Agrippa et d'Auguste). Deux as bien conservés; $9,49 \mathrm{~g}$ (inv. 167); 12,10 g (inv. 175).

Un demi-as (Agrippa; trace de marque préalable au partage de la pièce, ou trace de la pince); $4,75 \mathrm{~g}$ (inv. 162); RIC I, no 159 (palme tournée vers la gauche) : entre 10 et 14 après J.-C.

7-9 IMP/P P/ DIVI F (têtes d'Agrippa et d'Auguste). Trois as très bien conservés; $10,91 \mathrm{~g}$ (inv. 157); 11,78 g (inv. 166); (fig. 27) 12,10 g (inv. 171) : RIC I, no 160 (palme verticale) : cntro 10 et 14 après J.-C.

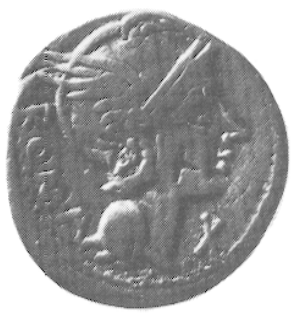

1
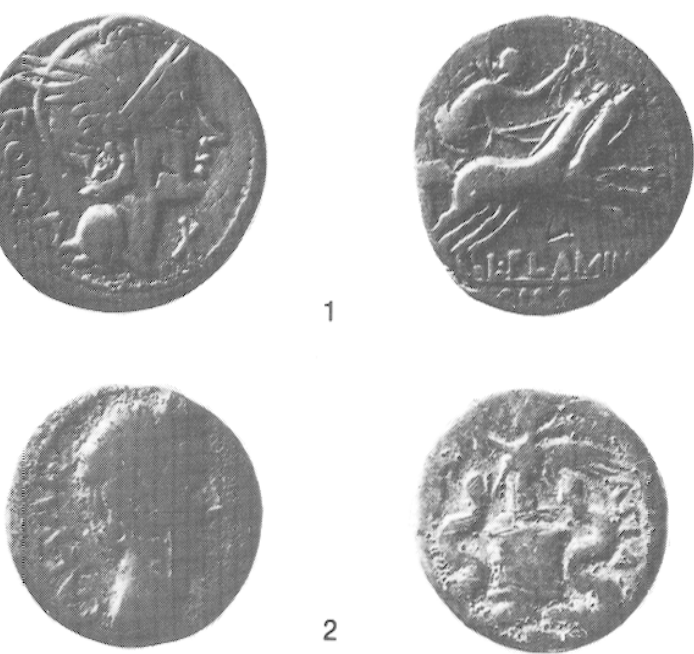

2
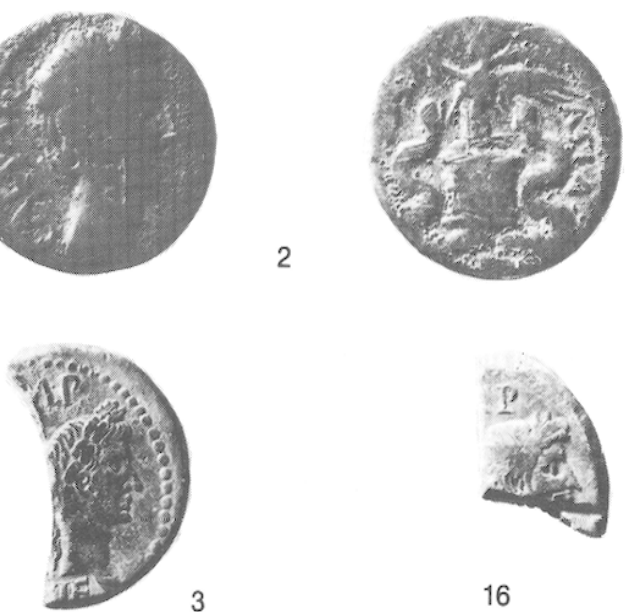

16
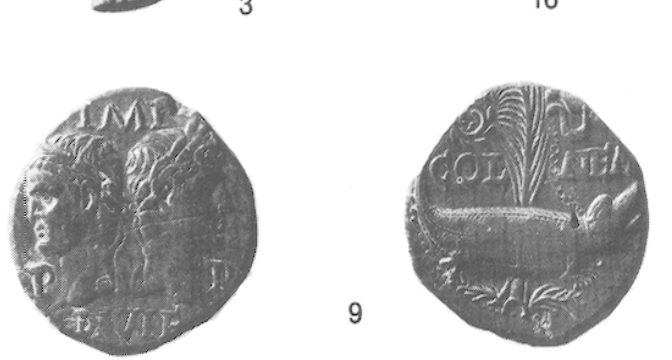

Fig. 27 - Monnaies d'argent ( $n^{\circ} 1$ et '2, au double) et as de Nîmes. 
10 IMP/P P/ DIVI F (têtes d'Agrippa et d'Auguste). As très bien conservé ; $12,08 \mathrm{~g}$ (inv. 174) : RIC I, no 159 ou 160 , entre 10 et 14 après J.-C.

11 IMP /P [p] / DIVI F (têtes d'Agrippa et d'Auguste).

COL - NEM ( $N$ et E liés).

As très bien conservé ; 11,74 g (inv. 165) : RIC I, $\mathrm{n}^{\circ} 161$ (palme verticale) : entre 10 et 14 après J.-C.

12-15 [ ] (tête d'Agrippa ( $\left.n^{\circ} 12\right)$ ou d'Agrippa et d'Auguste (n'13-15).

Quatre demi-as; $5,51 \mathrm{~g}$ (inv. 163); $4,75 \mathrm{~g}$ (inv. 159); $4,85 \mathrm{~g}$ (inv. 127); $5,21 \mathrm{~g}$ (inv. 140) : RIC $\mathrm{l}, \mathrm{n}^{\circ} 154 \dot{\mathrm{a}}$ 160 : entre 20 avant J.-C. et 14 après J.-C. (n'12) ou 159-161 : entre 10 et 14 après J.C. (n $13-15)$.

16 [ ] (tête à droite d'Auguste couronné de chêne). Fig. 27. Quart d'as très bien conservé; $3,35 \mathrm{~g}$ (inv. 138) : $R I C \mathrm{I}, \mathrm{n}^{\circ} 158$ à 161 : entre 10 avant J.-C. et 14 après $\mathrm{J}$.-C.

\section{Auguste (atelier de Lyon) :}

revers ROM ET AVG avec l'«autel» du Confluent encadré par deux Victoires monumentales

17 [Caesar Augustus] DIVI [f. pater patriae] (tête à droite, nue ou laurée, d'Auguste).

As très corrodé ; 6,45 g (inv. 170) : RIC I, nº 233 (droit $1 \mathrm{~B}$ avec légende écrite de droite à gauche) : entre 9 et 14 après J.-C.

18 TI CAESAR[ ] IMPE[r]A[t] V (tête laurée à droite de Tibère).

As ; $9,23 \mathrm{~g}$ (inv. 282) : RIC I, no 238 a (droit $2 \mathrm{~F}$ avec légende écrite de droite à gauche), entre 8 et 10 après J.-C.

19 [Ti Caesar August f imp]ERA[t] VII (tête laurée à droite de Tibère).

As mal conservé; 7,85 (inv. 161) : RIC I, no 245 (droit $5 \mathrm{~F}$ avec légende écrite de droite à gauche), entre 12 et 14 après J.-C.

\section{0 [Ti Caes]AR AVGVST F IMPER [ ] (tête à} droite de Tibère, laurée (type $F$ ).

As ; 8,90 g (inv. 220) : RIC I, no 238a ou 245 (titulatures diverses $n^{\circ} 2$ ou 5 ), entre 8 et 14 après $\mathrm{J}$.-C.

21-23 [ ].A[ ] (tête laurée à droite non identifiable).

Trois as; $5,44 \mathrm{~g}$ (inv. 164); 6,59 g (inv. 158); 8,17 g (inv. 160) : RIC I, no $230,233,238 \mathrm{a}, 245$ ? en fait indéterminable; entre 9 et 14 après J.-C.

\section{Caligula (atelier de Rome)}

24 C CAESAR AVG GERMANI[cu]S [pon m] TR POT (tête nue à gauche de Caligula).

VESTA $\underline{\mathrm{S} \text { C }}$ (Vesta assise à gauche ; attributs indéterminables).

As ; $8,58 \mathrm{~g}$ (inv. 231) : RIC I, $\mathrm{n}^{\circ} 38$ : en $37-38$.
25 [Germanicus] CAESAR [Ti August f divi aug] (tète nue à gauche de Germanicus).

[Cae]SAR AVG GERMAN[ ], S C de grande taille au centre.

As; 6,33 g (inv. 206) : RIC I, no 35 : entre 37 et 41 .

26-32 M AGRIPPA L F COS III (tête à gauche d'Agrippa avec la couronne rostrale).

S C (figure indéterminée entre ces lettres de grande taille).

Sept as (le $\mathrm{n}^{\circ} 30$ est très usé); 6,2l $\mathrm{g}$ (inv. 44); 6,44 g (inv. 168 ); $6,88 \mathrm{~g}$ (inv. 182); 7,14 g (inv. 132); 7,79 $\mathrm{g}$ (inv. 99) ; 8,01 g (inv. 66); 9,12 g (inv. 39) : RIC I, no 58 (pl. 14, 58) : entre 37 et 41 .

33-34 [ ] (tête nue à gauche de Caligula).

VESTA, S C (entre ces deux grosses lettres, Vesta assise).

Deux as en très mauvais ètat; $8,02 \mathrm{~g}$ (inv. 185); $8,84 \mathrm{~g}$ (inv. 315) : $R I C$ I, no 38,47 ou 54 (suivant la titulature, ici illisible) : en 37-38 ( $\left.n^{\circ} 38\right)$, 39-40 ( $n^{\circ} 47$ ) ou 40-41 (no 54).

35 [ ] AVG GER[M ] (tête imberbe laurée à droite).

[ ] [S] C (lisse).

As; 7,53 g (inv. 223) : référence indéterminable : Caligula plutôt que Néron.

\section{Claude (atelier de Rome seul représenté)}

36 [Ti Claudius Caesar Aug p]M TR P IMP (tête à gauche laurée (?) : sans doute Claude).

S C (entre deux grosses lettres, Minerve tenant un bouclier de la main gauche et lançant un javelot).

As ; 5,77 g (inv. 305) : RIC I, no 100 : entre 41 et 50.

37 [Ti Clau]DIVS CAESAR [aug p $\mathrm{m}$ tr p] IMP (tête nue (?) à gauche).

[ ] (lisse).

As très usé; $7,57 \mathrm{~g}$ (inv. 6) : RIC I, no 94, 95, 97 ou 100 : entre 41 et 50 .

38 [ ] (tête à droite d'Agrippine l'Ancienne plutôt qu'Antonia, d'après sa coiffure; cf. $R I C$ I, pl. 16, nº 102 qui est un sesterce).

「 \(Ceres Avgvsta assise à gauche (cf. sesterce $\left.R I C \mathrm{I}, \mathrm{n}^{0} 102\right)$.

As; 7,28 g (inv. 314) : as doublant le sesterce, $R I C \mathrm{I}$, $n^{\circ} 102$ ? Entre 50 et 54 .

39-43 [Ti] CLAVDIVS CAESA[r Aug $p$ m tr $p$ imp ou ....imp p p] (tête nue à gauche de Claude).

CON[stantiae] AVGVSTI S C (figure à gauche, avec un sceptre vertical).

Cinq as ; 6,09 g (inv. 38); 7,15 g (inv. 89); $8,10 \mathrm{~g}$ (inv. 285); 8,61 g (inv. 259); 9,50 g (inv. 295) : RIC I, $\mathrm{n}^{\circ} 95$ (pl. 16, 95 : imp) ou no 111 (imp p p) : entre 41 et 50 (imp) ou 51 et 54 (imp p p).

44 [mème incertitude sur la fin de la légende] (tête à gauche ?).

LIBERTAS [ ] (figure peu identifiable). 
As mince et très usé ; 7,93 g (inv. 110) : RIC I, no 97 (imp) ou $\mathrm{n}^{\circ} 113$ (imp p p) : entre 41 et 50 ou entre 50 et 54 .

45 [ ] AVG P M T $[\mathrm{r} \mathrm{p}]$ (indéterminé).

] AVGVS. [ ] (indéterminé).

As ou dupondius très usé $; 8,12 \mathrm{~g}$ (inv. 5) : référence et datation indéterminables : entre 41 et 54 .

46-50 [même incertitude sur la fin de la légende] (tête nue à gauche).

[ ] $\underline{\mathrm{S} \text { C }}$ (lisse).

Cinq as ou dupondii très usés; $6,01 \mathrm{~g}$ (inv. 267); 6,54 g (inv. 117); 6,91 g (inv. 52); 7,28 g (inv. 277); 8,02 g (inv. 221) : RIC $\mathrm{I}, \mathrm{n}^{\circ} 95,97,100(\mathrm{imp})$, entre 41 et 50 ; ou $n^{\circ} 111,113,116$ (imp p p); entre 50 et 54 .

51-54 [ ] (tête à gauche (laurée? nue?) de (laude).

] lisse $\left(n^{\circ} 51\right) ; \mathrm{S}[\mathrm{C}]$ : lettres de grande taille au centre ( $\left.n^{\circ} 52\right)$; Victoire debout à droitc $\left(n^{\circ} 53\right)$; figure entre deux grandes lettres S C ( $\left.{ }^{\circ} 54\right)$.

Quatre as ou dupondii médiocres; $5,29 \mathrm{~g}$ (inv. 53); $6,02 \mathrm{~g}$ (inv. 3); $6,95 \mathrm{~g}$ (inv. 1); 8,10 g (inv. 311) : référence et datation indéterminables : entre 41 et 54 .

\section{Néron (atelier de Rome seul représenté)}

55 NERO CAESAR AVG GERM [imp] (tête laurée à droite de Néron).

[ ] (lisse).

As; 9,59 (inv. 20) : référence indéterminable : entre 62 et 66 .

56 [ ] NE[.]O [ ] (tête laurée à droite).

As; $7,23 \mathrm{~g}$ (inv. 319 ) : référence et datation indéterminables.

\section{Empereurs julio-claudiens indéterminés}

57 [ ] (tête non identifiable).

[ ] ROM ET AUG à l'exergue (sanctuaire de Lyon avec les Victoires).

Quadrans très usé ; $1,62 \mathrm{~g}$ (inv. 128) : référence indéterminable : Auguste, Tibère ou Claude? Atelier de Lyon.

58-62 Légendes et figures indéterminables (têtes d'empereurs julio-claudiens).

Cinq as ou dupondii très usés; $6,64 \mathrm{~g}$ (inv. 238); 7,66 $\mathrm{g}$ (inv. 224); 8,43 g (inv. 237); 8,68 g (inv. 4); $10,39 \mathrm{~g}$ (inv. 36); références et datation indéterminables.

63 [ ]CAEs. AVG P. P[ ] (tête nue (?) à gauche de Tibère (?) ou Claude (?).

$[\mathrm{S}[], \underline{S C}$ (figure indéterminable; $\mathrm{S} C$ en grosses leltres).

As ou dupondius; $8,74 \mathrm{~g}$ (inv. 234) : référence et datation indéterminables.

\section{Vespasien}

64 [imp Ca]ESAR VESPASIAN [Aug Cos IIII] (tète radiée à droite de Vespasien).

gauche).
Dupondius; $9,70 \mathrm{~g}$ (inv. 91) : $R I C$ II, no 740 : atelier de Lyon en 72-7:3.

65 CAESAR AVG F DOM[itian ou Domitianus..] (tête à gauche apparemment, laurée de Domitien).

[ ] (lisse).

As très érodé; $7,78 \mathrm{~g}$ (inv. 84) : RIC II, p. 97 à 100 (référence indéterminable car la titulature peut être Caesar Aug Domitian ou Domitianus, assortie d'un consulat variable $[\operatorname{Cos} I I$ ou $\operatorname{Cos} V I$, avec l'effigie à gauche]) : Domitien sous le règne de Vespasien, atelier de Rome en 73 ou 79 .

66 [T Caes Imp Aug f tr p] COS [V] CENSOR (t⿳亠t八te laurée ou radiée à droite de 'Titus).

[ludaea cap]TA (trophée et captive).

As ; 7,49 g (inv. 245) : RIC II, no 784 (le plus probable) : Titus sous le règne de Vespasien; atelier de Lyon en 77-78.

Titus

67 [ ] DIVI VESP F DOMITIAN COS VII (lête laurée à droite de Titus).

[ ], S C (Minerve à droite casquée et armée). As; $6,78 \mathrm{~g}$ (inv. 45) : RIC II, $\mathrm{n}^{\circ}$ 170a : Domitien sous le règne de Titus; atelier de Rome en 80-81.

68 Légendes et figures indéterminables.

As; $8,53 \mathrm{~g}$ (inv. 152) : référence et datation indéterminables (tête imberbe laurée à gauche aux traits lourds : Titus?).

Domitien (atelier de Rome)

a) revers datés

69 [ ]DIVI VESP F DOMITIAN AVG P M (tête laurée à gauche de Domitien).

TR [p ] DES VIIII P P, $\underline{\mathrm{S} \mathrm{C}}$ (Minerve debout à droite casquée et armée).

Fig. 28. As en très bon état; $9,50 \mathrm{~g}$ (inv. 43) : RIC II, $\mathrm{n}^{\circ} 242 \mathrm{~b}$ (Imp Caes divi Vesp f. Domitian aug $p \mathrm{~m} / \mathrm{Tr} p$ cos des VIIII p p s. c.) : en 81 .

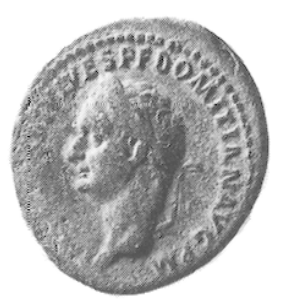

69

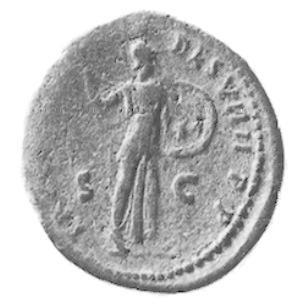

Fig. 28 - As de Iomitien.

70 [ ] (tête indéterminée (1)omitien?).

[ ]DES VIIII P P, S G (Minerve de face tenant un bouclier rond).

As; $8,65 \mathrm{~g}$ (inv. 15) : RIC II, no 239 (a ou b) : en 82 . 
71 [imp Caes] DOMITIAN AVG[ ] (tète laurée à droite (égide invisible, usée?).

MONET[ ] AVGVST[ ], S C (Monela avec corne d'abondance et balance).

As ; 8,81 g (inv. 193) : RIC II, $\mathrm{n}^{\circ} 248$ (10' consulat en $84)$ ou 270 (11 $1^{\text {e }}$ consulat en 85$)$.

72 [ ]CAES[ ] COS [ ] (tête nue ou laurée à droite de Domitien).

[ ] AVGVSTI, S C (Victoire debout à gauche, attributs indéterminés).

As; 7,61 g (inv. 317) : RIC II, n 305 (Imp Caes Domit Aug germ cos XI cens per / Victoria augusti / SC) ou 339 (Imp Caesar Domit Aug ger cos XII cens per p p / SC) : en 85 ou 86.

73 [Imp Caes]DOMIT AVG [Germ] COS XIII [? Cens] $\operatorname{PER}[\mathrm{p} \mathrm{p}]$ (tête nue ou laurée à droite).

[ ] (indéterminable).

As; $6,88 \mathrm{~g}$ (inv. 248) : référence indéterminable : en 87 (13 consulat) ou 88-89 (14 consulat).

74 IMP CAES DOMIT AVG GERM[ ] (tête radiée à droite)

FORTVNAE AVGVSTI (Fortuna debout à gauche, tenant une ancre dans la main droite et une corne d'abondance).

Dupondius bien conservé; 9,48 g (inv. 2) : RIC II, no 384 : en 88-89 (Imp Caes Domil Aug Germ $p$ m tr $p$ $V I I I \ldots)$.

75-76 IMP CAES DOMIT AVG GERM COS XV CENS [ ] P P (tête laurée à droite, buste nu).

[ ] AVGVST[ ], $\underline{\mathrm{SC}}$ (figure à gauche tenant une corne d'abondance sur le bras gauche; objet indèterminé dans la main droite).

Deux as ; $6,50 \mathrm{~g}$ (usé) (inv. 42) ; 9,33 g (inv. 121) : $R I C$ II, no 394 (Fortunae Augusti au gouvernail) ou 395 (Monela Augusti à la balance) : en 90-91.

77 IMP CAES DOMIT AVG GER[ ] COS XIII (ou XVII ?) CENS PER PP (tête laurée à droite).

FORTVNAE AVGVSTI, $\underline{\mathrm{S} C}$ (Fortuna debout à gauche, gouvernail dans la main droite).

As ; 7,88 g (inv. 180) : RIC II, no 353 (Cos XIII en 87) ou $\mathrm{n}^{\circ} 422(\operatorname{Cos} X V I I$ en $95-96)$.

b) revers lisses, donc référence et

datation impossibles

78-82 [Imp] CAES DIVI VESP F DO[M ] (tête à droite (laurée?).

As très usé ; $8,54 \mathrm{~g}$ (inv. 103).

79 IMP CAES [Domit ?] AVG GERM [] (tête laurée à droite).

As; 7,72 g (inv. 289).

80 [ ] DOMITIA[ ] (tête laurée à droite, buste nu). As; $9,12 \mathrm{~g}$ (inv. 291).

81-82 [ ] (tête laurée à droite de Domitien?). As ou dupondius; $6,78 \mathrm{~g}$ (inv. 297); 8,76 g (inv. 312).

\section{Empereurs du $\mathrm{i}^{\mathrm{er}} \mathrm{s}$. , sans précision}

83 Droit indéterminable / S C (lettres de très grande taille).

As ou dupondius très usé $; 7,52 \mathrm{~g}$ (inv. 51) : référence et datation indéterminables (Agrippa sous Caligula? Claude ou Titus?).

84-91 Légendes illisibles et revers lisses (tête à gauche $\left(\mathrm{n}^{\circ} 86,87,88,91\right)$ ou à droite $\left(\mathrm{n}^{\circ} 84,85,89,90\right)$.

Huit as ou dupondii parfois très usés; $6,04 \mathrm{~g}$ (inv. 187); $6,12 \mathrm{~g}$ (inv. 183 ); 6,68 $\mathrm{g}$ (inv. 57); $6,82 \mathrm{~g}$ (inv. 302); $6,84 \mathrm{~g}$ (inv. 222); 7,21 g (inv. 113); 7,86 g (inv. 313); $8,50 \mathrm{~g}$ (inv. 169); référence et datation indéterminables.

\section{Nerva (atelier de Rome)}

92 IMP NERVA CAES AVG P M TR P COS III P P (tète à droite laurée).

FORTVNA AVGVS', S C (Forluna à gauche tenant un gouvernail (main droite) et une corne d'abondance (main gauche).

As; $10,90 \mathrm{~g}$ (inv. 143) : RIC II, no 83 : en 97.

93 [Imp] NERVA CAES AVG [p m ....] (tête à droite laurée).

LIBERT[as publica], S C (Libertas debout à gauche).

As ; 9,77 g (inv. 189) : RIC II, $\mathrm{n}^{\circ} 64,76,86$ ou 100 : entre 96 et 98 .

94 [ ] (tête nue à droite, maigre, cheveux frisés, imberbe).

[F]ORTVNA[ ], s G (Forluna debout à gauche avec une corne d'abondance dans la main gauche; dans main droite, objet indéterminé).

As; $9,03 \mathrm{~g}$ (inv. 154) : RIC II, n $60,73,75,83-85,98$ 99 : entre 96 et 98 .

Trajan :

\section{a) titulature IMP CAES NERVA TRAIAN AVG GERM P M (atelier de Rome)}

95 Revers: TR POT COS II [. .], S G à l'exergue (figure assise à gauche).

Dupondius (tête radiée à droite); $10,75 \mathrm{~g}$ (inv. 8) : RIC II, $\mathrm{n}^{\circ} 382$ : en $98-99$.

96 Revers : TR POT[ ], S [C] (Victoire allant vers la gauche, tenant de la main gauche un bouclier inscrit : SPQR).

Fig. 29. As (tête laurée à droite); 7,14 g. (inv. 112) : RIC II, no 417 (Cos III: 99-100) ou no 434 (Cos IIII :101-102).

97-98 Revers : TR POT [ ] (même description que le $\left.\mathrm{n}^{\circ} 95\right)$.

Deux as (tête laurée à droite); 7,63 g (inv. 274); 12,26 g (inv. 256) : RIC II, no 395 ( $T r$ pot $\cos I I$ en 98-99) ou $\mathrm{n}^{\circ} 417$ (...Cos III en 99-100) ou $\mathrm{n}^{\circ} 434$ (...Cos IIII : 101-102). 
b) titulature IMP CAES NERVAE TRAIANO AVG GER DAC P M TR P COS V P P (atelier de Rome)

99 Revers : SPQR OPTIMO PRINCIPI S C (Roma debout tient une petite Victoire de la main droite; à sa gauche, la Dacie à genoux).

Fig. 29. As très bien conservé (tête laurée à droite, buste nu); 9,52 g (inv. 301) : RIC II, no 486 : de 103 à 111 .

100 Revers : [SPQR Optimo pr]INCIPI, S C à l'exergue (Salus assise à gauche nourrissant un serpent). Dupondius (tête radiée à droite, buste nu avec les attaches de l'amictus); $10,03 \mathrm{~g}$ (inv. 13): IRIC II, $\mathrm{n}^{\circ} 516$ : de 103 à 111.
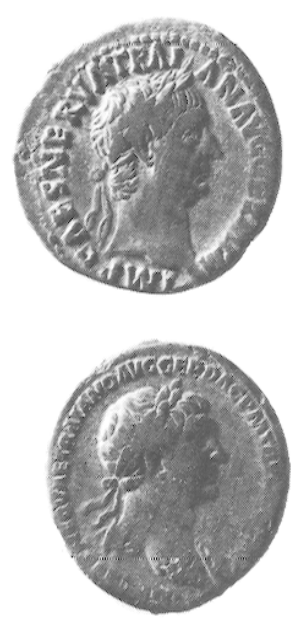

96

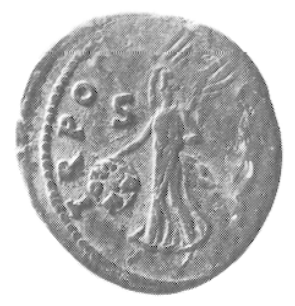

99
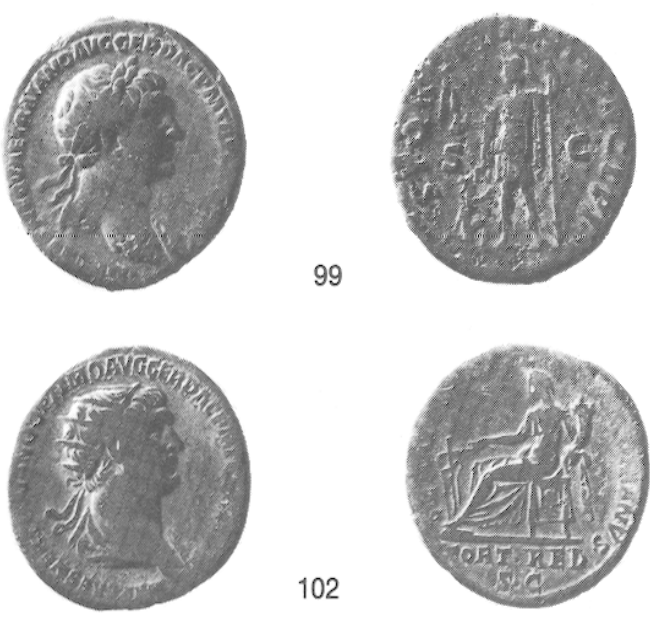

102
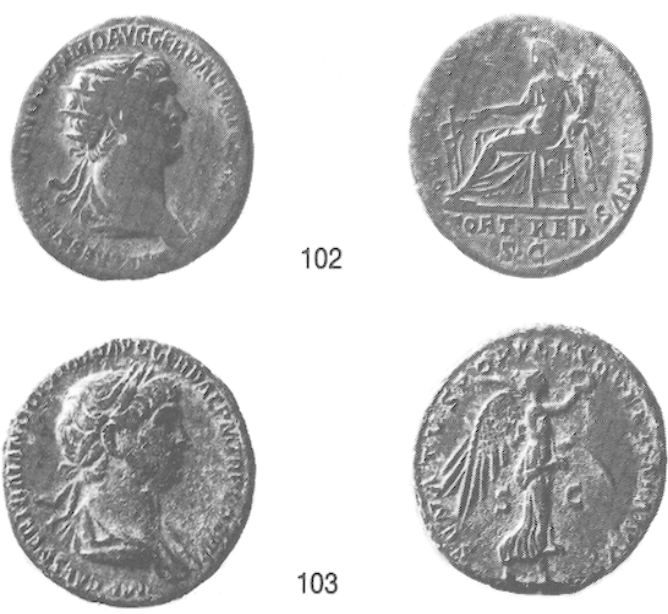

103
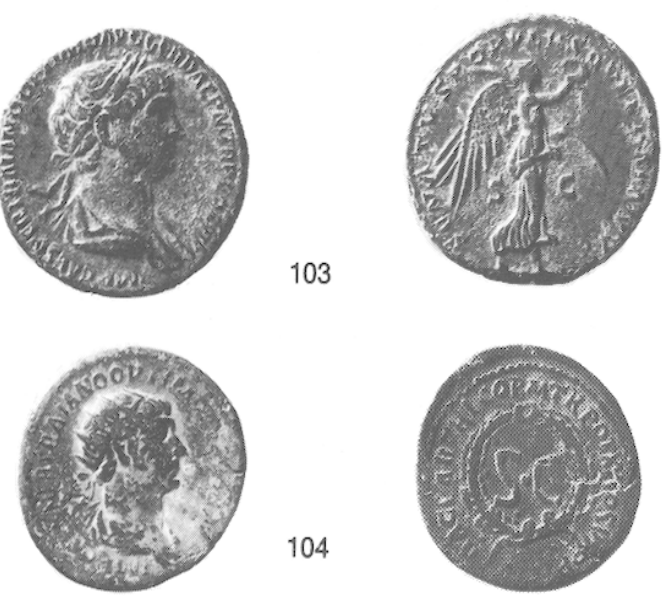

104

Fig. 2. - Monnaies de Trajan.
101 Revers : SPQR OPTIMO PRINC[], S [ ] (Victoire marchant vers la droite en tendant une couronne). As (tête laurée à droite, buste drapé); $8,84 \mathrm{~g}$ (inv. 276) : RIC II, no 593 (droit C 2) : en 112-114.

c) titulature IMP CAES NER TRAIANO OPTIMO AVG GER DAC P M TR P COS VI P $P$ (atelier de Rome entre août 114 et février 116) ${ }^{73}$

102 Revers : SENATVS POPVL[usque] ROMANVS, /FORT.RED / S. C (Fortuna assise à gauche, avec une corne d'abondance et un gouvernail).

Fig. 29. Dupondius (buste drapé à droite, couronne radiée); 11,93 g (inv. 201) : RIC II, n 653 .

103 Revers: SENATVS POPVLVSQVE ROMANVS $\underline{\mathrm{SC}}$ (Victoire marchant vers la droite, tenant une palme et une couronne).

Fig. 29. As très bien conservé (tête laurée à droite, buste drapé); $10,31 \mathrm{~g}$ (inv. 61) : RIC II, no 675 .

d) titulature IMP CAES NER TRAIANO OPTIMO AVG GERM (atelier de Rome entre février 116 et le 9 décembre 116$)^{74}$

104 Revers: DAC PARTHICO P M TR POT XX COS VI P P, S C au centre d'une couronne de laurier. Fig. 29. Dupondius (buste drapé à droite, couronne radiée) ${ }^{75} ; 9,69 \mathrm{~g}$ (inv. 217 ) : RIC II, no 647 .

e) revers lisses de Trajan de l'atelier de Rome (références indéterminables)

105 [ ]GER I)AC ...[ ] (tête laurée, radiée ou nue, à droite, buste drapé ).

As; 7,37 g (inv. 281).

106-108 [ ] (tête laurée à droite, buste avec les attaches de l'amictus ( $\left.\mathrm{n}^{\circ} 106\right)$; tête laurée à gauche ( $\left.\mathrm{n}^{\circ} 107\right)$; tête nue à droite $\left(\mathrm{n}^{\circ} 108\right)$.

Trois as très usés; 7,03 g (inv. 136); $9,19 \mathrm{~g}$ (inv. 228); $10,07 \mathrm{~g}$ (inv. 192).

109 [ ] (tête imberbe à droite, radiée [?]).

Dupondius; $9,72 \mathrm{~g}$ (inv. 230).

Hadrien :

a) titulature IMP CAESAR TRAIAN HADRIANVS AVG (atelier de Rome en 119$123)^{76}$

110 Revers : [ ] COS III / FORT RED / S C (Fortuna assise à gauche tient un gouvernail de la main droite et une corne d'abondance de la main gauche).

73 Selon la chronologie proposée dans l'étude du Trésor de Garonne, p. 166, différente de celle du RIC II.

74 Selon le Trésor de Garonne, p. 177.

75 Le RIC II appelle "as» ces pièces à couronne radiée ( $\mathrm{n}^{\text {os }} 644$ à 648 ); voir aussi p. 242 le commentaire sur l'éventuel amalgame des as et des dupondii.

76 Selon la chronologie proposée dans l'ẹtude du Trésor de Garonne, p. 197, différente de celle du RIC. 
As (tête laurée à droite, buste drapé); $10,19 \mathrm{~g}$ (inv. 290) : RIC II, $\mathrm{n}^{\circ} 578$ (revers Pont Max lr pot cos III/ Fort red/SC); en 119-121.

111 Revers :.P M TR P COS III S C (figure debout à gauche, avec une corne d'abondance).

As (tète laurée à droite); $9,22 \mathrm{~g}$ (inv. 239) : RIC II, $n^{\circ} 616$ : en 121-122.

112 Revers indéterminable.

As (tête laurée à droite ); $8,88 \mathrm{~g}$ (inv. 181); référence indéterminable : entre 117 et 125 .

\section{b) titulature HADRIANVS AVGVSTVS (atelier de Rome en 123-128) ${ }^{77}$}

113 Revers: COS[III], S C (Salus debout à droite et tenant un serpent).

As (tête à droite); $9,07 \mathrm{~g}$ (inv. 204) : RIC II, $\mathrm{n}^{\circ} 669$.

114-115 Revers : SALVS [Augusti]/ S C / COS III

(Salus à gauche nourrissant un serpent sur l'autel).

Deux as (tête à droite [nue? laurée ?]); $5,95 \mathrm{~g}$ (inv. 7); $9,40 \mathrm{~g}$ (inv. 142) : RIC II, n 678.

116 Revers : [ ] $\underline{\mathrm{S} \mathrm{C}}$ (scène d'Adventus?).

As très rogné (tête laurée à droite); $5,54 \mathrm{~g}$ (inv. 304) : RIC II, $\mathrm{n}^{\circ} 717$.

117 Revers: [ C? ] AE[ ] (figure debout à gauche tenant une patère dans main droite).

As ou dupondius (tête à droite, laurée ou nue); $5,83 \mathrm{~g}$ (inv. 266) : référence indéterminable.

c) titulature HADRIANVS AVG COS III P P (atelier de Rome en 130-138) ${ }^{78}$

118 Revers : S C / DACIA (la Dacie assise appuyée à un rocher, tenant un vexillum de la main droite).

As (tête laurée à droite, buste drapé); $9,27 \mathrm{~g}$ (inv. 300) :

$R I C$ II, $\mathrm{n}^{\circ} 880$ : série des provinces entre 134 et $138^{79}$.

119 Revers : S C (figure à gauche tenant une enseigne oblique).

As ou dupondius (buste drapé à droite, tète nue); $9,81 \mathrm{~g}$ (inv. 226) : référence indéterminable.

\section{d) titulatures indéterminables (atelier de Rome)}

120 Légendes indéterminables (revers Salus (?) debout à gauche nourrissant un serpent).

As (lêle laurée à droite d'Hadrien); $8,39 \mathrm{~g}$ (inv. 197) :

$R I C$ II, $\mathrm{n}^{\circ} 678$, en 125-128 ou $n^{\circ} 832$, en 134-138.

121 HADRIAN [ ] AVG [ ] (tête laurée à droite).

$$
\text { [ ], } \underline{\mathrm{S} C} \text { (figure indéterminable). }
$$

As très usé; $10,45 \mathrm{~g}$ (inv. 236) : référence indéterminable.

77 Selon la chronologie proposée dans le Trésor de Garonne, p. 229, différente de celle du RIC (qui proposait 125128). 134-138

78 Selon le Trésor de Garonne, p. 253, qui propose mème

79 Selon le Trésor de Garonne, p. 273, cette monnaie est de 137.
122 [ ] (tête à droite, laurée ou nue d'Hadrien).

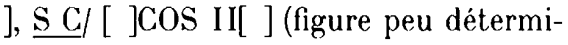

nable).

As ; 7,23 g (inv. 229) : référence indéterminable.

123 Légendes illisibles, figure du revers indéterminable.

Sesterce (tête laurée à droite, buste nu d'Hadrien); $20,20 \mathrm{~g}$ (inv. 10) : référence indéterminable.

e) famille impériale (atelier de Rome)

124 L AELIVS CAESAR (tête barbue à droite, nue, de L. Aelius).

$[\operatorname{Tr} p] O[\mathrm{t}] \operatorname{COS} \mathrm{II}[\mathrm{]}, \mathrm{S} \mathrm{C}$ (figure féminine à gauche tenant une fleur dans la main droite).

As ou dupondius très érodé; $5,97 \mathrm{~g}$ (inv. 85) : RIC II, $\mathrm{n}^{\circ} 1067$ : L. Aelius Caesar, sous le règne d'Hadrien; en 137.

125 [ ]VS CAESAR [ ] (tête barbue à droitc d'Antonin).

As très usé (revers lisse); $8,07 \mathrm{~g}$ (inv. 124): RIC II, no 1086 à 1091 (Imp T Aelius Caesar Antoninus) : Antonin, successeur désigné sous Hadrien entre le 25 février et le 10 juillet 138 .

126 [ Cae]S HADH[ ] (tête nue à droite d'Antonin).

[trib] POT[ ] COS DES II, S C (Pax à gauche avec une corne d'abondance).

As ; 10,44 g (inv. 227) : RIC II, no 1094 (Imp T Ael Caes Hadr Antoninus) : Antonin, sous Hadrien; même période que le $\mathrm{n}^{\circ} 125$.

127 SABINA AVGVSTA [Hadriani Aug p p] (tête à gauche, chignon bas (buste "b»).

[Pietas] (Pielas assise à gauche tenant un sceptre et une patère).

As; 6,33 g (inv. 23) : RIC II, nº 1039 var. : Sabine, règne d'Hadrien (sans date).

Antonin (atelier de Rome) :

a) titulature IMP T AEL CAES HADR ANTONINVS AVG PIVS

128 Revers: [ ] $\mathrm{CO}[\mathrm{s}], \underline{\mathrm{S} \mathrm{C}}$ (figure peu identifiable (Pax?).

As (tête laurée à droite); $9,79 \mathrm{~g}$ (inv. 194) : RIC III, $n^{\circ} 532$ ? en $139^{80}$.

b) titulature ANTONINVS AVG PIVS P P

129 Revers : TR PO[t c]OS[ ], S C (figure à gauche tenant une corne d'abondance de la main gauche et un objet indéterminable dans la main droite).

As usé (tête laurée à droite); $8,41 \mathrm{~g}$ (inv. 137) : RIC III, $\mathrm{n}^{\circ} 566$ (Felicitas tenant un caducée) ou 567 ou 569 (Pax tenant un rameau); en 139.

80 Selon le Trésor de Garonne, cette monnaie est de 138. 
130 Revers: TR PO[t] COS II, S C (Pax à gauche, tenant une fleur dans la main droite et une corne d'abondance).

As (tête laurée à droite); $9,89 \mathrm{~g}$ (inv. 190): RIC III, $n^{\circ} 567$ : en 139.

131 Revers : TR POT COS II (ou III ?), S C (figure à gauche tenant une corne d'abondance).

As (tête laurée à droite); $9,13 \mathrm{~g}$ (inv. 283) : RIC III, $\mathrm{n}^{\circ} 567(\operatorname{Cos} I I)$ ou $\mathrm{n}^{\circ} 701$ (Cos $I I I$, apparemment plus rare) : en 139 ou 140-141.

132 Revers lisse.

As ou dupondius tête à droite (nue ou laurée)? $9,90 \mathrm{~g}$ (inv. 118) : référence et datation indéterminables.

\section{c) titulature ANTONINVS AVG PIVS P P TR P COS IIII}

133 Revers : [p]AX [Aug] (figure mal conservée). As (tête laurée à droite); $7,36 \mathrm{~g}$ (inv. 191) : $R I C$ III, $n^{\circ} 822$ : entre 145 et 161 .

\section{d) titulatures datées}

134 [Antoninus Aug] PIVS P P TR P XVI (tête laurée à droite).

[Annona] AVG COS IIII, S G (Annona debout tête à droite, modius à gauche).

As très lourd ou sesterce très léger : $12,55 \mathrm{~g}$ (inv. 269) : RIC III, no 910 (as) : en 152-153.

135 AN'TONINVS AVG PIVS P P IMP [II] (tête laurée à droite).

[tr] P [XIX ou X]X C[os ] (figure peu déterminable: Providentia?).

As ; $10,04 \mathrm{~g}$ (inv. 32) : RIC III, no 957 ( $\operatorname{lr} p X I X$ en 155156) ou $\mathrm{n}^{\circ} 972$ (tr $p X X$ en 156-157).

136 [Antoninus] PIVS P P [tr p XXII] (tète laurée à droite).

FORTVNA [ ], S C (Forluna à gauche; patère et gouvernail dans main droite et une corne [?] d'abondance).

As; $8,09 \mathrm{~g}$ (inv. 151) : RIC III, no 1023 : en 158-159.

e) titulatures indéterminables

137 [ ] AVG [ ] (tête laurée ou nue d'Antonin).

TR POT [ ] COS[ ], S C (Spes debout à gauche lenanl une fleur de la main droite).

As; $7,93 \mathrm{~g}$ (inv. 278) : RIC III, $\mathrm{n}^{\circ}$ 703a (Anloninus Aug pius $p$ p / Tr pot cos $I I I)$ entre 140 et 144 ou $\mathrm{n}^{\circ} 1350$ (Aurelius Caes Anton Aug Pii f/ Tr pol XIII Cos II) en 158-159 (pour Marc Aurèle).

138 [ Antonin]VS AVG PIVS P P [ ] (tête laurée à droite d'Antonin).

[ ], [S] C (figure peu déterminable).

Sesterce ; $20,04 \mathrm{~g}$ (inv. 264) : référence et datation indéterminables.

139 [ ] ANTONIN[ ] (tête nue (?) à droite). ], [S] C (figure indéterminable).

As ou dupondius ?; $7,20 \mathrm{~g}$ (inv. 139) : référence et datation indéterminables.
140 [ ]VS AVG [ ] (tête laurée à droite (Antonin?). [ ], S [C] (figure à gauche tenant une corne d'abondance et levant la main droite).

As ou dupondius; $7,44 \mathrm{~g}$ (inv. 307 ) : référence et datation indéterminables.

141-143 Revers lisses ( $\underline{\mathrm{S} \text { C }}$ subsiste parfois dans le champ).

Trois as ou dupondii (tête à droite d'Antonin ?); $6,63 \mathrm{~g}$ (inv. 299); 8,37 g (inv. 219); 9,47 g (inv. 249) : référence et datation indéterminables.

f) famille impériale : Faustine I (nos 144 à 152) et Faustine II (n' 153)

144 DIVA FAVSTINA (tête à droite, chignon haut, buste drapé).

AETERNITAS, S C (Aeternitas à gauche, le globe au phénix dans la main droite).

Fig. 30. Sesterce ; $20,47 \mathrm{~g}$ (inv. 293) : RIC III, $\mathrm{n}^{\circ} 1105$ : à partir de 141 .

145 DIVA FAVSTINA (tête à gauche, chignon haut). [Augus]STA, S C (Vesta assise à gauche).

As mal conservé; $9,92 \mathrm{~g}$ (inv. 225) : RIC III, $\mathrm{n}^{\circ} 1181$, à partir de 141.

146 DIVA [Faustina] (tête à droite, chignon haut).

$[\mathrm{Au}] \mathrm{G}[\mathrm{u}] \mathrm{S}[\mathrm{ta}]$ (Vesta debout à gauche tenant une torche à droite (ou un sceptre?) et un palladium dans la main gauche).

As usé ; 6,64 g (inv. 98) : RIC I1I, no 1177a ou 1178, à partir de 141.

$147 \mathrm{D}$ [iva] FAVS[tina] (tête à droite, chignon haut).

[ ] (figure à gauche avec des attributs peu déterminables).

As ; $9,90 \mathrm{~g}$ (inv. 247) : référence indéterminable, à partir de 141 .

148 DIVA AVGVSTA FAVSTINA (tête à droite, chignon haut, voilée (type "b»).

A[e]TERNITAS, SG (Aeternilas à gauche, tenant un sceptre vertical).

As; 7,45 g (inv. 114) : RIC III, no 1163a, à partir de 141.

149 DIVA AV[G ] FAV[stina] (tête à gauche, chignon haut).

Revers lisse.

Sesterce très usé ; 22,63 g (inv. 48) : référence indéterminable, à partir de 141 .

150-152 [ ] (Faustine l'Ancienne (chignon haut).

[ ], $\underline{\mathrm{SC}}$ (vague figure).

Trois as; $6,34 \mathrm{~g}$ (inv. 271); 7,11 $\mathrm{g}$ (inv. 268); $8,57 \mathrm{~g}$ (inv. 148) : référence indéterminable, à partir de 141.

153 [Faustinae] AVG PII [avg fil] (tête à droite, chignon assez bas).

[p]VDI[citia], S C (figure non identifiable). As; 8,76 g (inv. 150): RIC III, $\mathrm{n}^{\circ} 1403$ : Faustine la Jeune, sous Antonin le Pieux, en janvier-mars 161. 

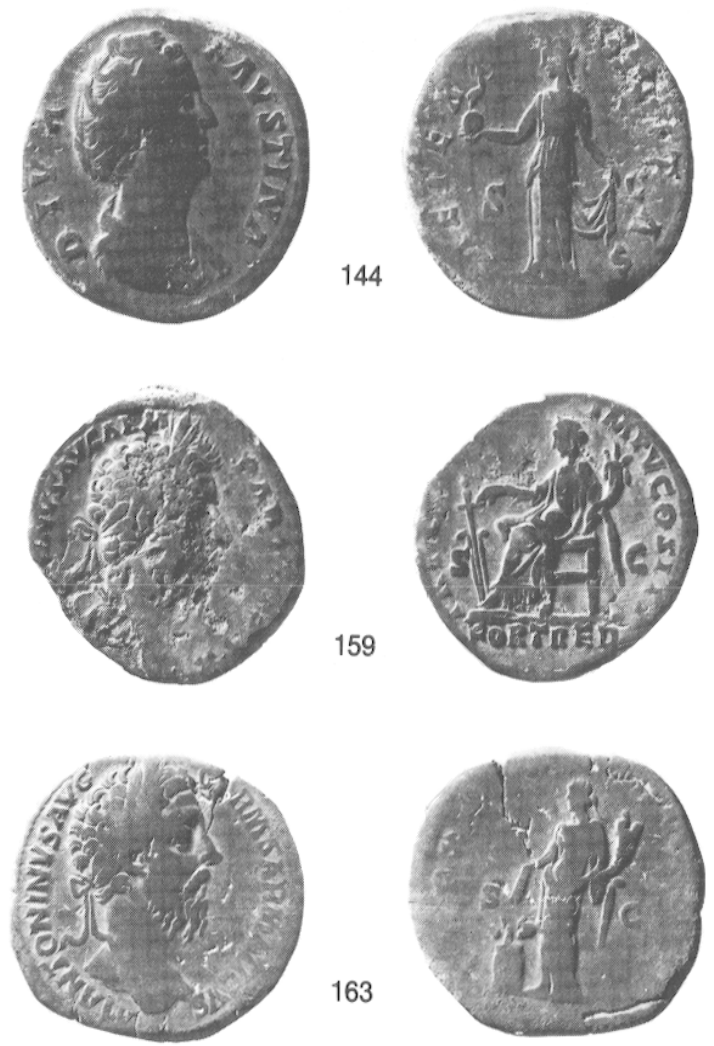

Fig. 30 - Monnaies de Faustine l'Ancienne et de Marc-Aurèle.

Marc-Aurèle (atelier de Rome) :

a) avec Lucius Verus, puis seul

$154[\mathrm{Im}] \mathrm{P}$ CAES [M Aurel Antoninus Aug? ou L. Aurelius Verus Aug?] (tête à droite laurée? nue? de Marc-Aurèle). face?).

$[\mathrm{co}] \mathrm{NCO}[\mathrm{rd} \ldots], \underline{\mathrm{S}} \mathrm{C}$ (deux personnages face à

As très usé ; $6,89 \mathrm{~g}$ (inv. 122) : RIC III, $\mathrm{n}^{\circ} 830$ ou 831

(Concord Augustor tr p XVI cos III) pour Marc-Aurèle et $n^{\circ} 1288$ ou 1291 (même légende avec seulement $\operatorname{Tr} p$ $\cos I I)$ pour Lucius Verus; en 161-162.

155 [Imp C]AES M AVREL [A]N[to]NINVS A[ug p] M (tête laurée à droite, buste nu de Marc-Aurèle).

[Saluti Augustor] TR P XVII COS III [ ] (Salus debout à gauche, nourrissant un serpent).

Sesterce; $18,63 \mathrm{~g}$ (inv. 25) : RIC III, no 843 : entre décembre 162 et décembre 163 .

156 [Imp] CAES M AVREL ANTONI[nus Aug] (tête nue (?) à droite, buste indéterminable de Marc-Aurèle).

[Saluti Augustor] TR P XVII[], S C (Salus debout à gauche).

As ; $9,20 \mathrm{~g}$ (inv. 254) : RIC III, n 847 à 849 selon le buste : entre décembre 162 et l'automne 163 .
157 IMP CAES L AVREL [Verus Aug] (tête à droite radiée de Lucius Verus?).

FORT RED TR POT III, S C / COS II (Fortuna assise, un gouvernail dans la main droite).

Dupondius? 9,12 g (inv. 294) : RIC III, $\mathrm{n}^{\circ} 1341$ : entre décembre 162 et l'automne 163.

158 L VERVS AVG [Armeniacus] (tête nue à droite de Lucius Verus)

TR P IIII IMP II COS [II], $\underline{\mathrm{S} C}$ (Mars allant vers Revers illisible sauf $\underline{\mathrm{SC}}$ (figure indéterminable).

As ; 9,07 g (inv. 11) : RIC III, n 1377 : entre décembre 163 et décembre 164 .

159 [M Anton]INVS AVG ARM PARTH MAX (tête laurée à droite de Marc-Aurèle).

Th P[ot XXIII] IMP V COS III, S C / FORT RED (Fortuna assise à gauche, tenant un gouvernail). Fig. 30. Sesterce; $16,55 \mathrm{~g}$ (inv. 47) : RIC III, $\mathrm{n}^{\circ} 962$ : entre décembre 168 et décembre 169 .

160

$$
\text { ] (lisse). }
$$

[ ] IMP V COS [ ], S C (Mars (ou Roma) casqué et cuirassé à gauche avec une lance dans la main droite). As ; 6,99 g (inv. 119) : RIC III, p. 290-291 (MarcAurèle) ou 330-331 (Lucius Verus) : entre février 168 et décembre 169 .

161 [M Antoninus] AVG TR P XXVI (tête laurée à droite de Marc-Aurèle). gauche).

[I]MP [VI C]O[s III] (la Victoire marchant vers la As; 7,04 g (inv. 153): RIC III, no 1028: entre décembre 171 et décembre 172 .

162 M ANT[oninus] AVG TR P XXVIII (tête laurée à droite)

MARTI VICTORI [imp VI C]O[s] III (Mars et un captif ; sur son bouclier S C).

As; $8,14 \mathrm{~g}$ (inv. 203) : RIC III, no 1106 : entre décembre 173 et juin 174 .

163 M ANTONINVS AVG GERM SARMATICVS (tête laurée à droite).

[TR] P XX[X imp VIII COS III], S C (Pietas sacrifiant sur un autel à gauche).

Fig. 30. Sesterce; $18,75 \mathrm{~g}$ (inv. 49) : RIC III, $\mathrm{n}^{\circ} 1170$ (titulature 13) : entre décembre 175 et décembre 176 .

\section{b) références et datation indéterminables}

164 [ ] M ANTON[ ] P[ ] (tête laurée à droite). As très usé (revers lisse); 6,62 g (inv. 90).

165 Légendes illisibles (tête nue à droite de Marc Aurèle/ revers : figure debout à gauche, avec une corne d'abondance).

As; 9,24 g (inv. 255).

\section{c) Faustine II sous Marc Aurèle :}

\section{titulature FAVSTINA AVGVSTA de 161 à 176}

166 Revers : F]ECVND[ ], $\underline{\mathrm{S} \mathrm{C}}$ (Fecunditas à gauche tenant un enfant sur le bras gauche). 
As (tête à droite, chignon bas sur la nuque, buste drapé); 7,88 g (inv. 145) : RIC III, no 1636.

167 Revers : [V]ENE[ri vi]C[trici], S C (Vénus à gauche, Mars à droite).

As médiocre (même figure); $6,87 \mathrm{~g}$ (inv. 93) : RIC III, $\mathrm{n}^{\circ} 1680$.

168-169 Revers lisse.

Deux as (tête à droite, chignon sur la nuque); $7,30 \mathrm{~g}$ (inv. 199); 9,09 g (inv. 104) : RIC III, p. 344-348: référence et datation indéterminables.

170 Légendes illisibles, revers lisse.

Sesterce très usé (tête à droite, chignon sur la nuque); $21,18 \mathrm{~g}$ (inv. 116) : référence indéterminable.

d) Faustine II divinisée :

\section{titulature DIVA FAVSTINA après 176}

171 Revers illisible (la Concorde debout à gauche tenant unc patère et une corne d'abondance).

As (tête à droite, chignon bas); $7,37 \mathrm{~g}$ (inv. 316) : $R I C$ III, p. 344-346.

e) Lucille sous Marc Aurèle : titulature LVCILLA AVG ANTONINI AVG F

172 Revers : PVD[icit]IA, [ ] C (Pudicitia debout à gauche, tenant son voile de la main droite)

As (buste drapé à droite; chignon bas sur la nuque et chevelure à grosses côtes); $7,03 \mathrm{~g}$ (inv. 233) : $R I C$ III, $n^{\circ} 1758$.

\section{Commode (atelier de Rome)}

173 DIVVS M $\Lambda$ NTONINVS PIVS (tête nue (?) à droite de Marc-Aurèle).

[ C]ONS[ecratio] (aigle tête à gauche, sur un globe peu visible).

As ; 8,13 g (inv. 92) : RIC III, $\mathrm{n}^{\circ} 663:$ en 181 ?

174 [M Co]MMODVS ANTONINVS A[u]G [pius] (tète laurée à droite).

[Tr p] VII[I imp V] COS IIII P [p] (Jupiter tenant un sceptre el une Victoire; à ses pieds, un aigle).

Sesterce; 21,19 g (inv. 9) : $R I C$ III, no 348 : en 183.

175 [M Commodus] ANTON AVG [pius] (tête laurée à droite).

TR P VIIII [imp VI Cos IIII p p], $\underline{\mathrm{S} C \text { (Minerve à }}$ droite appuyée sur son bouclier).

As; 9,72 g (inv. 186) : RIC III, no 428 : en 183-184.

176 COM[m Ant p] FELIX [Aug Brit] (buste nu, tête laurée à droite).

PI $[$ et senat $p \mathrm{~m}$ tr $\mathrm{p}$ XIIII $\cos \mathrm{V} p \mathrm{p}] /[\mathrm{S} \mathrm{C}$ ? (deux personnages face à face). As ; 8,45 g (inv. 286) : RIC III, n 538 : en 188-189.

Empereurs du $\mathrm{II}^{\mathrm{e}} \mathrm{s}$. : références et datations indéterminables (atelier de Rome)

177 Légendes illisibles; au revers S C à l'exergue (figure assise indéterminable).

As (traces de tête barbue [Hadrien ?]); $5,45 \mathrm{~g} \bullet$ (inv. 18).
178 [ ] AVG [ ] (tête barbue laurée à droite (Hadrien ou Antonin plutôt que Marc Aurèle?).

Revers illisible sauf $\underline{\mathrm{SC}}$ (figure indéterminable).

$\Lambda \mathrm{s} ; 8,21 \mathrm{~g}$ (inv. 156).

179 Légendes illisibles; au revers S C à l'exerguc (deux personnages, l'un à droite, debout, l'autre, accroupi à gauche).

As (tête laurée à droite d'Antonin? très effacée); $10,59 \mathrm{~g}$ (inv. 252).

180 [ ]'TR POT COS II [ ] (tête laurée à droite d'Antonin?).

[ ], S C (figure peu identifiable).

As ; 9,5l g (inv. 253).

181 Légendes illisibles et revers lisse.

As (tête à droite d'une impératrice à chignon bas (une des impératrices de la fin du $\mathrm{II}^{\mathrm{e}} \mathrm{s}$.); $8,45 \mathrm{~g}$ (inv. 260).

182 [Caes? ]AVG [ ] (tête barbue laurée à droite (Hadrien?).

[ ] MAXIMV[ ], $\underline{\mathrm{SC}}$ (figure féminine debout à gauche avec une corne d' abondance).

As ou dupondius; $7,17 \mathrm{~g}$ (inv, 216).

183-184 Légendes illisibles, revers lisses.

Deux as ou dupondius (tête nue ou laurée à droite (Antonin ?); 5,88 g (inv. 211); 6,22 g (inv. 235).

\section{Septime Sévère (atelier de Rome)}

185 [ ] AVG IMP [ ] (tête barbue laurée à droite de Septime Sévère).

[ ], S [c] (Mars allant vers la droite, avec lance el trophée).

As ; 9,62 g (inv. 263) : RIC IV, 1, n 683 (L. Sept Sev Pert Aug imp III / Mars Pater, S C) : fin 194.

\section{Sévère Alexandre}

186 IMP CAES M AVR SEV ALEXANDER AVG (tête laurée à droite, buste drapé de Sévère Alexandre). VI[ctoria Augusti], S C (Victoire marchant vers la gauche tenant une palme et une couronne).

Sesterce; $20,63 \mathrm{~g}$ (inv. 31 ) : $R I C$ IV $, 2, \mathrm{n}^{\circ} 622$ : atelier de lome entre 222 et 229 .

\section{Empereurs du milieu du $\mathrm{III}^{\mathrm{e}} \mathrm{s}$.}

187 IMP GORDIANVS PIVS FEL AVG (très beau portrait de Gordien III, buste drapé, tête laurée à droite).

AETERNITATI AVG, S C (Apollon nu à gauche, tenant un globe dans la main gauche).

Fig. 31. Sesterce; 18,93 g (inv. 251): RIC IV, 3, no $297 \mathrm{~b}$ : atelier de Rome entre 241 et 243 (4⿳⺈冂́mission).

188 MA[rcia Otacil] SEVERA AVG (tête diadémée à droite, coiffée d'une natte sur la nuque).

$\mathrm{P}[\mathrm{i}] \mathrm{E}[\mathrm{t}]$ AS [ Augg], S C (Pietas debout à gauche tendant la main droite).

Sesterce ; $14,07 \mathrm{~g}$ (inv. 70) : RIC IV, 3, no $205 \mathrm{~b}$ : sous Philippe l'Arabe, atelier de Rome entre 244 et 249. 


\section{Monnaies indéterminables, sans référence ni datation}

189-191 Légendes illisibles et revers lisses.

Trois sesterces très usés (tête nue et imberbe à droite); $16,35 \mathrm{~g}$ (inv. 258); 19,26 g (inv. 40); 20,56 g (inv. 205).

\section{2} ] (tête nue à droite).

[Fortu]NA ] (Fortuna debout à gauche, tenant une ancre dans la main droite et une corne d'abondance).

As ou dupondius très usé $7,24 \mathrm{~g}$ (inv. 41).

193-194 Droit et revers lisses; $\underline{\mathrm{S} \text { C }}$

Deux as ou dupondii; 4,40 $\overline{\mathrm{g}}$ (inv. 147); 7,65 $\mathrm{g}$ (inv. 202).

195-278 Droit et revers lisses.

Quatre-vingt-quatre as ou dupondii très usés.

$3,14 \mathrm{~g}$ (inv. 108); $3,75 \mathrm{~g}$ (inv. 60); $3,98 \mathrm{~g}$ (inv. 130); $4,00 \mathrm{~g}$ (inv. 86); 4,26 g (inv. 134); 4,40 g (inv. 318); $4,46 \mathrm{~g}$ (inv. 105); 4,50 g (inv. 178); 4,55 g (inv. $111 \mathrm{et}$ 135); 4,60 g (inv. 102 et 109); 4,71 g (inv. 81); 5,01 $\mathrm{g}$ (inv. 35); 5,03 g (inv. 213); 5,14 g (inv. 232); 5,23 $\mathrm{g}$ (inv. 141, 240 et 243); 5,41 g (inv. 34); 5,45 g (inv. 72); $5,52 \mathrm{~g}$ (inv. 210); 5,53 g (inv. 97); 5,56 g (inv. 94); $5,66 \mathrm{~g}$ (inv. 58); 5,72 g (inv. 55); 5,76 g (inv. 106); $5,80 \mathrm{~g}$ (inv. 177); 5,81 g (inv. 107); 5,84 g (inv. 155 et 244); $5,86 \mathrm{~g}$ (inv. 212); 5,88 g (inv. 275); 5,95 g (inv. 296); 5,99 g (inv. 218); 6,04 g (inv. 279); 6,06 $\mathrm{g}$ (inv. 77); 6,16 g (inv. 87); 6,19 g (inv . 262); 6,22 $\mathrm{g}$ (inv. 242); 6,25 g (inv. 75); 6,37 g (inv. 250);6,38 $\mathrm{g}$ (inv. 37 et 59 ); 6,41 g (inv. 64, 198 et 270 ); 6,43 $\mathrm{g}$ (inv. 144); 6,55 g (inv. 123); 6,56 g (inv. 133); 6,60 $\mathrm{g}$ (inv. 69); 6,67 g (inv. 173); 6,80 g (inv. 179); $6,84 \mathrm{~g}$ (inv. 172); 6,85 g (inv. 76); 6,89 g (inv. 265); 6,90 g (inv. 131); 7,02 g (inv. 146); 7,03 g (inv. 271); 7,05 g (inv. 306); 7,09 $\mathrm{g}$ (inv. 241); 7,17 g (inv. 292); 7,21 g (inv. 80 et 280); 7,24 g (inv. 101); 7,29 g (inv. 195); $7,40 \mathrm{~g}$ (inv. 120 ); $7,45 \mathrm{~g}$ (inv. 96); 7,58 g (inv. 287); $7,66 \mathrm{~g}$ (inv. 320); 8,18 g (inv. 115); 8,37 g (inv. 207); $8,48 \mathrm{~g}$ (inv. 246); $8,56 \mathrm{~g}$ (inv. 308 ); $8,78 \mathrm{~g}$ (inv. 303); $8,84 \mathrm{~g}$ (inv. 215); $9,18 \mathrm{~g}$ (inv. 214); $9,44 \mathrm{~g}$ (inv. 125); $9,53 \mathrm{~g}$ (inv. 129); $9,58 \mathrm{~g}$ (inv. 200); $9,76 \mathrm{~g}$ (inv. 288); $10,32 \mathrm{~g}$ (inv. 79); 10,44 g (inv. 184); 10,88 g (inv. 149).

279 [longue titulature] (tête radiée à droite non reconnaissable) / revers lisse.

Dupondius; 10,01 g (inv. 272).

\section{Gallien}

280 GALL[ienus Aug, ou P F Aug?] (tête radièe à droite, du "style» de Rome) / revers lisse.

Antoninianus officiel; $0,93 \mathrm{~g}$ (inv. 14) : référence indéterminée: Gallien, règne seul, atelier de Rome (260268).

281 GALLIENVS AVG (buste nu, tète radiée à droite).

PRO[vid Aug ]/ MP à l'exergue (figure à gauche avec, un long sceplre oblique dans la main gauche et un globe dans la main droite).

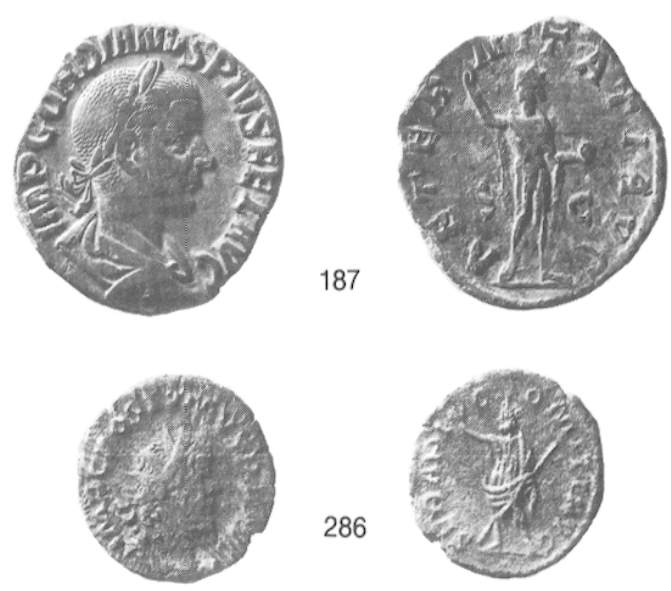

Fig. 31 - Monnaies de Gordien III et de Postume.

Antoninianus ; 2,02 g (inv. 284) : RIC V, 1, n $508 \mathrm{a}$ : atelier de Milan entre mi $\left.265^{\circ}\right)$ et 267 (6 $6^{\circ}$ et $7^{\circ}$ émissions dites du " $7^{\mathrm{e}}$ consulat»).

282 [ ]L[ ] (tête radièe à droite (Gallien?).

[ ] (Victoire tenant une grande palme).

Anloninianus (officiel ou d'imitation); $0,63 \mathrm{~g}$ (inv. 16) : référence et datation indéterminables.

\section{Claude le Gothique}

283 [imp (Cla- ou C Cla]VI)I[us p f aug] (tête radiée à droite, buste indéterminé) / revers lisse.

Anloninianus; $1,88 \mathrm{~g}$ (inv. 100 ) : référence et datation indéterminables; atelier officiel de Rome?

284 [imp C]LAVDIVS P F AVG (tète radiée à droite, buste drapé et/ou cuirassé).

[Pax ] (Pax courant vers la gauche).

Anloninianus; $1,81 \mathrm{~g}$ (inv. 56) : RIC V, 1, no 157 ? Atelier de Milan.

$285[\mathrm{Im}]$ P C CLAVDIVS IIVC (= Aug) (tête radiée à droite).

[ ] II (figure féminine non identifiable). Antoninianus d'imitation; $2,28 \mathrm{~g}$ (inv. 188) : référence et datation indéterminables.

\section{Empereurs gaulois}

286 IMP G POSTVMVS P F AVG (tête radiée à droite, buste drapé et cuirassé).

SERAPI COMITI AVG (Serapis debout à gauche, avec un sceptre oblique).

Fig. 31. Antoninianus avec des traces de pellicule argentée; 2,08 g (inv. 50) : Elmer, p. 49, nº 383 : atelier de Cologne fin 263 (11\% émission).

287 [ Vi]CTORINVS [ (tête radiée à droite). droite).

[ ] AV $[\mathrm{g}]$ (Pax tenant une fleur dans la main Antoninianus; $1,05 \mathrm{~g}$ (inv. 71) : Elmen, p. $66, \mathrm{n}^{\circ} 616 \mathrm{ou}$ 649 : atelier de Cologne fin 268-première moitié de 269. 
288 [i]MP G [ ]TI[ou E ou R? A]VG (tête radiée à droite, buste drapé, de Tétricus I) / revers lisse.

Antoninianus officiel; $1,57 \mathrm{~g}$ (inv. 68 ): référence et datation indéterminables : atelier de Cologne entre 270 et 274 .

289 [ ]'I'RICVS P F [Aug] (tête radiée à droite, buste drapé de Tétricus I).

[ ] (figure féminine à gauche tenant un sceptre vertical dans la main gauche et une couronne (?).

Anloninianus officiel usé; $1,34 \mathrm{~g}$ (inv. 88) : référence indéterminée : atelier de Cologne entre 270 et 274 .

290 [imp Tetri]CVS P F [Aug] (tête radiée à droite). ]I.VS [Augg?] (figure debout à gauche appuyée sur un bouclier (?).

Antoninianus d'imitation; $0,84 \mathrm{~g}$ (inv. 29) : référence indéterminable; Tétricus I, atelier local.

291 IMP TETRI[cus ] (tête radiée à droite, buste sans doute cuirassé de Tétricus I).

[P'a]X $\Lambda[\mathrm{ug}]$ (figure très schématique tendant une fleur de la main droite et tenant sa robe de la main gauche, plus proche de Spes Aug que de Pax Aug). Antoninianus probablement d'imitation; $0,72 \mathrm{~g}$ (flan très mince mais diamètre presque normal); (inv. 257) : référence indéterminable; atelier local.

292 [ ]TETRICVS CAES (tête radiée à droite, buste vêtu du manteau de Tétricus II).

[Hila]RITAS AV[ ] (Hilarilas debout à gauche tenant une palme et une corne d'abondance).

Antoninianus d'imitation de bonne qualité; $2,12 \mathrm{~g}$ (inv. 63) : référcnce indéterminable.

\section{Tacite}

293 IMP [ ] TACITVS AVG (tête radiée à droite, buste drapé et cuirassé).

MARTI $[\mathrm{Pa}] \mathrm{CIF}$ (figure indéterminable).

Antoninianus; $1,81 \mathrm{~g}$ (inv. 65) : RIC V, 1, $\mathrm{n}^{\circ} 145$ (Imp $C$ $M$ Cl Tacitus $A u g$ ) ; la marque d'officine, attendue à l'exergue, est invisible; atelier de Ticinum entre 275 et 276.

\section{Probus}

294 IMP PROBVS P F $\Lambda$ VG (tête radiée à droite, buste cuirassé).

SALVS AVG, étoile dans le champ / XXI à l'exergue (Salus à droite avec un serpent dans les bras). Fig. 32. Antoninianus avec des traces de pellicule argentée; 1,18 g (inv. 46) : RIC V, 2, n ${ }^{\circ} 748$ ? atelier de Siscia (?) entre 276 et 282.
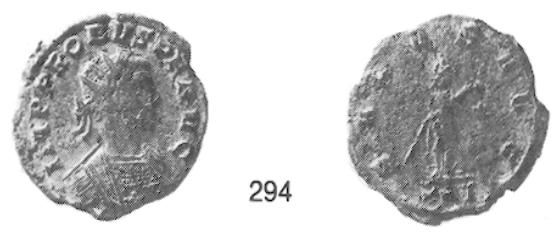

Fig. 32 - Monnaie de Probus.

\section{Autres antoniniani}

\section{(tête barbue radiée à droite)}

295-303 Légendes illisibles, revers lisses.

Neuf antoniniani très usés (flan souvent très mince); $0,44 \mathrm{~g}$ (inv. 82); 0,71 g (inv. 33); 0,72 g (inv. 95); 0,81 g (inv. 26); $0,88 \mathrm{~g}$ (inv. 83); $1,02 \mathrm{~g}$ (inv. 73); $1,05 \mathrm{~g}$ (inv. 12); 1,08 g (inv. 196); 1,51 g (inv. 28). Référence et datation indéterminables : imitations.

\section{IV siècle}

304 Revers (deux Victoires de part et d'autre d'un autel, tenant une couronne où on lit VOT / PR).

Nummus (tête à droite?); $0,65 \mathrm{~g}$ (inv. 27) : rélérence indéterminable : la légende de revers doit être Victoriae Laelae princ pr pour un membre de la famille constantinienne entre 318 et 320 .

305 CRISPVS NOB [Caes] (tête laurée à droite de Crispus).

C[aesarum n]oSTRORVM VOT V(ou X?) (couronne des vola et acclamation); marque d'atelier illisible.

Nummus; $1,91 \mathrm{~g}$ (inv. 30); référence indéterminable: sous Constantin, entre 320 et le 1/3/321.

306 [ ] (tête laurée à gauche de Crispus ou Constance).

[ ] VOT V (ou X?) (couronne des vola el acclamation); marque d'atelier illisible.

Nummus; $0,79 \mathrm{~g}$ (inv. 67) : référence indéterminable : sous Constantin, entre 320 et le 1/3/321 (ou après cette dat.e s'il s'agit des Vota $X$ ).

307 [ ] CONSTA [ ] (tête laurée à droite de Constantin (buste. B 1).

PR[ovi]DLN[tiae Caess] / marque datelier illisible avec une couronne à droite (porte de ville ou de (amp).

Nummus; $1,45 \mathrm{~g}$ (inv. 21) : référence indéterminable : Constantin, atelier de Rome en 326.

308 Légendes (au droit, lête à droite) et marque d'atelier illisibles /revers : porte de ville.

Nummus; $0,51 \mathrm{~g}$ (inv. 24) : référence indéterminable : un membre de la famille constantinienne, atelier indéterminable entre 324 et 326 .

309 D N VALENT[inianus $\mathrm{p} f$ aug] (tête diadémée à droite, buste drapé).

SECVRITAS REIPVBLIC[ae], OF II dans le champ, marque d'atelier illisible à l'exergue (Victoire marchant vers la gauche, avec une couronne dans la main droite).

Aes 3; 2,24 g (inv. 261) : RIC IX, $\mathrm{n}^{\circ} 9$ (entre le 25 février 364 et le 24 août 367) ou $n^{\circ} 17$ (entre le 24 août. 367 et le 17 novembre 375$)$ : Valentinien I, atelier d'Arles.

310 Lègendes illisibles, droit lisse / revers (type de Salus Rei Publice avec une Victoire?).

Aes $I V ? 0,29 \mathrm{~g}$ (inv. 19) : référence et datation indéterminables. 


\section{Espèces de références et datation indéterminables : droits et revers lisses}

311-315 Cinq antoniniani (d'imitation) ou Aes $I V$ : $0,46 \mathrm{~g}$ (inv. 298); 0,47 g (inv. 74); 0,49 g (inv. 17); $0,57 \mathrm{~g}$ (inv. 78);0,58 g (inv. 22 ).

316 Monnaie coulée (imitation); $1,12 \mathrm{~g}$ (inv. 62).
317-318 Espèce indéterminable (bronze); 2,37 $\mathrm{g}$ (inv. 208); 2,55 g (inv. 209).

\section{Monnaies modernes}

319 Monnaie de 1640 (inv. 310).

320 Monnaie du Xvil ${ }^{\mathrm{e}} \mathrm{s}$. (double tournois) trouvée hors stratigraphie avant la fouille ${ }^{81}$.
81 Nous remercions M. Guilbaut de nous autoriser à faire état des monnaies qu'il a récoltées dans l'angle sud-est du sanctuaire en 1991: $\mathrm{n}^{\circ} 1$ : as du $\mathrm{I}^{\mathrm{er}} \mathrm{s}$ ?; $\mathrm{n}^{\circ} 2$ : as du $\mathrm{II}^{\circ} \mathrm{s}$. (Antonin le Pieux?); $n^{\circ} 3$ : as d'Iladrien; $n^{\circ} 4$ : antoninianus de Tetricus I; $\mathrm{n}^{\circ} 5$ : as du $\mathrm{I}^{\mathrm{er}} \mathrm{s}$. (Néron?); $\mathrm{n}^{\circ} 6$ : as d'Antonin le Pieux; $n^{\circ} 7$ : as de Faustine l'Ancienne, sous Antonin; ${ }^{\circ} 8$ : as du II ${ }^{\circ}$ s. ?; no 9 : as de Claude. Faute de connaître leur référence exacte, quand c'est possible, et en tout cas leur poids, nous n'avons pas cherché à les intégrer dans le catalogue. On constate qu'elles ne modifient pas les données d'ensemble avec 8 as (sans doute 3 as du $\mathrm{I}^{\mathrm{er}}$ s. et $5 \mathrm{du} \mathrm{rr}^{\mathrm{e}}$ s., dont 3 d'Antonin le Pieux) et une seule pièce de billon (officielle ou d'imitation?) de Tetricus. Elles étaient toutes localisées entre les parois externes de la cella "a», mais aucune dedans, à l'endroit non touché par la fosse, et le péribole. Les monnaies $n^{o s} 1,6,7$ et 8 étaient devant le seuil de la chapelle, l'as $n^{\circ} 5$ près du socle "b", les $n^{\circ} 3,4$ et 9 près de l'entrée du sanctuaire, mais pas dans l' "éboulis" de tuiles déjà signalé. La pièce $n^{\circ} 2$ était non loin du mur d'enceinte à l'est.

\section{BIBLIOGRAPHIE}

Nous avons utilisé plus particulièrement les abréviations suivantes :

BALLESTER, Les sanctuaires...

Bat.tester C., Les sanctuaires gallo-romains en Midi-Pyrénées, Mémoire de maitrise de l'Univ. de Toulouse, inédit, 1983.

Belo IV

Belo IV, Les monnaies, Madrid, 1987.

BRUNAUX, Les Gaulois...

Brunaux J.-L., Les Gaulois, sancluaires et rites, Paris, Errance, 1986, (Ilespérides), p. 29-31.

DAF 6 : La terre sigillée...

Brimont C., JАСоB J.-P. (dir.), La terre sigillée gallo-romaine, lieux de production du Haut Empire : implantations, produits, relations, Paris, 1986, (Documents d'Archéologie Française, 6), p. 96-103, et Index des noms de potiers, p. 277-286.

\section{Dictionnaire des Mythologies}

Bonnefoy Y. (dir.), Dictionnaire des Mythologies, Paris, 1981, 2 vol.

D.S.

Darfmberg et Saglio, Dictionnaire des Antiquités grecques et romaines.

\section{ELMER, 1941}

Elmer G., Die Münzprägung der gallischer Kaiser in Köln, Trier und Mailand, Bonner Jahrbucher, 1941, p. 1-106.

Giard, Catalogue...

Giard J.-B., Catalogue des monnaies de l'Empire romain, I, Augusle, Paris, 1976.

\section{GrenIER, Manuel}

Grenier A., Munuel d'urchéologie gallu-romaine, IV, 2, Paris, 1960.
Histoire du Rouergue

Coldectif, Hisloire du Rouergue, Rodez, 1979.

MARICHAL, Les graffites...

Marichal R., Les graffites de La Graufesenque, Paris, Éd. CiNRS, 1988, 47" suppl. à Gallia.

Oswald, Potters'stamps

Oswald F., Index of Potters' Stamps on Terra sigillata (Samian ware), Margidunum, 1931.

Petit, Histoire générale

Petit P., Hisloire générale de l'Empire Romain, Paris, 1974.

RIC

Roman Imperial Coinage, t. I (édition de 1984) à VII.

$R R C$

Crawford M., Roman Republican Coinage, Cambridge, 1974.

Trésor de Garonne

Érienne R., Rachet M., Le trésor de Garonne; essai sur la circulation monétaire en Aquilaine à la fin du règne d'Antonin le Pieux (159-161), Bordeaux, 1984.

Vernhet, Création flavienne ...

Vernhet A, Création flavienne de six services de vaisselle à La Graufesenque, Figlina, 1976, p. 13-27.

VERnHet, Four...

Vernhet A., Un four de La Graufesenque (Aveyron) : la cuisson des vases sigillés, Gallia, 1981, p. 25-43.

Les abréviations des revues sont celles de l'Année philologique sauf :

PVSL Av. = Procès verbaux de la Société des Lellres de l'Aveyron. 